\title{
Applying Psychological Reactance Theory to Communication between Adult Child Caregivers and their Older Adult Parents
}

Hannah Ball

Follow this and additional works at: https://researchrepository.wvu.edu/etd

\section{Recommended Citation}

Ball, Hannah, "Applying Psychological Reactance Theory to Communication between Adult Child Caregivers and their Older Adult Parents" (2016). Graduate Theses, Dissertations, and Problem Reports. 5150.

https://researchrepository.wvu.edu/etd/5150

This Dissertation is protected by copyright and/or related rights. It has been brought to you by the The Research Repository @ WVU with permission from the rights-holder(s). You are free to use this Dissertation in any way that is permitted by the copyright and related rights legislation that applies to your use. For other uses you must obtain permission from the rights-holder(s) directly, unless additional rights are indicated by a Creative Commons license in the record and/ or on the work itself. This Dissertation has been accepted for inclusion in WVU Graduate Theses, Dissertations, and Problem Reports collection by an authorized administrator of The Research Repository @ WVU.

For more information, please contact researchrepository@mail.wvu.edu. 
Applying Psychological Reactance Theory to

Communication between Adult Child Caregivers and their Older Adult Parents

\title{
Hannah Ball
}

Dissertation submitted

to the Eberly College of Arts and Sciences at West Virginia University

in partial fulfilment of the requirements for the degree of

Doctor of Philosophy in

Communication Studies

\author{
Keith Weber, Ed.D., Chair \\ Alan K. Goodboy, Ph.D. \\ Christa L. Lilly, Ph.D. \\ Scott A. Myers, Ph.D. \\ Christine E. Rittenour, Ph.D. \\ Department of Communication Studies
}

Morgantown, West Virginia
2016

Keywords: Compliance, Family Caregiving, Health Communication, Older Adults, Paternalism, Psychological Reactance Theory, Trait Reactance

Copyright 2016 Hannah Ball 


\section{ABSTRACT \\ Applying Psychological Reactance Theory to Communication between Adult Child Caregivers and their Older Adult Parents}

\section{Hannah Ball}

Given the rapid growth of the older adult population in the US and the number of adult children providing informal care to their older adult parents, there is a need for a better understanding of how communication can be used to negotiate the tension between dependence and autonomy in these caregiving relationships (Egbert, 2014; Morgan \& Hummert, 2000). Guided by psychological reactance theory (Brehm, 1966; Brehm \& Brehm, 1981), which posits that individuals value their autonomy and are motivated to restore it when they perceive that it is being threatened, the purpose of this dissertation was twofold: (a) to explore the role of reactance in communication between adult child caregivers and their older adult parents and (b) to create messages that can be used by caregivers to simultaneously encourage older adult parents' healthcare compliance and optimize their perceived autonomy. These two purposes were addressed across three studies. In Study One, results of focus groups with older adults who receive care from at least one adult child $(N=19)$ revealed three types of caregiving messages used by adult children that older adults perceive as freedom-threatening (i.e., offering directives, expressing doubt, loss-framing), as well as themes related to the types of health behaviors usually at the crux of these messages and older adults' responses to these messages. In Study Two, results of interviews with adult child caregivers of at least one older adult parent $(N=14)$ revealed that adult children use a variety of messages in attempts to gain compliance from older adult parents, including types that overlap with what older adults perceive as freedom-threatening. In Study Three, older adults who receive care from at least one adult child $(N=288)$ were randomly assigned to either an autonomy-supporting caregiving message or one of multiple freedom-threatening messages, each created based on results of the first two studies. Results revealed that relative to the autonomysupporting message, messages in which caregivers were offering directives or expressing doubt triggered higher perceptions of freedom threat among older adults, which was related to greater experiences of reactance, which in turn was linked to greater intentions to engage in a variety of freedom restoration behaviors. With one exception, trait reactance and paternalism beliefs did not moderate older adults' experience of the reactance process following exposure to these caregiving messages. Taken together, these results provide evidence that the reactance process is applicable to communication between adult child caregivers and their older adult parents and yield suggestions for how to circumvent reactance in this context. 


\section{TABLE OF CONTENTS}

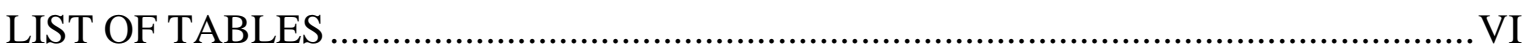

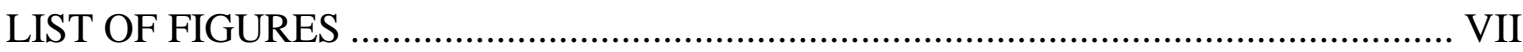

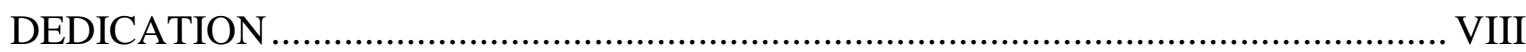

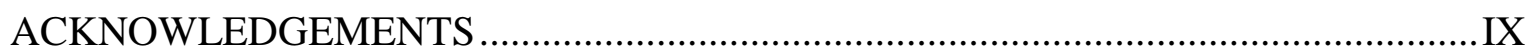

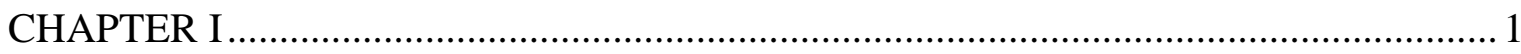

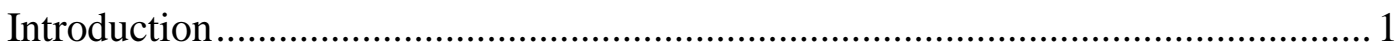

Theoretical Overview and Applications ............................................................ 3

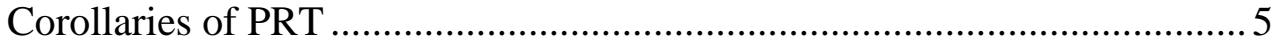

Contextual Scope of PRT........................................................................ 7

The Nature of Psychological Reactance ................................................................. 9

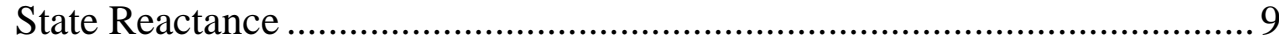

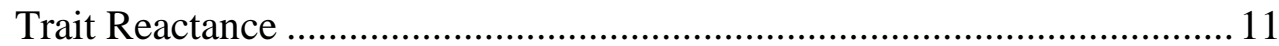

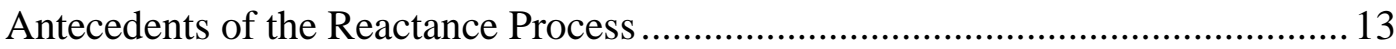

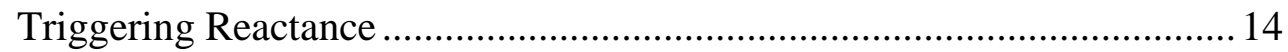

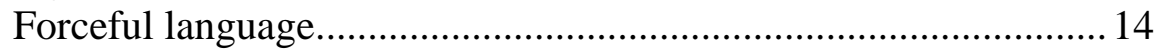

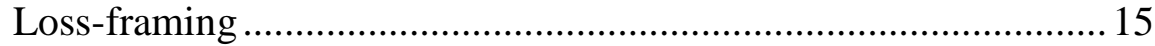

Vivid language ..................................................................... 16

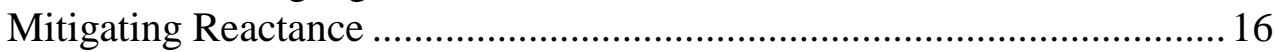

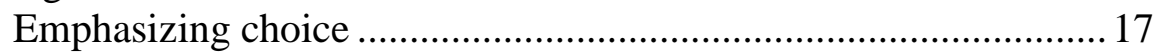

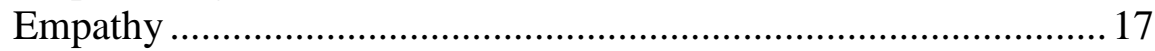

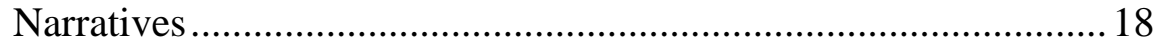

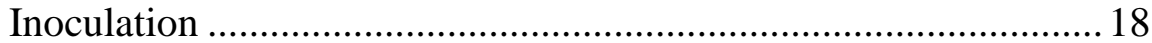

Integration of PRT within Other Theoretical Frameworks ..................................... 18

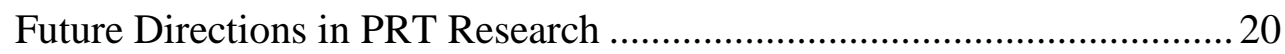

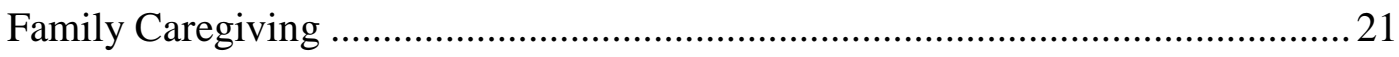

Family Caregiving and the Independence-Dependence Tension.................23

Effects of Family Caregiver Communication on Older Adults' Health .....25

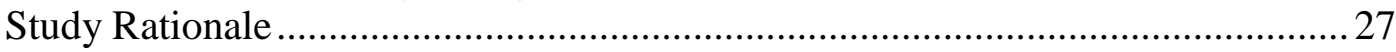

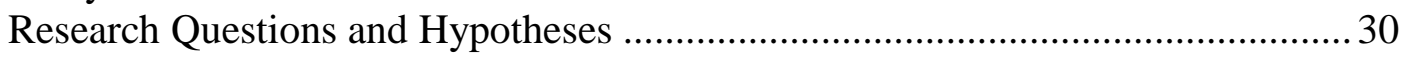

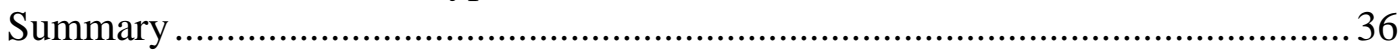

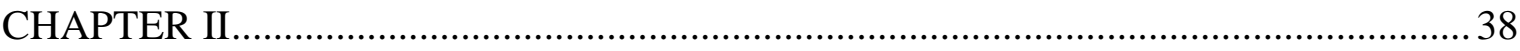

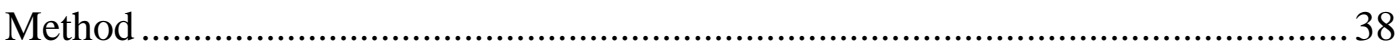

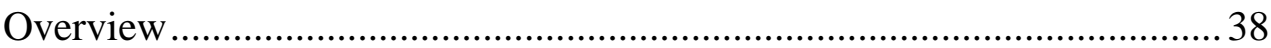

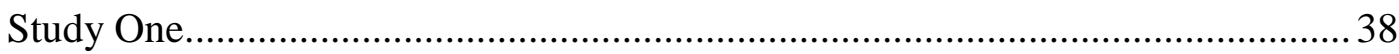

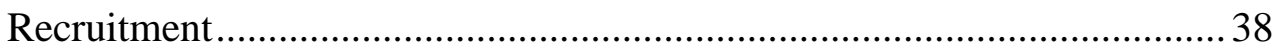

Participants and Procedures ..................................................................... 39

Data Analysis ................................................................................... 40

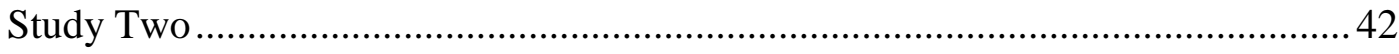




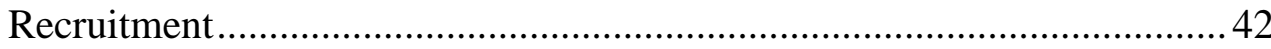

Participants and Procedures ................................................................. 42

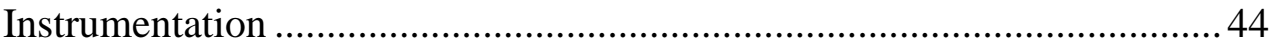

Data Analysis ............................................................................... 44

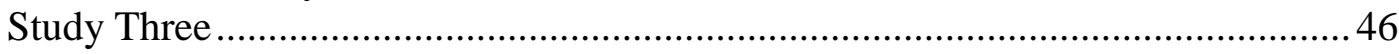

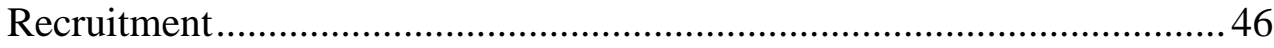

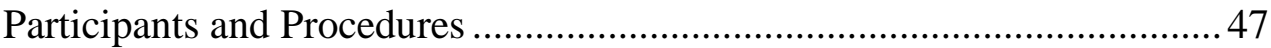

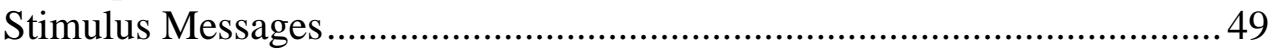

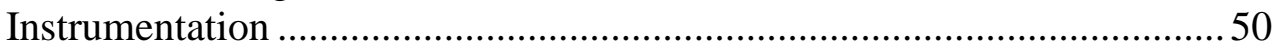

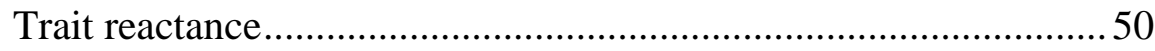

Paternalism beliefs ................................................................ 50

Perceived freedom threat ......................................................... 51

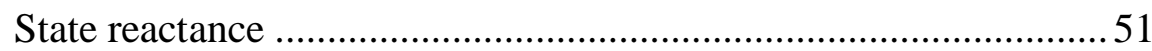

Freedom restoration ........................................................... 52

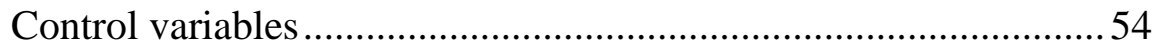

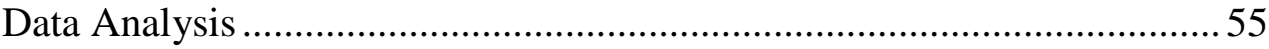

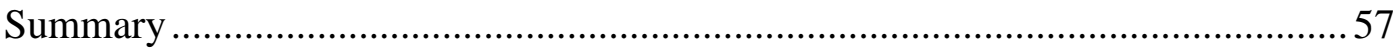

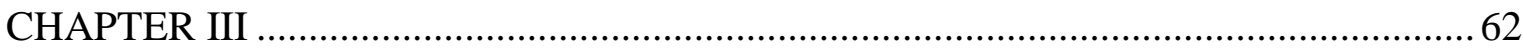

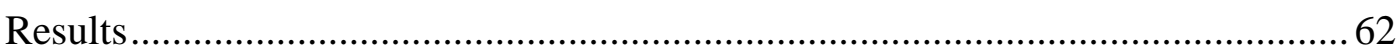

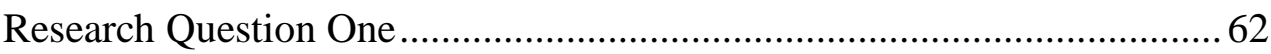

Research Question Two ..................................................................... 68

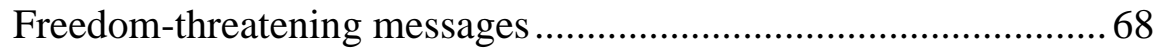

Non-freedom threatening messages ............................................ 72

Caregiver ratings of Study One messages ................................... 74

Research Question Three ..................................................................... 74

Research Question Four ...................................................................... 77

Older adult self-reports of nonadherence.................................... 77

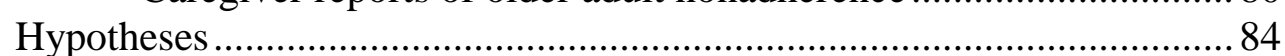

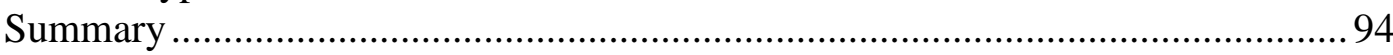

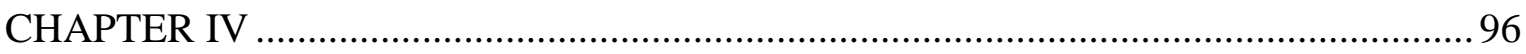

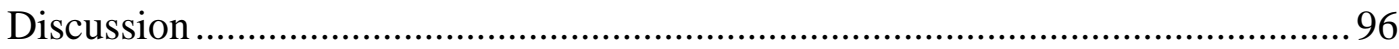

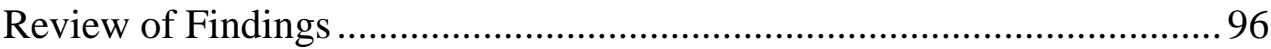

Persuasive messages used by adult child caregivers..................... 96

Older adult nonadherence to caregiving messages ..................... 101

Caregiving messages as triggers of the reactance process ............ 103

Lack of moderation of the reactance process.............................. 106

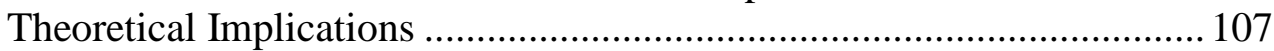

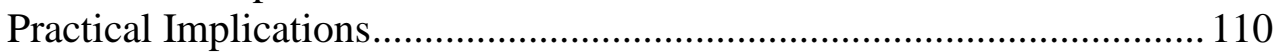

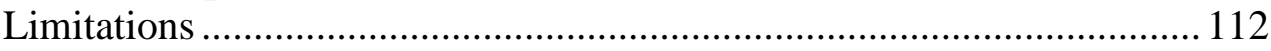

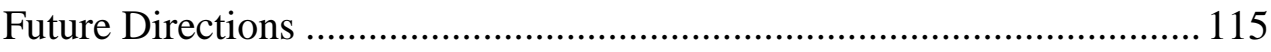

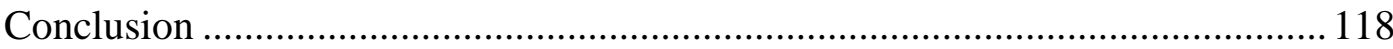




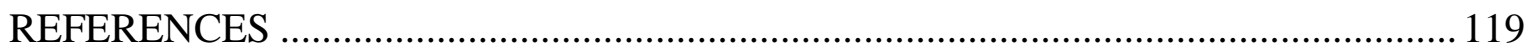

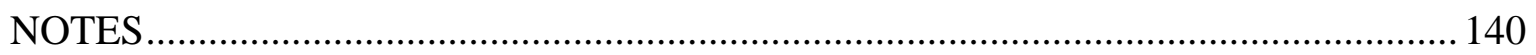

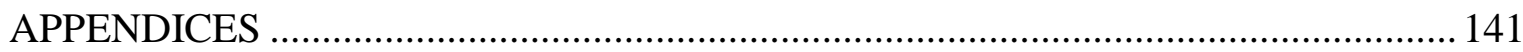

Appendix A: Study One Recruitment Script ............................................... 141

Appendix B: Study One Recruitment Flyer.................................................... 142

Appendix C: Study One Cover Letter........................................................ 143

Appendix D: Study One Moderator Guide ................................................. 144

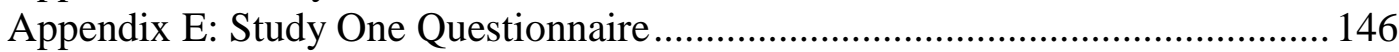

Appendix F: Study Two Recruitment Flyer....................................................... 148

Appendix G: Study Two Cover Letter.............................................................. 149

Appendix H: Study Two Interview Guide ..................................................... 150

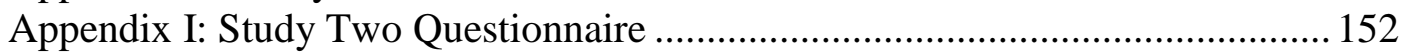

Appendix J: Study Three MTurk Recruitment Script ...................................... 156

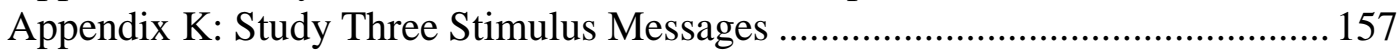

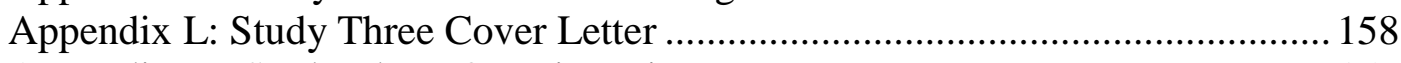

Appendix M: Study Three Questionnaire .......................................................... 159

Appendix N: Freedom Restoration Measure Pilot Test ..................................... 168 


\section{LIST OF TABLES}

Table 1: Study Three Sample Characteristics .48

Table 2: Study Two Results for Types of Messages Adult Child

Caregivers Use to Gain Compliance from Older Adult Parents

Table 3: Study One Results for Types of Caregiving Messages

Identified by Older Adults as Freedom Threatening

Table 4: Means and Standard Deviations for Caregiver Ratings of Realism and Effectiveness of Study One Messages ..... 75

Table 5: Study One Results for Health Behaviors Related to Freedom-Threating Messages

Table 6: Study One Results for Older Adult Self-Reports of Nonadherence to Caregiving Messages

Table 7: Study Two Results for Caregiver Reports of Older Adult Nonadherence to Caregiving Messages 81

Table 8: Pearson Correlations among Study Three Variables 85 


\section{LIST OF FIGURES}

Figure 1: Statistical Model of Serial Mediation for H1-H4 „........................................ 58

Figure 2: Statistical Model of Moderated Mediation for H5a and H6a ........................... 59

Figure 3: Statistical Model of Moderated Mediation for H5b and H6b .......................... 60 


\section{DEDICATION}

I would like to dedicate this dissertation to my parents, Jan and Roger, and my grandmother, "Gogie." I now have a better understanding of the challenges faced by family caregivers and care receivers, and respect the time and effort that family caregivers expend caring for their loved ones without so much as a second thought. 


\section{ACKNOWLEDGEMENTS}

Although writing a dissertation was, at times, like wearing a Horcrux (it makes you irritable for seemingly no reason, tries to kill you, etc.), completing this $\mathrm{PhD}$ program has been the most fulfilling task I have ever undertaken. And among the vast number of things I have learned during this program, I have found that it truly "takes a village" to earn a PhD. As such, I would like to thank the individuals whose support was invaluable throughout this process.

To my mom and dad - how lucky am I to have two of the greatest role models as my parents? Thank you for never once wavering in your love and support for me, no matter how far away I am (or how far away I'm telling you that I have to move to take on my next challenge). Knowing that the two of you have my back $100 \%$ and are there to talk things through has given me the strength I needed to persevere, no matter what life sends my way. Mom, thank you for the countless hours spent with me on the phone listening to me complain/swear/cry and reminding me that everything will work out. Dad, I appreciate more and more every day that you inspired my "math curse" by making me count to one million (by 10,000s, 100,000s, etc.) as a kid every night before bed (I can hear the people reading this thinking to themselves, "wow she makes so much more sense now"). Finally, thank you both for teaching me that "Hard work pays off."

To my brother, Danny-you are the hardest working person I know and your work ethic is an inspiration to me. I'm sorry that I have missed birthdays and milestones of yours over the last four years, but I hope you know that I could not be prouder of you. Here's to Mighty runs, questionable dance moves, O-72, TAH (or not), and our best memories being ahead of us. 
To Gogie - thank you for always offering to do whatever you can to help me out, for never leaving a doubt about how proud you are of me, and for teaching us all that feistiness is the key to successful aging.

To Emma-long-distance best friendship has not been easy for either of us, and I want to thank you from the bottom of my heart for never giving up on me wherever I move AND for always being on board to come visit (equipped with bottles of wine). I appreciate you for listening to me talk about work to the point that you know who everyone is and you can keep up with the latest happenings. Also, who and her family throw barbecues (yes, multiple) for their best friend's accomplishments? Only the best dooboo of all time.

To my ride-or-die, Jordan-I don't know what I would have done these past three years without you. Thank you for the literal hundreds of times you have had my back by being my confidant, keeping me company during long hours in the office, grabbing a beer with me when I'm stressed, rescuing me when I'm stranded in a snowstorm, making me laugh, and always being willing to drop everything to celebrate my triumphs (Dr. Myers, if you're reading this, celebrations were all postponed until after Jordan met your deadlines). Oh, and not to mention, you agreed to help move me across the country. You are the epitome of a loyal friend.

To my fellow members of \#4c1d (Molly, Dana, Mary, Jordan) and my little chalupa Julia— - having a support network of friends who understand what you are going through made this process a lot more bearable and fun(ish). Thank you for being there to laugh with me through the good and pull an all-nighter with me through the bad. 
To Sara, Zac G., and Zac J.—-thank for being exceptional role models of how to navigate a $\mathrm{PhD}$ program. I very much appreciate the friendship and support that each of you provided while we worked together at WVU and continue to provide as we work apart (but soon together again Sara!).

To Dr. Wanzer - having you as an undergraduate advisor was one of the best things to ever happen to me, because without you I probably would never have realized that graduate school was an option. Your passion for teaching is unparalleled and I'd like to think that, after taking basically all of your classes, I have incorporated at least a little bit of your teaching excellence into my own teaching style. I will always value your support, advice, optimism, and friendship.

I consider joining the Department of Communication Studies at WVU one of the best decisions I have ever made, and will forever be grateful to its faculty, staff, and students who helped me during my journey. Dr. Martin, I sincerely appreciate the generosity that you show your graduate students as the department chair, from supporting our travel to conferences to allowing us to teach classes that prepare us for our careers. I have basically been living my dream for the past two years because you trusted me to teach Research Methods. Also, a special thank you to Susanna, Shaun T., and Vivian for helping me code my dissertation data-I am lucky to have had help from some of our brightest undergrads.

I also would like to express my sincerest gratitude to my committee members, who helped me make my dissertation better than I could have ever made it on my own and who also prepared me to hold my own in our field. Dr. Rittenour, my self-efficacy for explaining my research ideas and leading graduate-level discussion skyrocketed after 
taking your courses. I also appreciate your genuine excitement about discussing research ideas - it is contagious. Dr. Goodboy, I enjoyed every single minute of your GLM course and appreciate the time and effort you put into equipping us with the tools we need to be statistical gladiators. I hope that we will sit together and compare notes when I start going to statistics seminars. Dr. Myers, although I did not fully understand what I got myself into as the only MA student in your advanced org. class, taking my first class with you so early on in my graduate career gave me that much more time to learn from you how to be a better thinker, writer, researcher, and teacher. Dr. Lilly, your Biostatistics classes were among my favorite classes and you opened my eyes to a whole new realm of knowledge that I will use for the entirety of my career.

Finally, to my advisor, Dr. Weber-I cannot begin to express how much I appreciate EVERYTHING you have done for me since I began my graduate career at WVU. One of the most reassuring things has been knowing that I have an advisor who is always looking out for my best interests. Also, I seriously learn a new career/life lesson from you during each of our meetings. Thank you for teaching me how to think about the big-picture, for taking the time to acknowledge the quality of my work without blowing smoke up my a $\$$, and for encouraging me to name-drop Harvard at least three times in every paragraph. Have I mentioned how glad I am that you encouraged me to spend a summer working at Harvard? HARVARD. I cannot wait to be your colleague, although it won't be too much different because you have always treated me like a peer.

I appreciate you all. Cheers to the next chapter and a lifetime of learning. 


\section{CHAPTER I}

\section{Introduction}

Persuasive health messages often attempt to encourage a target audience to engage in healthy behavior with that target audience's best interests in mind. Despite this prosocial intentionality to promote public health, however, persuasive health campaigns have been criticized for their modest effects on changing health attitudes and behavior (Silk, Atkin, \& Salmon, 2011; Snyder \& LaCroix, 2013) and their propensity to create both desired and undesired effects (Cho \& Salmon, 2007; Silk et al., 2011). As such, it has become a greater priority for health communication scholars to investigate why these persuasive messages do not always elicit the intended attitude and behavior change (Cho \& Salmon, 2007) and in some cases result in not only resistance but also an increase in an undesired health behavior (Burgoon, Alvaro, Grandpre, \& Voulodakis, 2002; Quick, Shen, \& Dillard, 2013).

One of the few theories that systematically explains unintended effects of persuasive communication is psychological reactance theory (PRT; Brehm, 1966; Brehm \& Brehm, 1981). The key construct of this theoretical framework is perceived autonomy; PRT acknowledges that when individuals perceive a threat to their freedom, they experience psychological reactance, which is a motivational state that triggers various forms of resistance to persuasive appeals (Brehm, 1966; Brehm \& Brehm, 1981; Burgoon et al., 2002). Thus, persuasive appeals that audience members perceive to infringe upon their autonomy may trigger psychological reactance and subsequently yield no behavior change and/or boomerang effects (i.e., more of the undesired behavior; Rains \& Turner, 2007). Considering the inherently manipulative and freedom-threatening nature of health 
campaigns (Witte, 1994), it is not surprising that PRT has advanced our understanding of a target audience's reaction to persuasive health messages.

The growing body of literature on PRT has provided substantial support for the theory as a viable explanation for resistance and increases in negative health behaviors that occur in response to persuasive appeals across a variety of health contexts. Additionally, PRT offers valuable implications for target audiences who may be prone to experiencing heightened levels of reactance upon receiving health-related advice or directives (Quick et al., 2013). For example, there is evidence that reactance proneness is a function of age such that young adults and older adults experience more reactance than middle-aged adults (Woller, Buboltz, \& Loveland, 2007) and that reactance is especially prevalent at transitional life stages (e.g., adolescence, older adulthood; Miller, Lane, Deatrick, Young, \& Potts, 2007). In fact, reactance has been established as a prominent predictor of adolescent and young adult health behavior in response to persuasive health messages (Quick et al., 2013). However, research efforts examining the antecedent and consequences of reactance have focused on adolescents and have largely overlooked older adult populations. Importantly, the unique experience of individuals transitioning into older adulthood, including the ways in which older adult parents and their adult children use communication to negotiate between autonomy and dependence in caregiving situations (Cicirelli, 1992; Hummert \& Morgan, 2001; Pecchioni \& Nussbaum, 2000), provide a prime context in which to explore the role of reactance. In the sections that follow, an overview of the theoretical constructs and corollaries of PRT are outlined and a review of existing theoretical applications is provided. This literature review will be followed by a discussion of a study designed to apply PRT to the context 
of family caregiving for older adults.

\section{Theoretical Overview and Applications}

Unlike the majority of persuasion theories, which predict when persuasive attempts will successfully elicit attitude or behavior change, PRT predicts when persuasive attempts are likely to be met with resistance or other unintended effects. For example, PRT has been identified as a viable explanation for the persuasiveness (or lack thereof) of television public service announcements (PSAs) on topics such as drunk driving, antismoking (Xu, 2015), condom use (Quick, 2013), and organ donation (Reinhart \& Anker, 2012); college students' negative credibility appraisals of graphic warning labels on cigarette packages (LaVoie, Quick, Riles, \& Lambert, 2015); and rates of underage alcohol consumption following changes in alcohol consumptions laws (Allen, Sprenkel, \& Vitale, 1994).

There are four core elements that comprise the foundation of PRT: free behaviors, freedom threat, psychological reactance, and freedom restoration (Dillard \& Shen, 2005; Quick et al., 2013). According to Brehm (1966; Brehm \& Brehm, 1981), individuals derive a sense of autonomy from a set of free behaviors, or actions that these individuals are aware of and have the capability and resources to perform, either immediately or at some point in the future. Important to note is that these free behaviors range in perceived importance based upon their ability to satisfy certain needs at a given time (Brehm, 1966).

PRT assumes that individuals highly value the ability to choose among these free behaviors at their discretion (Quick et al., 2013). Thus, a freedom threat is elicited when individuals perceive that some external influence (e.g., persuasive communication; 
Burgoon et al., 2002) impedes their ability to exercise one or more of these free behaviors at will. Specifically, individuals' freedom may either be completely eliminated or merely threatened with elimination. Moreover, individuals may perceive these freedom threats as either impersonal (i.e., accidental and not directed at oneself) or personal (i.e., intentional and directed at oneself), the latter usually occurring in the context of social relationships (Brehm, 1966; Dillard \& Shen, 2005).

Triggered by a perceived threat to one's freedom is the experience of psychological reactance (Brehm, 1966; Dillard \& Shen, 2005; Quick \& Bates, 2010; Quick \& Considine, 2008; Quick \& Stephenson, 2007a), which is defined as the "motivational state directed toward the re-establishment of the threatened or eliminated freedom" (Brehm, 1966, p. 15). Reactance tends to manifest as a combination of negative affective (i.e., anger) and cognitive states (Dillard \& Shen, 2005; Quick \& Considine, 2008; Rains, 2013) and is described as the "central explanatory mechanism" of PRT (Quick et al., 2013, p. 168).

As a consequence of experiencing reactance, individuals tend to act upon their motivation to regain autonomy by engaging in freedom restoration behaviors (Brehm, 1966). Existing literature proposes a variety of ways that individuals can restore their sense of autonomy, which fall within two distinct categories of freedom restoration behavior: direct and indirect (Burgoon et al., 2002). Direct freedom restoration is when individuals adopt attitudes or engage in behaviors that are in exact opposition of a recommendation (Burgoon et al., 2002; Worchel \& Brehm, 1970). Indirect freedom restoration is when individuals adopt attitudes or engage in behaviors tangentially related to the restricted freedom (Burgoon et al., 2002), and there are a variety of ways in which 
individuals can do so. For example, individuals may find the restricted behaviors more attractive than they did before exposure to a persuasive message (Brehm, 1966; Hammock \& Brehm, 1966; Worchel \& Brehm, 1971); seek more information about the restricted behavior (Burgoon et al., 2002); engage in behaviors similar to the restricted freedom (Brehm, 1966; Quick \& Stephenson, 2007b); vicariously observe others' engagement in restricted behaviors (Quick \& Stephenson, 2007b; Worchel \& Brehm, 1971); express disagreements or complaints (Ball \& Goodboy, 2014; Olison \& Roloff, 2012); and disparage the message source (Miller et al., 2007; Quick \& Bates, 2010) or the message itself (Grandpre, Alvaro, Burgoon, Miller, \& Hall, 2003; Quick \& Stephenson, 2007a).

\section{Corollaries of PRT}

Although the four aforementioned components of PRT function sequentially for all individuals, the experience of reactance itself may depend on contextual factors. Brehm (1966) proposed three factors that affect the magnitude with which individuals experience reactance, which continue to receive empirical support (for a summary, see Quick et al., 2013). First, individuals cognizant of their free behaviors as well as confident in their ability to engage in those behaviors tend to experience greater reactance than others when those behaviors are threatened (Allen et al., 1994; Brehm, 1966; Engs \& Hanson, 1989). For example, Allen et al. (1994) found that underage college students reported significantly greater alcohol consumption than their legal-age counterparts, yet no significant differences between these groups emerged for illicit drug use. In a more recent study, Quick and Bates (2010) found that upon exposure to a freedom-threatening message discouraging excessive alcohol consumption, individuals under the legal 
drinking age experienced greater reactance than participants of legal drinking age. In other words, reactance aroused by freedom-threatening sources (e.g., laws, persuasive messages) is more pronounced when restrictions are more salient.

Second, the magnitude of reactance arousal directly corresponds to the importance of a threatened freedom (Brehm \& Brehm, 1981; Burgoon et al., 2002). In other words, the experience of reactance depends on an individual's perception of the importance of the threatened or eliminated freedom, such that the more important the threatened freedom (e.g., in comparison to alternative behaviors), the greater the magnitude of reactance (Buller, Borland, \& Burgoon, 1998). For example, Quick and Bates (2010) found that college students reporting higher levels of alcohol consumption were more likely than those with lower levels of consumption to experience a freedom threat and engage in subsequent freedom restoration behaviors upon exposure to the antiexcessive alcohol consumption message. This result suggests that individuals who value their freedom to engage in excessive alcohol consumption, which is inferred based on their typical drinking behavior, experience heightened reactance when that freedom is threatened.

Third, reactance is a function of the extent to which a freedom is threatened or eliminated (Brehm, 1966; Brehm \& Brehm, 1981). For example, individuals should experience greater reactance as the number of freedoms that are threatened or eliminated increases (Brehm, 1966). For cases in which a freedom is threatened rather than completely eliminated, reactance is heightened as the implied freedom threat increases in severity (Brehm, 1966; Brehm \& Brehm, 1981). For example, Rains and Turner (2007) found that large requests related to campus illness prevention (e.g., wiping down any 
university desk one sits at with one's own cleaning supplies) evoked greater levels of reactance than small requests (e.g., wiping down any university computer keyboard/mouse one uses with university-provided cleaning supplies). Additionally, individuals should experience greater reactance if the source of the freedom threat could inhibit similar freedoms again in the future (e.g., in social relationships where one person has relational power over the other; Brehm, 1966). Reactance is also generally intensified if the message is explicitly (i.e., versus implicitly) freedom threatening, which is a characteristic often communicated in the form of a persuasive message (Quick et al., 2013). For example, persuasive messages featuring forceful or explicitly persuasive language (e.g., the use of words such as "must" and "ought") are often perceived as significantly more freedom threatening than similar messages using implicitly persuasive language (e.g., Ball \& Goodboy, 2014; Miller et al., 2007; Quick \& Considine, 2008).

\section{Contextual Scope of PRT}

Although initially intended for the interpersonal context (Brehm, 1966), PRT has been extended to explain reactions to persuasive messages in instructional settings (e.g., banning cell phone use in class, Kim, Levine, \& Allen, 2014; completing an extra ungraded assignment, Ball \& Goodboy, 2014) and family contexts (e.g., family discussions about organ donation, Scott \& Quick, 2012; divorced versus intact families, Johnson \& Buboltz, 2000; functioning independently of control from one's parents, Buboltz, Johnson, \& Woller, 2003). Most notably, however, may be the recent proliferation of PRT research in the health communication context (Shen, 2010) due to the innate nature of persuasive messages used in health communication campaigns (Quick, 2012; Rains, 2013). Indeed, as Rains (2013) asserted, “A pervasive challenge 
faced by campaign message designers is balancing the need to offer directives for behavior change with the potential consequences of threatening an audience's freedom" (p. 67). Considering that a major subset of health communication research is the development of persuasive messages to encourage adoption of prosocial health behaviors and that prescribed behavior lends itself to the reactance process, the role of psychological reactance in the persuasive health communication context should not be overlooked.

It follows as no surprise that PRT has demonstrated exceptional explanatory power in the health communication domain (for a review, see Quick et al., 2013; for a meta-analysis, see Rains, 2013). Specifically, PRT has been applied successfully to determine how to effectively avoid or mitigate adverse reactions to health promotion messages across a variety of health behaviors. A majority of these behaviors yield potential benefits to one's own or others' health, such as exercise (Miller et al., 2007; Quick \& Considine, 2008), flossing (Dillard \& Shen, 2005), sun safety (Buller et al., 1998; Cho \& Sands, 2011; Shen, 2015), campus-wide illness prevention (Rains \& Turner, 2007), condom use (Quick \& Stephenson, 2007a), diabetes self-care (Gardner \& Leshner, 2015), bone marrow donation (Lindsey, 2005), and organ donation (LaVail, Anker, Reinhart, \& Feeley, 2010; Quick, 2012; Quick, Kam, Morgan, Montero Liberona, \& Smith, 2014; Quick, Scott, \& Ledbetter, 2011; Reinhart \& Anker, 2012; Reinhart, Marshall, Feeley, \& Tutzauer, 2007; Scott \& Quick, 2012). Other studies have demonstrated the utility of PRT in explaining risky health behavior, such as excessive alcohol consumption (Dillard \& Shen, 2005; Kim, Levine, \& Allen, 2013; Quick \& Bates, 2010; Rains \& Turner, 2007; Richards \& Banas, 2015), drunk driving (Shen, 2010; 
$\mathrm{Xu}, 2015)$, smoking (Grandpre et al., 2003; Shen, 2010; Xu, 2015), and marijuana use (Quick, 2013).

In addition to explaining numerous health behaviors, PRT has also been used to explain responses to persuasive health communication across a variety of populations. Although many of Brehm's (1966) initial studies examined adolescents as a population more prone to experiencing reactance than other populations, PRT has more recently been validated not only among adolescents (e.g., Grandpre et al., 2003; Miller, Burgoon, Grandpre, \& Alvaro, 2006) but also among college students (e.g., Miller et al. 2007; Miller \& Quick, 2010; Quick \& Bates, 2010) and, to a lesser extent, adults (e.g., Buller et al., 1998; Quick \& Considine, 2008).

\section{The Nature of Psychological Reactance}

\section{State Reactance}

Brehm (1966) initially conceptualized reactance as a situational attribute. In other words, the reactance process is reactive rather than proactive (Miron \& Brehm, 2006), occurring in response to a situation in which an individual is being persuaded to relinquish a freedom (Brehm \& Brehm, 1981). Although Brehm asserted that reactance is a hypothetical variable, state reactance has more recently been conceptualized as an inseparable combination of negative cognitions and affect toward the freedomthreatening agent (Dillard \& Shen, 2005).

The absence of a conceptual explanation of reactance in Brehm's seminal work (Quick et al., 2013) has prompted extensive research on the reactance process. For example, Dillard and Shen (2005) proposed four possible conceptualizations of reactance, each of which defines reactance in terms of cognitive and/or affective states. First, 
Dillard and Shen suggested that reactance could be purely cognitive (i.e., negative thoughts and counterarguing toward the freedom-threatening agent). Second, reactance could be purely affective (i.e., negative emotional states such as anger and irritation). Third, reactance may involve cognitions as well as affective responses, with the experience of these two states occurring separately (e.g., in parallel [Dillard \& Shen, 2005] or in tandem [Rains \& Turner, 2007]). Finally, reactance could again be cognitive as well as affective, but experienced as an inseparable combination of the two states. Dillard and Shen's results indicated that reactance is best conceptualized as the inseparable combination of cognitive and affective states, and this intertwined model of state reactance has received overwhelming support in subsequent studies (Kim et al., 2013, 2014; Quick, 2012; Quick \& Considine, 2008; Quick \& Kim, 2009; Quick \& Stephenson, 2007a, 2008; Rains \& Turner, 2007; Shen, 2010). Moreover, results of Rains' (2013) meta-analysis, which compiled the path coefficients from published and unpublished studies using the intertwined model of state reactance, yielded a significant indirect effect of antecedents on consequences through state reactance.

The body of literature on PRT has explored the role of freedom threat as a trigger of state reactance. Important to note is that reactance is proposed to arise contextually as an "intervening, hypothetical variable" (Brehm \& Brehm, 1981, p. 37) such that it is triggered by a freedom threat and carries the effect of this freedom threat to the enactment of freedom restoration behavior. Although there is evidence that message features can produce reactance and subsequent freedom restoration independent of a perceived threat (Kim et al., 2013, 2014), it is theoretically inconsistent to consider the reactance process sans freedom threat. Quick et al. (Quick \& Bates, 2010; Quick \& 
Considine, 2008; Quick \& Stephenson, 2008) asserted that it is more theoretically consistent to model reactance as a two-step process; that is, to ensure that exposure to a persuasive message triggers a perceived threat to one's autonomy (i.e., by conducting a freedom threat induction check) and that this freedom threat subsequently triggers the experience of reactance. In sum, perceived threat and reactance should sequentially mediate the effects of message features and freedom restoration. Importantly, this supports the crux of PRT, which is that individuals' experience of reactance does indeed arise from a perceived threat to their autonomy (Brehm \& Brehm, 1981) rather than other sources of negative cognitions and/or affect.

\section{Trait Reactance}

Although most PRT research has focused on Brehm's (1966) initial conceptualization of reactance as situation-specific, there is evidence that within any given reactance-arousing situation, state reactance may not occur uniformly for all individuals (Shen \& Dillard, 2005). Brehm and Brehm (1981) reasoned based on known individual differences in the need for autonomy that reactance proneness may be an enduring personality trait that accounts for disparities in individuals' reactions to freedom threats. Specifically, some individuals may be more predisposed than others to experience reactance in regard to any instance of an inability to choose, expectations of conformity, others' behavioral influence, and offerings of advice and recommendations (Burgoon et al., 2002; Hong \& Faedda, 1996; Shen \& Dillard, 2005). It has also been suggested that trait reactance is a function of age, with reactance levels following a “trimodal trajectory" (Miller et al., 2007, p. 221) across the lifespan; specifically, reactance may peak around age two, again during the transition into adolescence, and a 
third time during the transition into older adulthood (Burgoon et al., 2002; Hong, Giannakopoulos, Laing, \& Williams, 1994; Miller, 2015; Miller et al., 2006; Voyer et al., 2005).

Subsequent research examining trait reactance has empirically supported differentiated effects of reactance proneness. High trait-reactant individuals tend to score higher in state anger (Quick \& Stephenson, 2008), trait anger (Hong \& Faedda, 1996), and sensation seeking (Quick \& Stephenson, 2008) than their low trait-reactant counterparts. There is also evidence that trait reactance positively predicts unhealthy attitudes and behavioral intentions. For example, individuals high in trait reactance hold more positive beliefs about alcohol and greater intentions to consume alcohol (Russell, Russell, Boland, \& Grube, 2014) as well as greater intentions to engage in tobacco use and risky sexual behavior (Miller \& Quick, 2010) than individuals low in trait reactance. In fact, Miller et al. (2006) found that trait reactance was a "prominent predictor" (p. 246) of adolescent smoking behavior second only to prior experimentation with smoking, such that adolescents high in trait reactance have about twice the risk for tobacco use as their low-reactant counterparts.

Trait reactance also plays a role in predicting individuals' responses to persuasive messages. In comparison to individuals low in trait reactance, individuals high in trait reactance tend to perceive greater threats to their freedom (Miller et al., 2007; Quick et al., 2011; Quick \& Stephenson, 2008; Shen \& Dillard, 2005). High trait-reactant individuals also have a greater likeliness for engaging in various behaviors to restore their threatened freedom and act in contrast to a recommended health behavior (Dillard \& Shen, 2005; Quick \& Stephenson, 2008; Shen \& Dillard, 2005) across multiple health 
contexts (e.g., sunscreen use, exercise; Quick \& Stephenson, 2007b). Moreover, there is evidence that these positive associations between perceived freedom threat and state reactance as well as between state reactance and boomerang effects are strengthened among individuals high in trait reactance (Quick \& Stephenson, 2008).

Given the effects of reactance proneness on the processing of persuasive health messages, trait reactance has been identified as a key variable for audience segmentation in health communication (Miller et al., 2006; Miller \& Quick, 2010; Quick et al., 2013; Shen \& Dillard, 2005). Quick et al. (2013) provided two reasons for exploring trait reactance as a segmentation variable when developing persuasive messages. First, research detailed above supports reactance proneness as an important predictor of risky health behaviors (Miller et al., 2006; Miller \& Quick, 2010; Russell et al., 2014) above and beyond the effects of sensation-seeking (Miller \& Quick, 2010), one of the most proliferated segmentation variables in health communication research (for a review, see Palmgreen, Donohew, \& Harrington, 2001). Second, reactance proneness has been found to interact with certain message features of persuasive appeals (e.g., forceful language, vivid language; Dillard \& Shen, 2005; Quick \& Stephenson, 2008) to intensify individuals' reactions to persuasive messages. As such, there has been a call for additional research that examines the role of trait reactance across various health contexts (Miller et al., 2006).

\section{Antecedents of the Reactance Process}

Miller (2015) notes that a "trade-off" inherent to designing effective persuasive health messages is whether to use explicit or implicit recommendations. On one hand, explicit messages provide target audience members with clarity regarding the health 
behavior to enact, but are reactance-inducing; on the other hand, implicit messages elicit lower levels of reactance, but are less easily understood by a target audience. To examine how persuasive messages contribute to the reactance process, the bulk of PRT literature examines specific characteristics of persuasive health messages that are associated with perceived freedom threats and the subsequent experience of reactance (Quick et al., 2013). Two conclusions can be drawn from this body of research. First, certain message factors trigger a heightened experience of state reactance by increasing the perception of a freedom threat and therefore should be avoided when creating a persuasive health message. Second, certain other message factors mitigate the experience of state reactance by reducing the perception of a freedom threat and therefore should be incorporated into persuasive health messages that are likely to evoke a freedom threat. Importantly, these implications offer theoretical guidance to health campaign designers attempting to avoid or minimize reactance and the resulting undesired effects (Quick et al., 2013).

\section{Triggering Reactance}

Given the freedom-threatening nature of persuasive health messages (Witte, 1994), it seems reasonable that certain message elements make evident the underlying persuasive intent of these messages. Therefore, researchers have addressed the call for theoretically-driven implications for message design and offer advice about what to avoid by isolating message factors that intensify the experience of reactance (Shen, 2015). Three message factors known to trigger heightened levels of reactance are forceful language, loss-framing, and vivid language.

Forceful language. The determinant of heightened reactance that has received the most empirical support is forceful language (Shen, 2015), which has also been researched 
under the guise of freedom-threatening (Quick, 2012; Quick et al., 2011; Scott \& Quick, 2012), dogmatic (Quick \& Stephenson, 2008), controlling (Miller et al., 2007, 2013; Xu, 2015), explicitly persuasive (Grandpre et al., 2003), threat-to-choice (Quick \& Stephenson, 2007a), and threat-to-freedom (Dillard \& Shen, 2005) language. Experimental manipulations of messages containing high versus low forceful language generally include words such as "must" and "should" rather than "might" and "consider" (Bessarabova, Fink, \& Turner, 2013; Dillard \& Shen, 2005; Miller et al., 2007) and phrases that emphasize individuals' lack of choice such as "do it because you have to," "there is really no choice," and "you simply have to do it" rather than "you may want to try it" (Bessarabova et al., 2013; Dillard \& Shen, 2005). There is overwhelming support that messages containing forceful language trigger greater reactance than messages containing less forceful language, a finding that has been validated in adolescent (Grandpre et al., 2003; Quick \& Kim, 2009), college student (Quick \& Stephenson, 2008; Rains \& Turner, 2007), and adult (Buller et al., 1998; Quick \& Considine, 2008) populations; among collectivistic cultures (Quick \& Kim, 2009) and individualistic cultures (Quick \& Considine, 2008); and across a variety of health contexts (e.g., exercise, smoking; Dillard \& Shen, 2005) as well as in non-health domains (e.g., instructor-student communication; Ball \& Goodboy, 2014). There is also evidence that forceful language can be combined with other message factors to produce even greater levels of reactance (e.g., reactance-enhancing inoculation, Miller et al., 2013; lossframing, Shen, 2015).

Loss-framing. Existing research also suggests that loss-framed messages, which emphasize the consequences of not engaging in a recommended behavior, trigger 
reactance arousal (Cho \& Sands, 2011; Reinhart et al., 2007; Shen, 2015). This result may be due in part to the positive association between loss-framed messages and guilt (Quick et al., 2014), an emotional response known to elicit heightened levels of freedom threat and reactance (Lindsey, 2005; Reinhart et al., 2007). However, the link between message-framing and perceived threat has received mixed support when other message factors are taken into account. For example, Quick et al. (2014) found that when combined with radio narratives about organ donation, gain-framed messages (i.e., which emphasize the benefits of engaging in a recommended behavior) elicited greater perceived freedom threat than loss-framed messages.

Vivid language. Another language factor related positively to perceived freedom threat is vivid language (Quick \& Stephenson, 2008), which entails detailed descriptions of the consequences of a behavior that allow participants to envision these consequences. For example, in their message recommending sunscreen use, Quick and Stephenson (2008) manipulated vivid versus pallid language by describing the consequences as "premature wrinkling, severe skin blisters that ooze and become crusty, and even skin cancer" versus "skin injuries, skin diseases, and in general, declining health" (pp. 450451), respectively. As a result, the use of vivid language heightened reactance indirectly through perceived freedom threat, which Quick and Stephenson rationalized is due to the increased elaboration required to process these types of messages.

\section{Mitigating Reactance}

Although the studies highlighting message factors that trigger reactance yield important implications for message design, these results are limited because they suggest what to avoid rather than what to include in a message (Shen, 2015). Therefore, for cases 
in which high perceived freedom threat may be unavoidable, it is important to examine what elements can be included in a message so that this inevitable freedom threat may be counteracted. Subsequently, researchers have identified certain message elements that alleviate the effects of a perceived freedom threat and the subsequent experience of reactance (Quick et al., 2013). Message factors known to mitigate reactance include emphasizing choice, empathy, narratives, and inoculation.

Emphasizing choice. One method of mitigating reactance is by drawing individuals' attention to ways they can restore their threatened freedom. For example, Shen (2015) found that providing multiple behavioral options to enact a recommended health behavior versus only one way to engage in the recommendation elicited lower levels of reactance when incorporated in high freedom-threatening messages. Another tactic that emphasizes choice is the use of restoration postscripts, which are brief messages at the end of a longer persuasive message that remind individuals that despite the health recommendations they may have read, the decision of how to behave is ultimately their choice (Miller et al., 2007). Importantly, the efficacy of restoration postscripts in reducing perceived threat is maximized when these messages also utilize freedom-threatening language (Bessarabova et al., 2013).

Empathy. High-empathy appeals, which evoke a vicarious experience of a character's situation, are also associated with lower levels of reactance (i.e., than those evoked by low-empathy appeals; Shen, 2010). Important to note is that empathy contains three components: affective, which entails sharing characters' emotions; cognitive, which involves adopting characters' perspectives; and associative, which consists of processing a message as if the events experienced by a character are also happening to oneself (Shen, 
2010, 2011). Shen $(2010,2011)$ tested PRT with PSAs utilizing empathy-arousing messages that addressed these three components and found that empathy had a positive indirect effect on persuasion by alleviating reactance.

Narratives. Conveying persuasive health messages through the use of a narrative testimonial is related negatively to perceived freedom threat (Gardner \& Leshner, 2015; Quick et al., 2014). For example, Gardner and Leshner (2015) found that the use of narratives rather than informational arguments to advocate for diabetes self-care behaviors, especially those that highlighted the benefit to others rather than oneself, attenuated diabetic adults' perceptions of freedom threat. Notably, the effectiveness of narratives in mitigating the experience of reactance has been attributed to the ability of narratives to disguise the underlying persuasive motive of the message (Moyer-Gusé, 2008; Moyer-Gusé \& Nabi, 2010).

Inoculation. In addition to elements incorporated within or following a persuasive message, there is evidence that reactance can be assuaged through the use of persuasive tactics that occur prior to exposure to a persuasive message. For example, Richards and Banas (2015) presented participants with an inoculation message that warned them about the potential freedom threat that may occur upon exposure to the impending persuasive appeal about binge drinking, and also provided participants with reasons not to experience reactance. Results revealed that inoculation reduced perceived freedom threat and subsequent experience of reactance.

\section{Integration of PRT within Other Theoretical Frameworks}

The heuristic value of PRT has arguably been on the rise due to its successful integration with other empirically-supported theories to explain individuals' responses to 
persuasive requests. There has recently been a surge in the number of studies that integrate PRT with other theories, some well-known in the persuasion and health domains and some from other communication domains. For instance, Reinhart and Anker (2012) explored how PRT and narrative transportation theory function together to promote positive reactions to PSAs about organ donation. They found that psychological reactance mediated the effect of transportation (i.e., the extent to which individuals become emotionally involved in the narrative), such that more transported individuals experienced lower levels of reactance and subsequently had more favorable reactions toward organ donation, regardless of their organ donor status. In addition to transportation theory, PRT has been applied in conjunction with Galileo theory (Bessarabova et al., 2013), the dominant thought disruption hypothesis (Quick, 2013), the activation model of information exposure (Xu, 2015), and inoculation theory (Miller et al., 2013; Richards \& Banas, 2015). Prospect theory has been utilized the most in conjunction with PRT (Cho \& Sands, 2011; Quick \& Bates, 2010; Shen, 2015), particularly within the context of organ donation (e.g., Quick et al., 2014; Reinhart et al., 2007).

Tests of PRT have also drawn from well-known components of theories used in health communication and persuasion. For example, Rains and Turner (2007) examined severity, a widely-used construct within the domain of fear appeals (see Mongeau, 2013), as antecedent to the reactance process. Nabi, Roskos-Ewoldsen, and Carpentier (2008) also incorporated constructs adapted from the fear appeal literature, including fear and efficacy. Yet another line of reactance research has drawn from the narrative-based entertainment education influence strategy (Moyer-Gusé, Jain, \& Chung, 2012; Moyer- 
Gusé \& Nabi, 2010).

\section{Future Directions in PRT Research}

Despite the success with which PRT has been applied to a wide range of contexts and theoretical frameworks, there are still strides to be made in the reactance literature and connections that need to be forged between the constructs underlying PRT and similar constructs in other frameworks. For example, drawing from the literature on communication and aging, the Communication Predicament of Aging Model (Ryan, Giles, Bartolucci, \& Henwood, 1986) and the Communication Enhancement Model (Ryan, Meredith, MacLean, \& Orange, 1995), which are detailed later in this chapter, each examine caregiver communication as it relates to older adult recipients' perceptions of autonomy and dependence, but neither have been explored with a reactance lens. Moreover, as previously mentioned, there is evidence that reactance is especially prevalent during the transition into older adulthood (Miller et al., 2007). Therefore, a context suitable for examining communication and health-related freedom threats may be communication between older adults and their adult child caregivers.

Important to consider is that approximately $36 \%$ of older adults experience some limitation to their free behavior due to natural age-related health changes, such as hearing impairment, vision difficulty, and decline in mobility (Administration on Aging, 2014), and older adults are also at increased risk for chronic conditions that further limit functioning (Centers for Disease Control and Prevention [CDC], 2009). Beyond these natural health changes, research suggests that independence in older age is also threatened by negative expectations, perceptions, and communication about older age (Baltes, 1996; Ouwehand, de Ridder, \& Bensing, 2007). For example, individuals' 
communication with older adult family members may serve to unnecessarily limit the autonomy of these older adults, as many of the problems arising within families with an older adult member stem from issues of power and control (Fox, 1999).

As previously noted, PRT posits that individuals value their autonomy and experience reactance when they perceive that this autonomy is being threatened. Working from this framework, there are important autonomy-based parallels between the transition into older adulthood and the transition into adolescence, the latter being a period ridden by heightened reactance (Burgoon et al., 2002; Quick et al., 2013). Within the family communication context specifically, both transitional stages are typified by a need to negotiate between one's dependence on and independence from family members (Baltes, 1996; Cicirelli, 1992). Examples of family communication-based challenges specific to maintaining one's autonomy during older adulthood include family members' stereotyped expectations about older adults' lack of competence irrespective of their actual capacity for independence (Ryan et al., 1986) and the ways in which adult children and their older adult parents use communication to negotiate between autonomy and dependence in caregiving situations (Cicirelli, 1992; Egbert, 2014; Hummert \& Morgan, 2001; Pecchioni \& Nussbaum, 2000).

\section{Family Caregiving}

Older adults comprise the nation's fastest growing demographic; one in seven Americans (14.1\%) is age 65 or over and individuals who have reached the age of 65 are expected on average to live another 19.3 years (Administration on Aging, 2014). Therefore, it is not surprising that the need to provide informal (i.e., unpaid) care for an older adult family member is also on the rise to meet these increased demands for care 
and also to offset healthcare costs (Feinberg, Reinhard, Houser, \& Choula, 2011). In fact, family caregivers are becoming integral to older adult care; as Piercy and Chapman (2001) noted, "despite persistent myths that families abandon their aged relatives to nursing home and other care facilities, reviews of research findings show that family members provide the majority of assistance needed by their dependent elders" (p. 386).

Currently, 34.2 million individuals provide informal care for an older adult family member (National Alliance for Caregiving and AARP Public Policy Institute [NAC and AARP], 2015a). The majority of these family caregiving relationships are between adult children and their older adult parents; $72 \%$ of family caregivers provide care for a parent, step-parent, mother-in-law, or father-in-law (Mendes, 2011) who are, on average, over the age of 69 (NAC and AARP, 2015a). Given that family caregivers themselves are typically women (60\%; NAC and AARP, 2015a), the most common caregiving dyad is that of the biological mother and daughter (Cicirelli, 1992).

Adult child caregivers spend an average of 23.9 hours per week providing care to their older adult parent or parent-in-law (NAC and AARP, 2015b). Caregiving duties tend to fall within two categories: activities of daily living (ADLs), which entail assistance with basic personal needs such as dressing, eating, and bathing; and instrumental activities of daily living (IADLs), which entail assistance with everyday tasks including taking medication, shopping for groceries, and transportation (CDC, 2009). On average, caregivers assist with 1.7 ADLs and 4.2 IADLs (NAC and AARP, 2015a, 2015b). Important to note is that most family caregivers do not receive adequate training prior to assuming primary caregiving responsibilities for their older adult parent (NAC and AARP, 2015a). 


\section{Family Caregiving and the Independence-Dependence Tension}

Themes of negotiating between independence and dependence are pervasive in the family caregiving literature. This may be due in part to the changing roles and power status within the aging parent-child relationship, which is a struggle for adult children and older adults alike. On one hand, older adult parents find themselves struggling to maintain independence as they adjust to the changes that accompany the transition into older adulthood (e.g., whether to continue to drive; Hummert \& Morgan, 2001; Morgan \& Hummert, 2000; Wenzel \& Poynter, 2014). On the other hand, adult children face the dilemma between meeting the autonomy needs of their parents and meeting their own need of protecting their parents' health (Baltes, 1996; Hummert \& Morgan, 2001). On the whole, these tensions inherent to the aging parent-child relationship, especially within caregiving situations, influence the communication quality of this relationship as well as health outcomes for both parties.

Hummert and Morgan (2001) suggested that problematic family caregiving interactions and their subsequent health and relational outcomes can be understood through the framework of the Communication Predicament of Aging Model (CPA; Ryan et al., 1986). Grounded in communication accommodation theory (CAT; Giles, Coupland, \& Coupland, 1991), the CPA explains that problematic intergenerational interactions sometimes arise due to younger interlocutors' tendencies to modify their communication with older adults based on negative stereotypes of old age. For example, individuals may communicate in a manner that reflects their stereotyped expectation that older adults are incompetent and dependent (for a review, see Hummert, Garstka, Ryan, \& Bonneson, 2004). What follows is the communication predicament of aging, a term 
used to describe instances in which there is an undesired discrepancy between stereotyped expectations for communication with an older adult and the older adult's actual level of communication competence (Ryan et al., 1986). Following the assumptions of CAT, these unnecessary modifications in communication behavior toward an older adult are considered overaccommodation. The CPA predicts that communication overaccommodation results in a negative feedback cycle involving constrained opportunities for communication and negative physiological outcomes for the older adult - including a loss of autonomy - that ultimately reinforces negative age-stereotyped behavior (Ryan et al., 1986).

Within intergenerational interactions, including those between an adult child caregiver and their older adult parent, there are various manifestations of overaccommodation that result from age-stereotyped expectations. For example, Morgan and Hummert (2000) used scenario-based research to examine perceptions related to the use of various control strategies with older adults versus younger adults. Use of the direct control strategy was perceived more negatively than the indirect and no control strategies by young, middle-aged, and older adult participants; however, participants from all age groups deemed the use of the direct control strategy as more appropriate and the no control strategy as less appropriate when addressing a problem behavior with an older adult mother versus a younger adult daughter. In other words, participants were more likely to support dependence among older adults than younger adults and support autonomy among younger adults than older adults. Besides control strategies, patronizing communication (also identified as elderspeak [Kemper, 1994] and secondary baby talk [Caporael, 1981]) is also considered overaccommodative and is characterized by 
unnecessary modifications like referring to the older adult using terms of endearment (e.g., sweetie), using simple vocabulary or exaggerated intonation, and speaking loudly (for a review, see Ryan, Hummert, \& Boich, 1995). Additionally, communication that reinforces an older adult's dependent behavior may also arise from age-stereotyped expectations; Baltes and Wahl (1996) established that caregivers of older adults tend to engage in dependence-support and independence-ignore scripts, such that these caregivers reinforce or reward dependent behavior and largely ignore or discourage independent behavior. Important to note is that although caregivers' intentions for engaging in these communication behaviors are neither selfish nor manipulative (Pecchioni \& Nussbaum, 2000), older adults typically interpret overaccommodation negatively, especially in non-institutional settings (Fowler \& Fisher, 2009; O’Connor \& Rigby, 1996; Ryan, Hummert, et al., 1995).

\section{Effects of Family Caregiver Communication on Older Adults' Health}

Researchers have suggested that maintaining autonomy is essential for successful aging (e.g., Ford et al., 2000; Pecchioni \& Nussbaum, 2000), particularly within cultures like the US that prioritize the ability to live independently (Fowler \& Fisher, 2009; Pecchioni, Ota, \& Sparks, 2004). As such, whether adult child caregivers engage in communication behavior that supports increased dependence or maintains their parents' need for autonomy influences the health and well-being of older adult care recipients (Hofland, 1988). In fact, one prediction of the CPA is that periodic constrained opportunities for communication may result in negative outcomes for older adults, including a loss of personal control and self-esteem as well as diminished psychological activity and social interaction (Ryan et al., 1985). This prediction has received empirical 
support; for example, Edwards and Noller (1998) found that patronizing communication from family caregivers was related negatively to the well-being of older adult care recipients and positively to conflict within the caregiver-recipient relationship. Similarly, O'Connor and Rigby (1996) found that exposure to elderspeak coupled with negative perceptions of elderspeak was related to lower self-esteem among older adults. There is also evidence that reinforcement of negative age stereotypes negatively affects older adults' functional health (e.g., walking speed, ability to complete memory tasks) and physiological functioning (e.g., cardiovascular stress; for a review, see Levy, 2003).

A solution to overcoming the negative effects of the CPA is the Communication Enhancement Model (CEM; Ryan, Meredith, et al., 1995), which posits that individualized communication facilitates positive intergenerational interactions. Specifically, caregivers who modify their communication behavior to meet the actual rather than stereotyped needs of older adults can serve to empower the older adult. Subsequently, these feelings of empowerment rather than dependency result in optimization of the older adult's health, well-being, and competence (Ryan, Meredith, et al., 1995). For example, Williams, Kemper, and Hummert (2003) implemented a training program that reduced the use of elderspeak among nursing home staff and found that residents rated nursing assistants' communication as more respectful and less controlling as compared to pre-training. Given that the role of communication in negotiations between autonomy and dependence is central to both the CPA and CEM, it may be the case that PRT at least partially explains older adult's processing of and responses to caregiving messages; indeed, messages of autonomy-support are known to trigger lower perceptions of reactance than high-controlling messages (Miller et al., 2007), whereas 
high-controlling messages reinforce a sense of "helpless dependence" among older adults (Lanceley, 1985, p. 125).

Beyond the established negative effects of diminished autonomy and positive effects of empowerment on older adults' health, there is evidence that older adults have adverse affective and behavioral reactions to autonomy threats. For example, Tucker (2002) found that older adults experience negative affect toward significant others (e.g., children) attempting to influence their health behavior using direct social control strategies (e.g., direct requests, threats), especially when older adults are not satisfied with this relationship. Results of another study (Rook, Thuras, \& Lewis, 1990) indicated that similar direct social control attempts have no effect on discouraging older adults' risky health behavior; in fact, control attempts to deter medication misuse actually encouraged more of the behavior. Similarly, Tucker, Orlando, Elliott, and Klein (2006) found that older adults experience negative affect toward significant others' use of negative control strategies, and this negative affect is related to the increased likelihood that older adults will ignore the health-related influence attempt or hide their unhealthy behavior. Notably, similar experiences of negative affective and cognitive states are involved in the reactance process following a perceived freedom threat (see Dillard \& Shen, 2005).

\section{Study Rationale}

As previously noted, the number of older adults in the US as well as the demand for family caregiving are on the rise. Therefore, the paucity of research examining communication processes involved in caregiving for older adult parents (Miller, Shoemaker, Willyard, \& Addison, 2008) and communication challenges later in life 
(Hummert, 2007) is surprising and perhaps a cause for concern. Morgan and Hummert (2000) noted that significant strides in this area of research, especially related to individuals' struggle to maintain independence in older age, still need to be made:

The literature on family communication and the gerontology literature have directed little attention to [communication situations involving issues of dependency and autonomy]. As our aging population increases and family members are required to provide informal care for their aging members, we will need a better understanding of how to negotiate these issues in order to ensure the well-being of all those involved. (p. 60)

One avenue related to communication challenges within the adult child-older adult parent caregiving relationship is further exploration of the processes and health outcomes triggered by exposure to freedom-threatening messages; in particular, the experience and consequences of psychological reactance.

When adult children engage in caregiving-related communication with their aging parents, issues of freedom threat are involved. Indeed, existing literature suggests that older adults favor their sense of autonomy (Dickson, Hughes, \& Walker, 2005), indicating that they may perceive instances in which they are dependent on others as freedom threatening. Moreover, various types of overaccommodation characterizing problematic intergenerational interactions within the context of family caregiving are inherently freedom threatening. For example, Hummert and Ryan (1996) noted that patronizing communication can be used by family caregivers to assert power over older adults. Additionally, patronizing communication imposes conversational constraints on older adults and encourages dependent behavior (Baltes \& Wahl, 1996; Ryan et al., 
1986), which itself is inherently freedom threatening.

Given these links to freedom threat - the trigger of psychological reactance (Quick \& Bates, 2010; Quick \& Considine, 2008; Quick \& Stephenson, 2008) exploring the role of reactance in family caregiving interactions may provide further insight into the types of communication that threaten older adults' autonomy and result in negative health effects. Notably, reactance is a function of age such that the experience of reactance tends to be particularly salient during transitional periods, including the transition into older adulthood (Burgoon et al., 2002; Miller, 2015; Voyer et al., 2005). However, research examining reactance as a function of age has focused on adolescents as a population prone to experiencing reactance because of their emerging sense of freedom (Burgoon et al., 2002; Grandpre et al., 2003; Miller et al., 2006) and has largely ignored how reactance functions during the transition into older adulthood, despite the aforementioned parallels between these two transitional periods (Baltes, 1996; Cicirelli, 1992). Indeed, the transition into older adulthood is characterized by the tension between dependency and autonomy, which yields "a developmental struggle as much for the elderly in their environment as for adolescents in their environment” (Baltes, 1996, p. 23). Therefore, considering that individuals transitioning into older adulthood may experience heightened levels of reactance and also tend to receive messages that support dependency rather than independence (Baltes \& Wahl, 1996) due to others' stereotyped expectations for communication with older adults (Ryan et al., 1986), PRT can provide a framework for a communicative way in which adult child caregivers can effectively manage their older adult parents' need for autonomy. Specifically, PRT can be applied to examine family caregiving messages that are reactance-inducing and how older adults' 
reactions to these types of freedom-threatening health messages may result in healthrelated boomerang effects.

This manuscript seeks to contribute to the study of PRT as it applies to caregiving communication in the aging parent-child relationship by addressing two specific purposes. The first purpose of this study is to explore the role of reactance in caregiving communication between adult children and their older adult parents. That is, this study will identify the types of health-related messages exchanged between older adults and their adult child caregivers that are reactance-inducing, the health contexts in which the exchange of these messages occur, and the outcomes of reactance-inducing persuasive health messages in the context of healthcare compliance among older adults. The second purpose of this study is to create messages that can be used by caregivers to simultaneously encourage older adult parents' healthcare compliance and optimize their perceived autonomy. That is, this study will test PRT and determine which caregiving messages to avoid to circumvent older adults' experience of reactance and subsequently promote their healthcare compliance.

\section{Research Questions and Hypotheses}

A precursor to testing PRT in the context of caregiving for older adult parents is to identify the messages that adult child caregivers typically use to persuade their older adult parents to engage in health-related behaviors. However, existing literature on informal caregiving focuses largely on spousal caregivers and the topic of relieving caregiver burden, rather than on other caregiving relationships (e.g., intergenerational caregiving) and the actual communication between the care provider and recipient (Egbert, 2014). In fact, Morgan and Hummert (2000) noted a need for descriptive studies 
about various control strategies used in caregiving conversations between adult children and their older adult parents to further advance our understanding about how aging families negotiate the independence-dependence tension. Therefore, the first portion of this dissertation is formative in nature and is designed to identify the messages that adult child caregivers use to gain compliance from older adult parents and particular caregiving messages that older adult parents perceive as freedom threatening.

Given that caregiving communication between adult children and their aging parents involves issues of freedom threat (Baltes \& Wahl, 1996; Dickson et al., 2005; Hummert \& Ryan, 1996; Ryan et al., 1986), which is the trigger of psychological reactance (Quick \& Bates, 2010; Quick \& Considine, 2008; Quick \& Stephenson, 2008), it is possible that caregiving messages used by adult child caregivers to gain compliance are perceived as autonomy threatening by older adult parents. However, given that most studies on informal caregiving consider the perspective of the caregiver but neglect to take into account the perspective of the care recipient (Egbert, 2014; Lyons, Zarit, Sayer, $\&$ Whitlatch, 2002), it is important to identify the messages that older adults themselves perceive as particularly freedom threatening. Therefore, two research questions reflecting each of these perspectives were asked:

RQ1: What types of caregiving messages do adult children use to gain healthcare compliance with their older adult parents?

RQ2: What types of caregiving messages received from adult children do older adults perceive as freedom threatening?

Another important avenue to explore in formative research connecting PRT to caregiving for older adult parents is whether some caregiving requests elicit a greater 
magnitude of reactance than others because of the particular health behavior requested. The health context is important to consider given some inconsistencies in existing PRT literature related to the ability of certain message factors to trigger reactance across all health behaviors. For instance, Gardner and Leshner (2015) found discrepancies between messages advocating physical activity and those advocating diet among diabetic adults. Specifically, diet messages were perceived as significantly more freedom threatening than physical activity messages, despite the authors' use of similar language features across all message conditions. Consistent with Brehm and Brehm (1981), Gardner and Leshner recommended that researchers consider the role of the behavior being threatened because some free behaviors are more important than others and consequently elicit a greater magnitude of reactance upon being threatened. Thus, the following research question was asked:

RQ3: In caregiving messages received from adult children, which health behaviors are most related to perceptions of freedom threat among older adults?

Given that reactance manifests as the motivation to restore autonomy (Brehm, 1966; Brehm \& Brehm, 1981), it is also important to understand what behaviors older adults engage in to restore their autonomy as a result of exposure to caregiving messages that arouse reactance. Moreover, by identifying these behavioral outcomes, we can better assess the extent to which reactance-inducing messages have problematic implications for the health and well-being of older adults. Therefore, the following research question was asked:

RQ4: What behaviors do older adults engage in to restore their autonomy in 
response to freedom-threatening caregiving messages received from their adult children?

Once the persuasive messages used by adult child caregivers to gain healthcare compliance from their older adult parents are identified, PRT can be empirically tested to examine the extent to which these caregiving messages trigger or mitigate the experience of reactance. As previously mentioned, existing research on PRT makes it abundantly clear that controlling language intensifies the experience of reactance (Dillard \& Shen, 2005; Grandpre et al., 2003; Quick et al., 2013). In contrast, messages that emphasize choice (e.g., by providing behavioral options [Shen, 2015] or include a restoration postscript [Bessarabova et al., 2013; Miller et al., 2007]) are less likely to induce reactance. Therefore, it is likely that caregiving messages that feature freedomthreatening language will elicit greater reactance arousal in comparison to those that acknowledge and support older adults' autonomy.

Based on recommendations by Quick and colleagues (Quick \& Bates, 2010; Quick \& Considine, 2008; Quick \& Stephenson, 2007a), reactance arousal following a controlling message should be treated as a two-step process. That is, a persuasive, freedom-threatening caregiving message should first elicit the older adult's perception of a freedom threat, which subsequently triggers their experience of reactance. In addition, because reactance motivates individuals to re-establish their threatened or eliminated freedom (Brehm, 1966; Brehm \& Brehm, 1981), the older adult's response to reactance should be to engage in behavior that serves to restore their sense of independence (i.e., freedom restoration behavior). Based on this conceptualization of the reactance process, the following hypotheses were posited: 
H1: Freedom-threatening caregiving messages will result in greater perceived freedom threat than autonomy-supporting caregiving messages.

H2: $\quad$ Perceived freedom threat will be related positively to state reactance.

H3: State reactance will be related positively to freedom restoration behavior.

H4: Relative to autonomy-supporting caregiving messages, there will be a significant indirect effect of freedom-threatening caregiving messages on freedom restoration behavior sequentially through perceived freedom threat and state reactance.

It is important to consider that the experience of reactance by older adults in the caregiving context may be conditional upon perceptions related to communication and control. As mentioned previously, individuals' levels of trait reactance, or the predisposition to experience heightened reactance in response to any limitation to one's freedom to choose (Burgoon et al., 2002; Hong \& Faedda, 1996; Shen \& Dillard, 2005), influences interpretations of and responses to persuasive health messages. Specifically, the experience of reactance in response to a persuasive message is strongest when both trait reactance and freedom threat are high and weakest when both are low (Dillard \& Shen, 2005; Miller et al., 2007; Quick et al., 2011; Quick \& Stephenson, 2008; Shen \& Dillard, 2005). Additionally, individuals high in trait reactance are more likely than others to act in opposition of a persuasive health request (Dillard \& Shen, 2005; Quick \& Stephenson, 2007b, 2008; Shen \& Dillard, 2005). Given that trait reactance may be especially prevalent during the transition into older adulthood (Miller et al., 2007), these findings should hold in the context of family caregiving. Thus, the following hypothesis was posited: 
H5a: Trait reactance will moderate the indirect effect of freedom-threatening caregiving messages on state reactance through perceived freedom threat such that the indirect effect is strengthened as trait reactance increases.

H5b: Trait reactance will moderate the indirect effect of perceived freedom threat on freedom restoration behavior through state reactance such that the indirect effect is strengthened as trait reactance increases.

A perception related to communication and control known to affect intergenerational caregiving communication is the notion of paternalism, or the belief that restricting an individual's freedom is warranted if it benefits the well-being of that individual (Cicirelli, 1992). Notably, paternalistic decision making by adult children on behalf of their older adult parents can be manipulative and forceful in nature and is often interpreted negatively (Fowler \& Fisher, 2009; Morgan \& Hummert, 2000). However, the extent to which individuals believe in paternalism appears to influence perceptions about the appropriateness of paternalistic interventions. For instance, Pecchioni and Nussbaum (2000) found that when older adult mothers strongly believed in paternalism, daughters tended to control conversations about caregiving prior to their mother's dependency. Moreover, these communication tendencies are expected to endure as the older adult enters stages of dependency and the need for informal caregiving increases (Pecchioni \& Nussbaum, 2000).

Along these same lines, Cicirelli (2003) found that older adult mothers' and their daughters' paternalism beliefs are related to daughters' paternalistic caregiving decisions and conflict within the dyad about caregiving decisions. Older adult mothers with adult daughter caregivers who hold high paternalism beliefs tend to report greater amount of 
conflict about their daughters' caregiving decisions than those with low paternalism beliefs. Additionally, as reported by daughters, the greatest amount of conflict occurred between mothers with high paternalism beliefs and mothers with low paternalism beliefs.

Given that paternalism implies the belief that older adults do not have the capacity to engage in free behavior (Pecchioni \& Nussbaum, 2000) but that older adult parents with strong beliefs in paternalism appear to relinquish control to their adult child caregivers (Pecchioni \& Nussbaum, 2000), a strong belief in paternalism may mitigate the experience of reactance towards controlling messages as well as the proclivity to restore freedom following the experience of reactance. Thus, older adults' beliefs in paternalism should be taken into consideration when examining the role of PRT in the caregiving context. As such, the following hypothesis was posited:

H6a: Older adults' paternalism beliefs will moderate the indirect effect of freedom-threatening caregiving messages on state reactance through perceived freedom threat such that the indirect effect is weakened as paternalism increases.

H6b: Older adults' paternalism beliefs will moderate the indirect effect of perceived freedom threat on freedom restoration behavior through state reactance such that the indirect effect is weakened as paternalism increases.

\section{Summary}

The purpose of this dissertation is to examine the antecedents and consequences of psychological reactance in the context of family caregiving for older adults. Specifically, the first research question (RQ1) identifies persuasive caregiving messages 
from the perspective of an adult child providing care for an older adult parent. The second and third research questions (RQ2-RQ3) explore perceptions about caregiving messages from the perspective of an older adult receiving care from an adult child. The fourth and final research question (RQ4) is designed to explore older adults' responses to caregiving messages from the perspectives of older adults and adult child caregivers. The first four hypotheses (H1-H4) are designed to test PRT and explore the extent to which freedom-threatening caregiving messages trigger the reactance process. The remaining two hypotheses (H5-H6) examine two potential moderating factors (i.e., trait reactance and paternalism beliefs) and their effects at two different points in the reactance process; namely, on perceptions of freedom threat and enactment of freedom restoration behavior. In addition to providing theoretical implications that extend existing research on PRT, results will yield practical implications related to caregiving messages that can be used to promote health-related compliance among older adult parents. 


\section{CHAPTER II}

\section{Method}

\section{Overview}

The four research questions and six hypotheses specified above were addressed in three studies. Study One, which informed research questions two, three, and four, identified health messages that older adults receive from their adult child caregivers and perceive as freedom threatening; health behaviors that tend to be the subject of these freedom-threatening messages; and older adults' behavioral responses to these freedomthreatening messages. Study Two, which informed research questions one and four, identified health messages that adult child caregivers to gain health behavior compliance from their older adult parents, as well as the behaviors in which their older adult parents engage that exemplify nonadherence. Study Three, which assessed the hypotheses, tested PRT as it applies to older adults' responses to persuasive caregiving messages from their adult children and examined potential moderators of the reactance process in this context (i.e., trait reactance and paternalism beliefs).

\section{Study One}

\section{Recruitment}

To participate in Study One, participants were required to be older adults (i.e., age 65 and above; Cicirelli, 2003) who receive at least 10 hours per week of care/assistance (i.e., IADLs and/or ADLs) from at least one adult child (e.g., biological daughter, adopted daughter, daughter-in-law, etc.). After obtaining approval by the university's Institutional Review Board, participants were recruited from a community senior center $(n=9)$ as well as a nursing and rehabilitation center $(n=10)$ both of which were located 
in North Central West Virginia. Recruitment occurred through the use of flyers posted around the facilities as well as with the help of volunteers and staff at each facility. The recruitment script and recruitment flyer can be found in Appendices A and B, respectively.

\section{Participants and Procedures}

Study One participants $(N=19 ; 2$ male, 17 female) ranged in age from 68 to 96 $(M=83.62, S D=8.16)$. Most participants $(n=12,63.16 \%)$ identified their ethnicity as White/Caucasian, with four Native American and three who did not report their ethnicity. Regarding their highest level of education, one participant reported having less than a high school education, eight reported high school graduate/G.E.D. or equivalent, four reported having some college but no degree, and six did not report their highest level of education. Regarding relationship status, 12 participants were widowed, 1 participant was married, 1 reported living with her partner, and 5 did not disclose their relationship status. More than half of the participants $(n=10,52.63 \%)$ reported receiving the most care from their biological daughter, with four receiving the most care from their biological son. Five participants did not indicate their relationship to the child from whom they receive the most care. In addition to receiving care from an adult child, 11 participants reported receiving care from a nurse/aide. On average, participants reported receiving assistance from a caregiver for 4.09 IADLs $(S D=2.63)$ and 1.00 ADL $(S D=1.73)$.

All discussions were held at the recruitment facilities. Each participant received a cover letter informing them about the purpose of the study and that their participation was voluntary (see Appendix C). Participants were also notified that the discussions would be audiotaped for data analysis purposes and were assured that the research team would 
keep their responses confidential. I served as the moderator for each discussion and used a moderator guide (see Appendix D) to ensure each research question was addressed at some point during the discussion and also provided participants with a written definition of "freedom-threatening messages," a term which was used repeatedly during the focus group. At the end of the discussion, participants completed a short demographic questionnaire (Appendix E). Data were gathered until theoretical saturation was reached (i.e., no new themes emerged from the data; Glaser \& Strauss, 1967), which resulted in four focus groups and one in-depth interview. The final sample size of 19 is comparable to existing qualitative research conducted with older adults who are dependent on an adult child caregiver (e.g., Wenzel \& Poynter, 2014). The average length of the focus group discussions and in-depth interview was 35 minutes and 37 seconds.

\section{Data Analysis}

Prior to analysis, the focus groups and interview were transcribed verbatim from audio recordings and checked for accuracy. To ensure confidentiality, participants' names were changed to pseudonyms; specifically, using an online name generator, these pseudonyms were created based on the first letter of the participant's given first name and popular baby names from the decade in which the participant was born. Transcripts were then analyzed, separately for each of the three research questions, using the grounded theory approach (Glaser \& Strauss, 1967; Strauss \& Corbin, 1998), such that themes emerged inductively from the data rather than the literature previously published on PRT. To begin, I read through the focus group and interview transcripts several times to gain a full understanding of the data (Strauss \& Corbin, 1998). Next, I open-coded the transcripts (Strauss \& Corbin, 1998) to identify potential themes, and labeled each full 
thought or idea with a word or phrase to capture its meaning. Next, axial coding (Strauss $\&$ Corbin, 1998) was used to compare related words and phrases across the focus groups and interview and to condense the data into common, overarching themes (i.e., categories).

Using Owen's (1984) criteria, these categories emerged from the responses based on recurrence (i.e., instances of shared meaning across different words or phrases), repetition (i.e., multiple uses of a certain word or phrase), and forcefulness (i.e., vocal emphasis on particular words or phrases). Based on the emergent categories, I generated a codebook for each of the three research questions explored in this study. A definition was provided for each category and example quotes taken directly from the transcripts were added to further distinguish the categories from one another.

Intercoder reliability for each of the three research questions was assessed to ensure consistency of the codebooks. Two independent coders (i.e., upper-level undergraduate students trained in communication research methods) who did not have knowledge of the specific research questions were trained to code data using the established codebooks. After thorough explanation about the codebooks and coding process, the two independent coders individually coded one full focus group transcript, which comprised approximately $20 \%$ of the data; this proportion falls within the recommended $10 \%$ to $25 \%$ (Lombard, Snyder-Duch, \& Bracken, 2002; Wimmer \& Dominick, 2014). I segmented the transcript data into units of analysis comprised of one or more sentences of various lengths such that each unit represented participants' full thoughts and ideas (i.e., rather than specific speech turns or phrases; Lindlof \& Taylor, 2002). 
An agreement consisted of both coders either selecting the same category to represent a unit of analysis or deciding that the unit was a non-code. Discrepancies between the coders were resolved through discussion and consensus. Intercoder reliability for each codebook was calculated using Cohen's (1960) kappa, a conservative measure of agreement that accounts for agreement by chance (Lombard et al., 2002). Reliability was $\kappa=.73$ for RQ2, $\kappa=.82$ for RQ3, and $\kappa=.79$ for RQ4. After obtaining acceptable reliability for each of the three research questions (i.e., a value of kappa greater than or equal to the recommended .70 for exploratory research and when using conservative indices; Lombard et al., 2002), I coded the remaining transcripts with the established codebooks.

\section{Study Two}

\section{Recruitment}

To participate in Study Two, participants were required to be adult child caregivers who provide at least 10 hours per week of care/assistance (i.e., IADLs and/or ADLs) to at least one older adult parent (e.g., biological mother, adoptive mother, mother-in-law, etc.). Following approval by the university's Institutional Review Board, participants were recruited using a purposive, network sampling technique, such that I was put in touch with individuals who met the inclusion criteria with the help of volunteers and staff from the facilities used for recruitment in Study One as well as other members of my networks. The recruitment flyer used for Study Two can be found in Appendix F.

\section{Participants and Procedures}

Study Two participants ( $N=14 ; 3$ male, 11 female) ranged in age from 47 to 67 
$(M=58.00, S D=5.27)$. All participants $(n=14)$ reported their ethnicity as White/Caucasian. Regarding their highest level of education, two participants reported having a high school graduate/G.E.D. or equivalent, three reported having some college but no degree, six reported having an undergraduate college degree, and three reported having a graduate degree. Regarding relationship status, 12 participants were married, 1 was widowed, and 1 was single. On average, caregivers had 2 children $(S D=0.78)$. More than half of the participants $(n=9,64.29 \%)$ reported providing care for their biological mother, with four providing care for their biological father and one for their mother-inlaw. On average, caregivers had been providing care for their parent for 7.80 years $(S D=$ 6.32). Four caregivers reported that the parent for whom they provided care/assistance lived in their household; the remaining caregivers, on average, lived 5.06 miles from their parent $(S D=4.06)$. Five caregivers reported that in addition to the informal care they provided, their parent also received formal care from a provider associated with a service system $(M=17.00$ hours per week, $S D=17.02)$.

Interviews were conducted either face-to-face $(n=9)$ or over the phone $(n=5)$. At the beginning of each interview session, participants received a cover letter which informed them about the purpose of the study and that their participation was voluntary (see Appendix G). Participants were also notified that interviews would be audiotaped for data analysis purposes and assured that their responses would remain confidential. I conducted each interview using a semi-structured interview guide (see Appendix $\mathrm{H}$ ) to ensure that each research question was addressed at some point during the interview and to aid in obtaining rich data from participants. Similar to Study One, interviews were conducted until theoretical saturation was reached (i.e., no new themes emerge from the 
data; Glaser \& Strauss, 1967), which resulted in 14 in-depth interviews; this sample size is comparable to existing communication research employing interviews with adult child caregivers of older adult parents (e.g., Miller et al., 2008; Plander, 2013). The average length of the interviews was 29 minutes and 13 seconds. Upon completion of the interview and the questionnaire detailed in the following section, each participant received a $\$ 10$ gift card.

\section{Instrumentation}

At the end of the interview, participants completed a questionnaire (see Appendix I) that consisted of two parts. The first part contained demographic questions. The second part featured five caregiving messages informed by results from Study One: one offering directives message, one expressing doubt message, one loss-framing message, and two autonomy-supporting messages. Participants were asked to rate each of the five caregiving messages based on two items: (a) how realistic it is that they would use the caregiving message with their older adult parent $(1=$ not realistic, $7=$ extremely realistic), and (b) how effective they think that caregiving message would be for gaining compliance from their older adult parent $(1=$ not effective, $7=$ extremely effective $)$. For ratings of 4 or below on realism and/or effectiveness, participants were also asked to provide an open-ended response about why they rated the message as such.

\section{Data Analysis}

Data analysis procedures for Study Two were similar to the procedures detailed for Study One. Prior to analysis, all interviews were transcribed verbatim from audio recordings and checked for accuracy. To ensure confidentiality, participants' names were changed to pseudonyms; specifically, using an online name generator, these pseudonyms 
were created based on the first letter of the participant's given first name and popular baby names from the decade in which the participant was born. The transcripts were then analyzed, separately for each research question, using the grounded theory approach (Glaser \& Strauss, 1967; Strauss \& Corbin, 1998). Specifically, following Strauss and Corbin (1998), I read through the interview transcripts several times to gain a full understanding of the data before open coding the transcripts to identify potential themes. Next, axial coding was used to compare related words and phrases across the interviews and to condense the data into categories. Categories emerged based on Owen's (1984) criteria of recurrence, repetition, and forcefulness. Based on the emergent categories, I generated a codebook for both of the research questions explored in this study. A definition was provided for each category and example quotes taken directly from the transcripts were added to further distinguish the categories from one another.

To ensure the consistency of these codebooks, intercoder reliability was assessed using procedures similar to those in Study One. Specifically, two independent coders (i.e., upper-level undergraduate students trained in communication research methods) who did not have knowledge of the specific research questions were trained to code data using the established codebooks. The two independent coders individually coded three full interview transcripts, which comprised approximately $20 \%$ of the data; this proportion falls within the recommended $10 \%$ to $25 \%$ (Lombard et al., 2002; Wimmer \& Dominick, 2014). I segmented the transcript data into units of analysis comprised of one or more sentences of various lengths such that each unit represented participants' full thoughts and ideas (Lindlof \& Taylor, 2002). Intercoder reliability between the coders was calculated using Cohen's (1960) kappa, which resulted in $\kappa=.74$ for RQ1 and $\kappa=$ 
.72 for RQ4. Discrepancies between the coders were resolved through discussion and consensus. After obtaining acceptable reliability (i.e., .70 or greater; Lombard et al., 2002), I coded the remaining interview transcripts with the established codebooks.

\section{Study Three}

\section{Recruitment}

Following approval from the university's Institutional Review Board, participants for Study Three were recruited online via Mechanical Turk (MTurk; www.mturk.com). Owned by Amazon.com, MTurk is an online crowdsourcing labor market in which "requesters" post "human intelligence tasks" (HITs) to be performed by "workers" for compensation. For the current study, participants were offered $\$ 1.00$ to complete the online survey. MTurk offers access to hard-to-reach populations (Mason \& Suri, 2012) and has been previously validated as a tool to obtain self-report survey data in social science research (Buhrmester, Kwang, \& Gosling, 2011; Mason \& Suri, 2012; Rand, 2012), particularly within older adult samples (Golding, Nardorff, Winer, \& Ward, 2015; Lemaster, Pichayayothin, \& Strough, 2015). The post on MTurk (see Appendix J) provided the purpose of the study, the inclusion criteria, and a link that redirected participants to the online survey hosted on Qualtrics (Provo, UT).

Participants for this study were required to be older adults age 60 and above who receive 10 or more hours per week of care/assistance (i.e., IADLs and/or ADLs) from at least one adult child (e.g., biological daughter, adopted daughter, daughter-in-law, etc.). Additionally, following recommendations about screening MTurk workers based on their qualifications to obtain high quality data, participants were required to be based in the US (Bell, McGlone, \& Dragojevic, 2014; Grasso \& Bell, 2015; Leroy, Kauchak, \& Hogue, 
2016) with a HIT approval rating on their completed tasks of $90 \%$ or greater (Mason \& Suri, 2012).

\section{Participants and Procedures}

A total of 318 members of the MTurk community, all residents of the US, completed the study. Data from 30 of these participants were discarded based on two criteria. First, 17 participants $(5.35 \%)$ were discarded because they spent fewer than three minutes completing the survey, a cut-off criteria used in previous research with similar survey length (Grasso \& Bell, 2015). Second, 13 participants (4.09\%) were removed because they spent fewer than eight seconds reading the caregiving message, a cut-off criteria calculated based on previous research (Bell et al., 2014). The final sample of 288 participants comprised $90.6 \%$ of the original sample, and there were no significant differences between discarded cases and the final sample. On average, these participants spent 10 minutes and 8 seconds completing the survey (median $=8$ minutes, 1 second) and 30.32 seconds reading the caregiving message (median $=22.5$ seconds). Detailed characteristics of the sample are provided in Table 1 . The majority of the older adults who participated in this study was female (55.6\%) and Caucasian (80.2\%). Participants ranged in age from 60 to 88 with a mean age of 67.46 years $(S D=5.36)$. More than half of participants were either currently married or widowed, reported receiving a college education, and received the most care from their biological daughter. On average, participants received 17.07 hours of care per week $(S D=8.95)$ from their adult child caregiver. In addition to this informal care received from an adult child, 136 participants (47.2\%) reported receiving formal care from a provider associated with a service system; the mean amount of formal care reported among these participants was 12.26 hours per 
Table 1

Study Three Sample Characteristics $(N=288)$

\begin{tabular}{|c|c|}
\hline Characteristic & $n(\%)$ \\
\hline Female & $160(55.6)$ \\
\hline \multicolumn{2}{|l|}{ Ethnicity } \\
\hline White/Caucasian & $231(80.2)$ \\
\hline Black/African American & $21(7.3)$ \\
\hline Asian/Asian American & $14(4.9)$ \\
\hline Hispanic & $13(4.5)$ \\
\hline Other & $9(3.1)$ \\
\hline \multicolumn{2}{|l|}{ Relationship to caregiver } \\
\hline Biological daughter & $146(50.7)$ \\
\hline Biological son & $121(42.0)$ \\
\hline Daughter-in-law & $8(2.8)$ \\
\hline Son-in-law & $4(1.4)$ \\
\hline Adopted daughter & $4(1.4)$ \\
\hline Adopted son & $5(1.7)$ \\
\hline \multicolumn{2}{|l|}{ Marital Status } \\
\hline Married & $105(36.5)$ \\
\hline Widowed & $100(34.7)$ \\
\hline Divorced/separated & $61(21.2)$ \\
\hline Single, never married & $11(3.8)$ \\
\hline Living with partner & $11(3.8)$ \\
\hline \multicolumn{2}{|l|}{ Overall health } \\
\hline Good & $121(42.0)$ \\
\hline Fair & $149(51.7)$ \\
\hline Poor & $18(6.3)$ \\
\hline \multicolumn{2}{|l|}{ Education } \\
\hline Less than high school & $8(2.8)$ \\
\hline High school diploma or GED equivalent & $63(21.9)$ \\
\hline Some college, no degree & $72(25.0)$ \\
\hline College graduate or above & $145(50.3)$ \\
\hline
\end{tabular}


week $(S D=10.67)$.

\section{Stimulus Messages}

Stimuli for this experiment were brief (i.e., between 44 and 51 words) caregiving messages advocating the use of a non-slip bathmat to prevent falls in the bathroom (see Appendix K). The message features incorporated into these caregiving messages were guided by results of Study One (RQ2) and Study Two (RQ1). Specifically, characteristics from all three types of freedom-threatening messages (i.e., offering directives, expressing doubt, and loss-framing) as well as one ${ }^{1}$ of the non-freedom threatening message types (i.e., autonomy-supporting) that emerged from older adults' responses in Study One (RQ2) and corroborated by adult child caregivers in Study Two were used as the basis for the experimental stimuli.

A single health behavior, fall prevention, was used in all messages for Study Three for consistency. Important to note is that the topic of fall prevention was deemed appropriate as the health behavior basis of the messages created to test PRT for several reasons. First, results from Study One (RQ3) revealed that fall prevention was the health behavior subcategory most frequently reported by older adults as linked to freedom-threatening messages from their adult children $(n=15,32.61 \%)$. Second, there is existing empirical evidence that older adults may demonstrate resistance toward caregiving messages and advice about fall prevention (Lee, McDermott, Hoffmann, \& Haines, 2013). Third, national data indicate that falls are a common occurrence among older adults; approximately one-third of older adults fall each year (CDC, 2016), and this percentage increases with age as well as for those living in nursing homes (World Health Organization [WHO], 2007). Moreover, older adults are most likely to fall in their home 
environment, particularly in the bathroom due to wet floor rugs (Rosen, Mack, \& Noonan, 2013). Therefore, the scenarios each depicted fall prevention by recommending that the older adult place a non-slip, rubber bathmat outside of their shower, which is a common recommendation to prevent falls in the home environment (CDC, 2016). Given that the loss-framing message had to provide a consequence for not engaging in this behavior, the consequence highlighted was fracturing a hip, as fractures have been identified as the most frequently occurring type of non-fatal injury resulting from falls among older adults (Stevens, Corso, Finkelstein, \& Miller, 2006).

\section{Instrumentation}

Participants were provided with an informed consent statement once they accepted the HIT and were redirected to the cover letter and survey on Qualtrics (see Appendices L and M). Before being randomly assigned to view one of the four caregiving messages, participants responded to scale items that assessed trait reactance and paternalism beliefs.

Trait reactance. Individuals' reactance proneness was assessed using the 14-item Hong Trait Reactance Scale (HTRS; Hong \& Faedda, 1996). Items were rated on a 7point Likert scale ranging from 1 (strongly disagree) to 7 (strongly agree). Example items included "I become frustrated when I am unable to make free and independent decisions" and "Regulations trigger a sense of resistance in me." Previous studies have obtained reliabilities ranging from .77 to .82 (Miller \& Quick, 2010; Quick et al., 2011; Quick \& Stephenson, 2008). Reliability in the current study was .90 $(M=4.49, S D=$ 0.99). Items were averaged into a composite score.

Paternalism beliefs. Beliefs in paternalism was assessed using a shortened 8-item 
version of Cicirelli’s (1992) Paternalism Scale adapted by Fowler and Fisher (2009). Responses were rated using a 7-point Likert scale ranging from 1 (strongly disagree) to 7 (strongly agree). Example items included "If a child can explain why a certain diet is best for the parent's health, the adult child should insist that the older adult parent follow the diet" and "An adult child should insist upon making changes in an older adult parent's living environment when something is unsafe for the parent." Fowler and Fisher obtained a reliability of .85 . Reliability in the current study was also $.85(M=4.02, S D=1.15)$. Items were averaged into a composite score.

Perceived freedom threat. Immediately after viewing the caregiving message to which they were randomly assigned, participants completed scale items assessing their experience of the reactance process. First, participants rated their perceived freedom threat toward the caregiving message, which was assessed using the 4-item scale from Dillard and Shen (2005). These items also constituted an induction check to ensure that the messages were perceived as intended (Miller et al., 2007). Example items included "The message tried to make a decision for me" and "The message threatened my freedom to choose." Participants rated items on a 7-point Likert scale ranging from 1 (strongly disagree) to 7 (strongly agree). Previous studies have obtained reliabilities for the scale ranging from .79 to .84 (Gardner \& Leshner, 2015; Quick et al., 2014; Richards \& Banas, 2015; Shen, 2015). Reliability in the current study was $.86(M=3.65, S D=1.48)$. Items were averaged into a composite score.

State reactance. Adhering to recommendations by Quick (2012) and Dillard and Shen (2005), state reactance experienced toward the caregiving message was operationalized as a combination of anger and negative cognitions. Negative cognitions 
toward the message were assessed using an abbreviated 4-item version of a measure of cognitive appraisal initially used by Dillard, Kinney, and Cruz (1996) and Miller et al. (2007), and validated by Gardner and Leshner (2015). The four items included "The message was pleasant" (reverse-coded), "The message got in the way of what I wanted," "The message was reasonable" (reverse-coded), and "The message was fair" (reversecoded). Items were rated on a 7-point Likert scale ranging from 1 (strongly disagree) to 7 (strongly agree). In their previous study, Gardner and Leshner obtained a reliability of .87. Reliability in the current study was $.77(M=3.40, S D=1.23)$.

Anger toward the caregiving message was assessed using a 4-item scale from Dillard and Shen (2005) following the prompt, "Imagining that the message you read was something your adult child actually said to you, how did you feel while reading the message?" Sample items included "I felt angry while reading the message" and "I felt aggravated while reading the message." Items were rated on a 7-point Likert scale ranging from 1 (none of this feeling) to 7 (a great deal of this feeling). Previous studies have obtained reliabilities ranging from .90 to .97 (Gardner \& Leshner, 2015; Quick et al., 2011, 2014). Reliability in the current study was .98 $(M=3.25, S D=2.02)$.

Negative cognitions and anger were highly correlated $(r=.72, p<.001)$, which is consistent with previously reported results (e.g., Gardner \& Leshner, 2015). Composite state reactance scores were created similarly to previous research by summing the standardized scores of negative cognitions and anger (Ball \& Goodboy, 2014; Dillard \& Shen, 2005; Shen, 2010; Zhang \& Sapp, 2013).

Freedom restoration. Three measures were used to assess freedom restoration behavior in response to the request in the hypothetical caregiving message. Participants 
were instructed to imagine that they do not currently use a non-slip bathmat on the floor outside of their shower. First, participants completed Gardner and Leshner's (2015) abbreviated 4-item version of Dillard and Shen's (2005) measure of attitudes toward the message advocacy. Following a prompt ("Based on the message you read, how would you rate your attitude toward using a non-slip bathmat on the floor outside of your shower instead of a towel?"), participants responded to four 7-point semantic differential questions. Word pairs included bad/good, unfavorable/favorable, negative/positive, and unnecessary/necessary. Reliabilities for the full scale ranged from .84 to .89 in Dillard and Shen's original study, and Gardner and Leshner obtained a reliability of .94 on the abbreviated version. Reliability in the current study was $.95(M=5.35, S D=1.60)$. Items were averaged into a composite score.

Second, participants completed a single-item probability estimate of behavioral intention to comply with the message, which has been used in previous reactance studies (e.g., Dillard \& Shen, 2005; Gardner \& Leshner, 2015; Miller et al., 2007; Richards \& Banas, 2015). Specifically, participants were asked: "Based on the message you read, how likely is it that you will use a non-slip bathmat on the floor outside of your shower instead of a towel within the next week?" Participants responded to the item on a scale ranging from 0 (definitely will not) to 100 (definitely will) using a horizontal slider that participants could drag in 1-point increments to record their answer $(M=67.32, S D=$ 28.18). Lower ratings represented noncompliance and direct freedom restoration (Gardner \& Leshner, 2015).

Third, participants completed the 15-item Freedom Restoration Measure (FRM; Ball, 2015), which assessed three dimensions of freedom restoration behavior: message 
derogation (e.g., "This message is valuable" [reverse-coded]), direct restoration (e.g., "I plan to do the opposite of what the message tells me to do"), and indirect restoration (e.g., "I am inspired to get other people to do the opposite of what the message says to do"). Items were rated on a 7-point Likert scale ranging from 1 (strongly disagree) to 7 (strongly agree). Previous reliabilities for the three dimensions ranged from .80 to .86 (Ball, 2015). Reliability in the current study was .87 for direct $(M=2.93, S D=1.39), .90$ for indirect $(M=2.91, S D=1.35)$, and .92 for message derogation $(M=2.77, S D=1.26)$. Items corresponding with their respective dimension were averaged into a composite score.

Items from the FRM were pilot tested across two samples for their readability and clarity (see Appendix $\mathrm{N}$ for the pilot test questionnaire). The first sample $(n=19)$ consisted of undergraduate students at a large Mid-Atlantic university and the second sample $(n=20)$ consisted of older adults recruited online via Mechanical Turk (MTurk; www.mturk.com). Participants in the first sample ranged in age from 19 to $22(M=$ 20.47, $S D=0.84)$ and participants in the second sample ranged in age from 60 to $67(M=$ $62.53, S D=2.34)$. In total, there were 24 male participants and 14 female participants. The majority of participants was Caucasian $(n=29,74.4 \%)$. One participant from the second sample did not report demographic characteristics. Participants provided feedback on the instructions of the questionnaire as well as the readability and comprehension of the scale items. This feedback was incorporated into the FRM that was administered in Study Three.

Control variables. Two control variables were included as covariates in the main analyses of this study: perceived realism of the caregiving message and perceived 
communication quality with one's adult child caregiver. Perceived realism of the caregiving message was assessed using one 7-point semantic differential item with word pairs not realistic/realistic following the prompt "How realistic is it that your adult child has used similar language with you when providing assistance?" $(M=4.52, S D=1.97)$. Perceived communication quality between older adult participants and their adult child caregivers was assessed using the respect dimension of a measure of emotional tone used by Morgan and Hummert (2000). Following a prompt ("To what extent is the communication that you typically receive from your adult child...”), participants responded to four items: respectful, condescending (reverse-coded), dominating (reversecoded), and polite. Items were rated on a 7-point Likert scale ranging from 1 (not at all) to 7 (extremely) and averaged to into a composite score $(\alpha=.78, M=5.68, S D=1.11)$.

\section{Data Analysis}

Prior to analyzing the hypotheses, data were screened for outliers and missing data, and continuous variables were checked for normality assumptions. Because less than $5 \%$ of the data were missing (i.e., only $0.24 \%$ of all data were missing), missingness was not deemed problematic (Tabachnick \& Fidell, 2007) and was addressed using pairwise deletion unless otherwise noted. Four univariate outliers on trait reactance and the message derogation dimension of the FRM were detected using a cut-off of \pm 3 standard deviations from the mean; however, examination of boxplots revealed that these values were not extreme outliers.

An induction check was performed using an analysis of variance (ANOVA) to examine whether there were significant differences in perceived freedom threat among the multiple caregiving messages. Because the data did not violate the assumption of 
homogeneity of variances, a Scheffe post hoc comparison was used to examine differences among means. Results of an ANOVA revealed significant differences in perceived freedom threat based on caregiving message type, $F(3,280)=18.47, p<.001$, $\eta^{2}=.17$. Post hoc comparison of means of the three freedom-threatening conditions (i.e., offering directives, expressing doubt, loss-framing) versus the one autonomy-supporting condition indicated that participants in the offering directives condition $(n=69, M=$ 4.41, $S D=1.25)$ and the expressing doubt condition $(n=71, M=4.10, S D=1.32)$ perceived a significantly greater freedom threat than participants in the loss-framing condition ( $n=71, M=3.13, S D=1.50)$ as well as the autonomy-supporting condition ( $n$ $=77, M=3.02, S D=1.35$ ). Although participants in the loss-framing condition reported, on average, higher perceived freedom threat than participants in the autonomy-support condition, this mean difference was not significant $(p=.97,95 \%$ CI $[-.52, .74])$. Because the induction check was not successful for the loss-framing condition, the loss-framing condition was excluded from subsequent analyses. Therefore, the independent variable for this study (i.e., caregiving message condition) contained three levels (i.e., offering directives, expressing doubt, and autonomy-supporting).

Because this independent variable was multicategorical (i.e., contained at least three levels), all mediation analyses were conducted following guidelines provided by Hayes and Preacher (2014) to test for relative indirect effects in mediation models with a multicategorical independent variable. Specifically, indicator coding with $k-1$ dummy variables was used, with the freedom-threatening message condition $(\mathrm{D} 1=$ offering directives, D2 = expressing doubt) as the independent variable and the autonomysupporting message condition as the reference category. Subsequently, the independent 
variable in each model included the dummy variable of interest and included the other dummy variable as a covariate. This approach is equivalent to performing an analysis of covariance (Hayes \& Preacher, 2014).

To test H1-H4, a serial mediation analysis (i.e., sequential multiple mediation; see Figure 1) was conducted using Model 6 from the PROCESS macro in SPSS (Hayes, 2013). This analysis utilizes ordinary least squares path analysis to test for direct and indirect effects of the proposed model (i.e., caregiving message type $\rightarrow$ perceived threat $\rightarrow$ state reactance $\rightarrow$ freedom restoration behavior). H5-H6 were tested using moderated mediation in PROCESS to examine the conditional effects of moderators (i.e., trait reactance and paternalism beliefs) at two points in the reactance process: between message type and perceived freedom threat (H5a, H6a; see Figure 2), as well as between state reactance and freedom restoration behavior (H5b, H6b; see Figure 3). All variables were standardized before they were entered into the analyses, with the exception of the categorical variable (i.e., message condition); thus, coefficients are partially standardized. Indirect effects were examined using percentile bootstrapped standard errors and 95\% confidence intervals from 5,000 resamples (Hayes, 2013). Confidence intervals that did not contain zero were interpreted as being statistically significant.

\section{Summary}

This chapter provided an overview of methodologies used to execute the three studies outlined in this dissertation. In Study One, focus groups and an in-depth interview were conducted with older adults who receive care from an adult child to explore older adults' perceptions about freedom-threatening caregiving messages they receive from their adult children, the health behaviors that tend to be at the crux of those messages, and 
Figure 1

Statistical Model of Serial Mediation for H1-H4

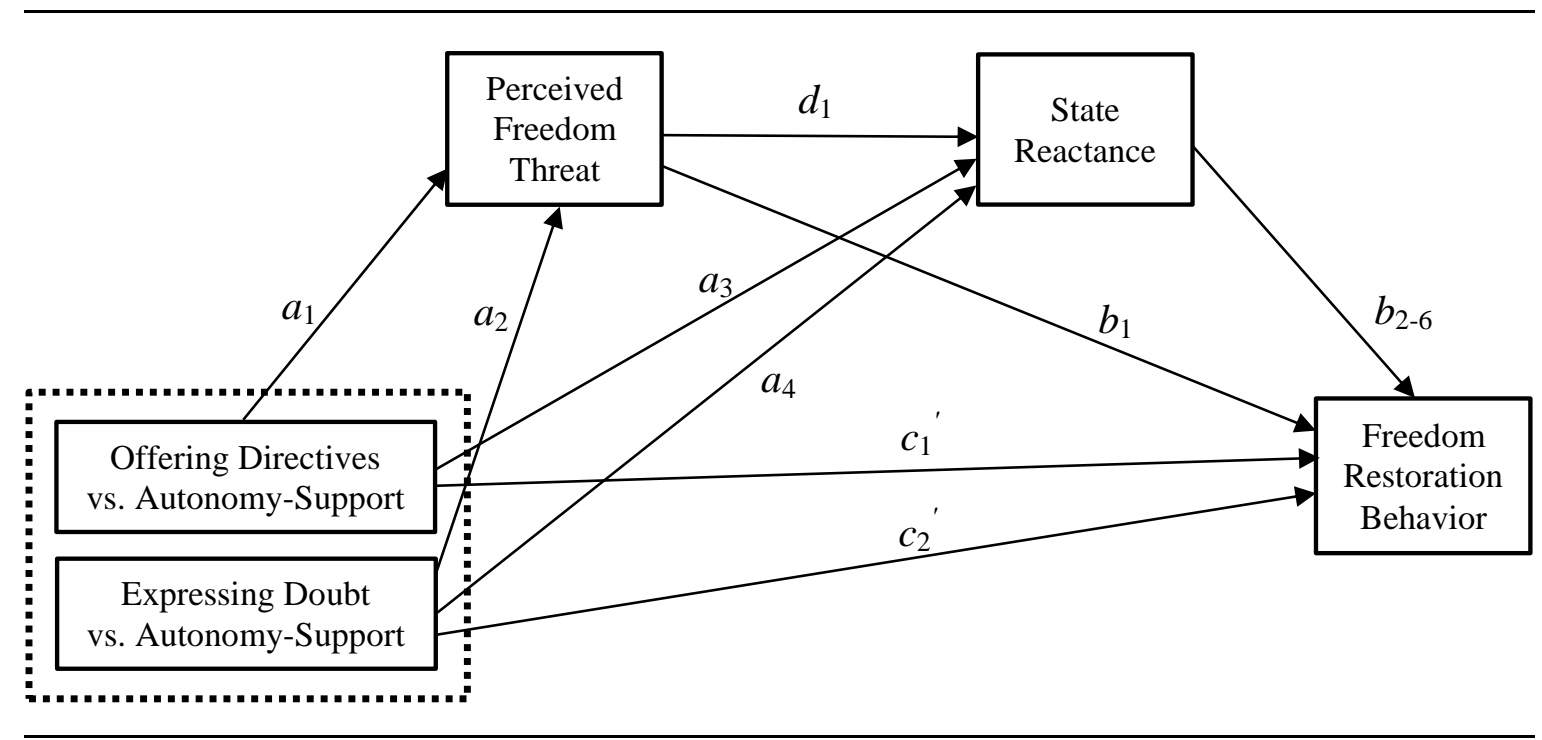

Note. Serial Mediation Analysis using PROCESS Model 6. Covariates are not pictured for simplicity but statistical controls include perceived realism of the caregiving message and communication quality from one's own adult child caregiver on perceived freedom threat, state reactance, and freedom restoration behavior. 
Figure 2

\section{Statistical Model of Moderated Mediation for H5a and H6a}

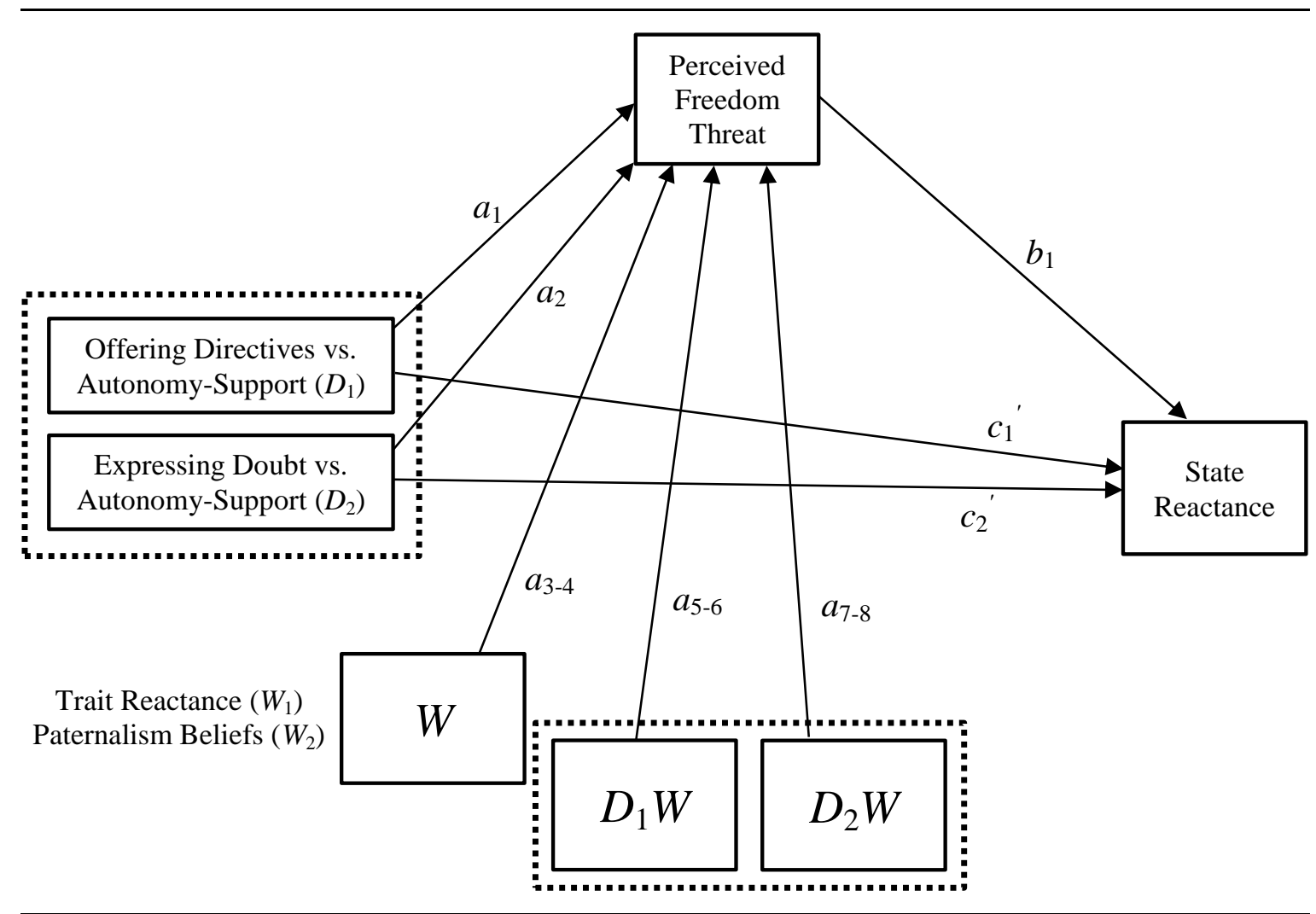

Note. Moderated Mediation Analysis using PROCESS Model 7. Covariates are not pictured for simplicity but statistical controls include perceived realism of the caregiving message and communication quality from one's own adult child caregiver on perceived freedom threat and state reactance. 
Figure 3

Statistical Model of Moderated Mediation for H5b and H6b

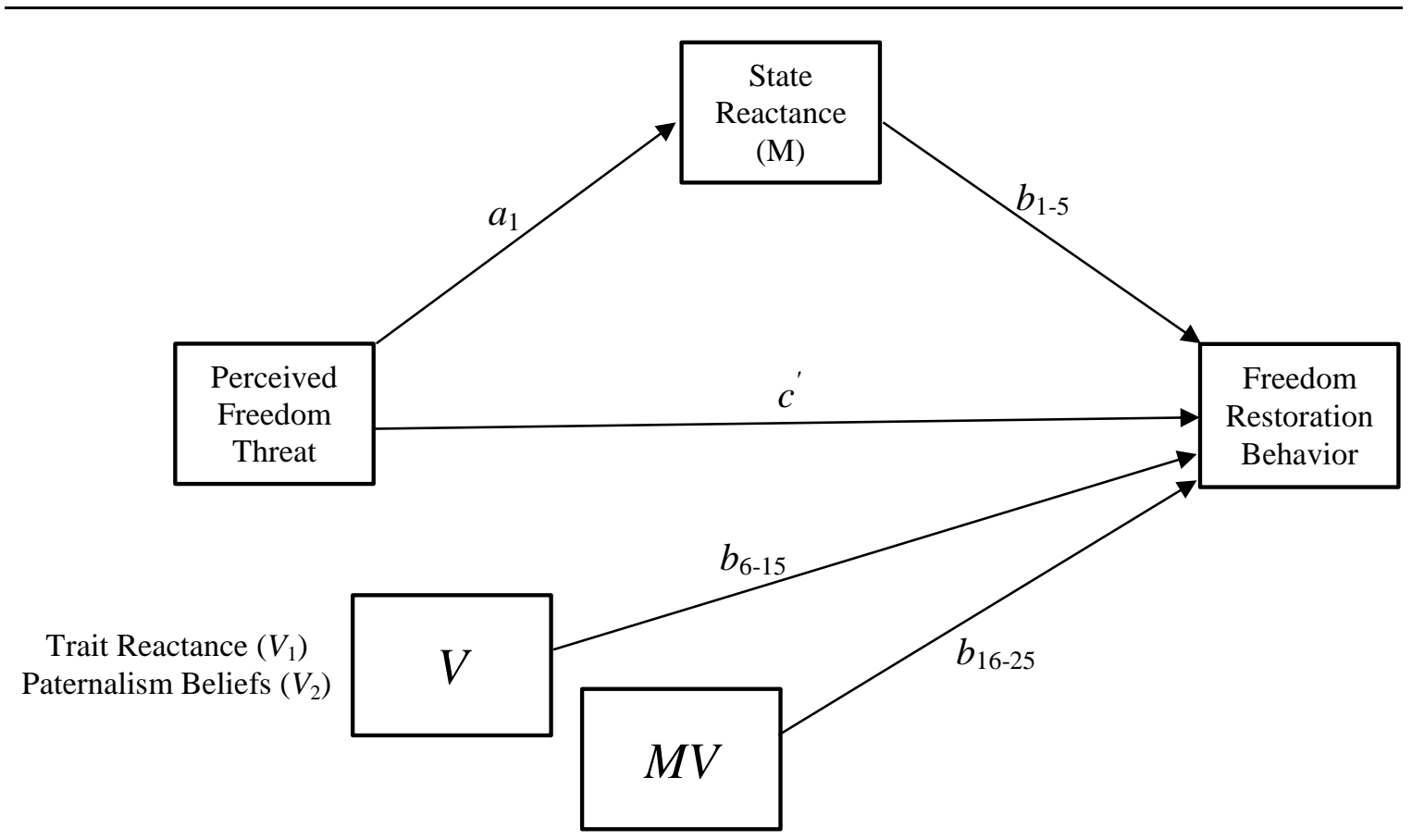

Note. Moderated Mediation Analysis using PROCESS Model 14. Covariates are not pictured for simplicity but statistical controls include perceived realism of the caregiving message and communication quality from one's own adult child caregiver on state reactance and freedom restoration behavior. 
the behaviors in which they engage in response to those messages to restore their freedom. In Study Two, interviews were conducted with adult child caregivers of their older adult parents to explore the messages they use to gain health behavior compliance from their parents as well as the behaviors their parents engage in to resist health-related recommendations. In Study Three, older adults who receive care from an adult child caregiver were randomly assigned to one of four caregiving messages conditions and completed an online survey, the purpose of which was to test PRT as it applies to older adults' experience of reactance toward freedom-threatening versus autonomy-supporting caregiving messages from their adult child caregivers. The outline of the methodologies for each of these three studies in this chapter contains procedures for recruitment of participants, data collection, instrumentation, and data analysis. Results of these three studies are discussed in Chapter III. 


\section{CHAPTER III}

\section{Results}

\section{Research Question One}

The first research question, which asked about the caregiving messages that adult children use to gain healthcare compliance with their older adult parents, was addressed in Study Two during interviews with adult child caregivers. When caregivers were asked to share these messages, using the actual language they would use with their parent, participants' responses yielded five types of messages used to gain health-related compliance (see Table 2). Three of these message types, including offering directives, expressing doubt, and providing justification, either fully or partially overlapped with accounts from older adults that informed the second research question and are discussed later in this chapter. The remaining two message types, providing emotional support and appealing to authority, were unique to the perspectives of adult child caregivers.

The first message strategy that caregivers identified using with their older adult parents is offering directives. In these messages, adult child caregivers order the older adult to engage in a health behavior in the form of an explicit, imperative sentence using forceful language terms (e.g., don't, should, need to), rather than in the form of a suggestion or through the use of indirect language (e.g., "why not"). For example, Maria, who cares for her biological mother, noted that in negotiations about hygiene she often has to tell her mother, "You do need a shower." Similarly, Jennifer, who also cares for her biological mother, revealed that in response to her mother eating processed foods despite being a diabetic, she tells her, "You can't do it!"

Important to note is that caregivers' accounts of their use of directives were often 
Table 2

Study Two Results for Types of Messages Adult Child Caregivers Use to Gain

Compliance from Older Adult Parents

\begin{tabular}{|c|c|c|}
\hline Category & Definition & Examples \\
\hline Offering directives & $\begin{array}{l}\text { Adult child caregiver offers a } \\
\text { command or directive, which } \\
\text { may include the use of forceful, } \\
\text { controlling language (e.g., don't, } \\
\text { should, have to, need to, ought, } \\
\text { must). }\end{array}$ & $\begin{array}{l}\text { "You do need a shower." } \\
\text { "You seriously need to be on [your] } \\
\text { medication." }\end{array}$ \\
\hline Expressing doubt & $\begin{array}{l}\text { Adult child caregiver expresses } \\
\text { skepticism or disbelief that } \\
\text { their older adult parent is } \\
\text { engaging in a positive health } \\
\text { behavior. }\end{array}$ & $\begin{array}{l}\text { "She has to wear Depends, but yet she } \\
\text { won't. She just at times won't. So I ask } \\
\text { every day, 'Do you have your Depends } \\
\text { on?'” } \\
\text { "Usually I'll just ask her and she'll be } \\
\text { very adamant that she had already taken } \\
\text { [her pills]. So [...] I'll say, 'No, you } \\
\text { didn't take 'em."” }\end{array}$ \\
\hline $\begin{array}{l}\text { Providing } \\
\text { justification }\end{array}$ & $\begin{array}{l}\text { Adult child caregiver provides } \\
\text { a rationale by either } \\
\text { accentuating the positive } \\
\text { outcomes of engaging in a } \\
\text { desired behavior or the } \\
\text { negative outcomes of not } \\
\text { engaging the behavior. }\end{array}$ & $\begin{array}{l}\text { "You need to have apples, bananas, tuna } \\
\text { fish because it would give you more } \\
\text { energy and is just healthier for you." } \\
\text { "Going to [physical therapy] would at } \\
\text { least enable you to get a little more } \\
\text { comfortable in your own skin." }\end{array}$ \\
\hline $\begin{array}{l}\text { Providing } \\
\text { emotional support }\end{array}$ & $\begin{array}{l}\text { Adult child caregiver } \\
\text { communicates empathy and/or } \\
\text { assurances of care and concern } \\
\text { for the older adult parent and } \\
\text { their well-being. }\end{array}$ & $\begin{array}{l}\text { "Let's give this a try, I'm right here with } \\
\text { you, you know I've always got your } \\
\text { back." } \\
\text { "I love you very much. I want you to get } \\
\text { the best possible care that you can." }\end{array}$ \\
\hline $\begin{array}{l}\text { Appealing to } \\
\text { authority }\end{array}$ & $\begin{array}{l}\text { Adult child caregiver displaces } \\
\text { the source of a health-related } \\
\text { directive to an authority figure; } \\
\text { specifically, a healthcare } \\
\text { professional. }\end{array}$ & $\begin{array}{l}\text { "Dad, do you remember what the doctor } \\
\text { said? He told us that you need to..." } \\
\text { "Your doctor said you have to take this } \\
\text { pill." }\end{array}$ \\
\hline
\end{tabular}


followed by instances of resistance on the part of the older adult parent. For example, Donna recounted a scenario in which she provided a behavioral recommendation to her biological mother over the phone:

I can't say no [to my mother]. If I say no, then oh my heaven's sake. [...] She tells me, “This is what we're going to do." And I'll say, "No it's not." Then she gets short and abrupt with me and hangs up.

Donna's mother's attempts to regain control through communicating that she will make the decision, as well as by becoming more antagonistic in her communication style, illustrate the ineffectiveness of this type of message in gaining compliance - which Donna acknowledged at the beginning of her narrative. Like Donna, other caregivers also acknowledged that the use of directives is often ineffective in gaining compliance with their parents, and that they have learned to avoid using this type of message through “trail-and-error." Indeed, Maria reflected that "most of the resistance that I get from [my mother] is when she wants to do something that I'm telling her that she can't do." Additionally, Sarah explained that this message type is ineffective with her biological father "because I'm not using any kind of tact when I say it. It's definitely the truth but you can't present it like that." Joyce explained alternate types of wording she uses in place of forceful language with her biological father:

The more direct you are, the less likely he'll do what you want him to do. It's kind of like persuasion. "Dad, do you think we should..." trying to make it as though it's not me directing him, he is making that decision through the persuasion of "what do you think of the idea that we should do this," and so it almost gives him that power. 
In these examples, the caregivers recognize that phrasing plays a large role in the effectiveness or ineffectiveness of compliance-gaining messages.

Another type of message that adult child caregivers reported using was expressing $d o u b t$, or instances in which caregivers conveyed skepticism that their older adult parent was engaging in a prosocial health behavior. For example, Valerie noted about her biological mother's medical adherence, “Usually I'll just ask her [whether she has taken her pills] and she'll be very adamant that she had already taken them. So [...] I'll say, 'No, you didn't take 'em."' Although Valerie begins by asking whether her mother was compliant, the fact that this question was coupled with an accusatory statement conveys that she was doubtful that her mother actually engaged in the health behavior. Another instance of expressing doubt was evidenced by Joanne's explanation of her attempts to get her biological mother to wear adult diapers on a regular basis: "She has to wear Depends, but yet she won't. She just at times won't. So I ask every day, 'Do you have your Depends on?"' Given that Joanne acknowledges how her mother tends not to adhere to this health behavior, she implies that she asks this question doubtful that her mother is actually engaging in the behavior.

A third tactic that adult child caregivers reported using to persuade their older adult parents to engage in a health behavior was providing justification. In these messages, caregivers coupled a health behavior recommendation with a rationale for why they believe their parent should adhere to the recommendation. Caregivers noted that they found it effective to either "accentuate the positives" or convey that "there could be repercussions"; these message types are consistent with the definitions of gain-framing (i.e., emphasizing positive outcomes of engaging in a prosocial health behavior) and loss- 
framing (i.e., emphasizing the negative outcomes of not engaging in a prosocial health behavior) from the literature on prospect theory (Tversky \& Kahneman, 1981). In one example, James noted how he tailors his messages to outcomes he knows his mother-inlaw values most, such as inclusion in family activities. Similarly, Jay explained that he targets his biological mother's "love for living" in his gain-framed messages:

She was thinkin' about not going for this test that she's going for, she's got an angiogram. [So I said to her] "I know how much you love life. Goin' out and doin' things, goin' to the movies, and goin' out to eat. Why wouldn't you do this? Why take a chance? This could improve the rest of your life and how much ever you got left."

Jay also noted that he has used the loss-framing approach with his mother in the context of her nutrition when recovering from pneumonia: "She wasn't eating. And I said, 'you're not gonna gain any of your strength if you don't!'”

Fourth, caregiver reports yielded a theme of providing emotional support as a way to persuade older adult parents to engage in prosocial health behavior. These caregiving messages were characterized by showing understanding of a parent's health condition and acknowledging their needs, as well as conveying support and concern for the older adult parent and their well-being with phrases such as "I love you," "I understand," and "I've always got your back." For example, Sarah mentioned that this approach was particularly effective in encouraging her biological father to attend physical therapy as part of his treatment plan for Parkinson's disease by telling him, "I want you to get the best possible care that you can. I want you to be able to enjoy or to some extent, get some kind of enjoyment out of the time you have left." Sarah also commented on why, in her 
experience, messages that provide emotional support are effective in gaining compliance with her biological father:

The sense that I'm acknowledging [my father's] fears and his understanding of the long term effects of his illness. I'm not minimizing that, I'm accepting that and acknowledging; that I think helps him with the message I'm trying to give him.

As evident in Sarah's explanation, persuasive messages that incorporate emotional support appear to discount any possibility of manipulative intent behind these messages by conveying that the intent is related to maximizing the older adult parent's well-being.

The last type of message that adult child caregivers reported using with their older adult parents is appealing to authority. Caregivers used this type of message to displace the source of a health-related directive to an authority figure; specifically, a healthcare professional. Maria, who noted that her biological mother "will do anything for her doctor," provided a specific example of how she communicates this type of message to her mother: "Your doctor said you have to take this pill. And if you don't take this pill, [your doctor] will be very mad at you. Cause he's going to ask if you took your pills." Along the same lines, Joyce noted in regard to her biological father, "If there's any question about him not wanting to do something, I'll say 'remember what the doctor said,' and I'll reiterate what the doctor said so it's not coming from me personally, it's a medical professional who said it." Maria and Joyce corroborated that crucial to the effectiveness of this type of message is that the directive is no longer coming from the caregiver. As Joyce noted, "The reason I think it's effective is because it's not his daughter telling him what to do, or what not to do. It's the fact that it's coming from a 
health professional." Similarly, Maria explained "I think it's effective because the doctor said. [An] authority figure."

\section{Research Question Two}

The second research question inquired about the messages received from adult child caregivers that older adults perceive as freedom threatening. In Study One, older adults were asked to provide examples of freedom-threatening messages that they have received from their adult child when the adult child provides them with care or assistance during a typical week, and were encouraged to use the actual language their child uses with them. Important to note is that in some cases, older adults did not perceive that their adult child caregivers always used freedom-threatening messages $(n=11,30.56 \%)$. However, the majority of participants was able to identify at least one example of a freedom-threatening message, yielding three ways that adult children communicate freedom-threatening messages to their older adult parents: offering directives, expressing doubt, and loss-framing. Table 3 provides emergent themes for freedom-threatening and non-freedom threatening messages. Important to note is that each type of freedomthreatening message identified by older adults overlapped at least in part with messages that caregivers reported using in Study Two.

Freedom-threatening messages. The first type of freedom-threatening message reported by older adult participants is instances in which they perceive that their adult child caregiver is offering directives. Similar to the results of the first research question, this category included messages in which the adult child caregiver conveys a health recommendation in the form of a command. For example, a resident of the nursing and rehabilitation center, Richard, disclosed a directive that he received most recently from 
Table 3

Study One Results for Types of Caregiving Messages Identified by Older Adults as Freedom Threatening

\begin{tabular}{|c|c|c|}
\hline Category & Definition & Examples \\
\hline \multirow[t]{2}{*}{ Offering directives } & \multirow[b]{2}{*}{$\begin{array}{l}\text { Adult child caregiver offers a } \\
\text { command or directive, which } \\
\text { may include the use of forceful, } \\
\text { controlling language (e.g., don't, } \\
\text { should, have to, need to, ought, } \\
\text { must). }\end{array}$} & "Go to the doctor." \\
\hline & & $\begin{array}{l}\text { "You should wear your hearing } \\
\text { aid more often." }\end{array}$ \\
\hline \multirow[t]{2}{*}{ Expressing doubt } & \multirow{2}{*}{$\begin{array}{l}\text { Adult child caregiver expresses } \\
\text { skepticism or disbelief that their } \\
\text { older adult parent is engaging in } \\
\text { a positive health behavior. }\end{array}$} & $\begin{array}{l}\text { "Have you been taking [your } \\
\text { meds]?" }\end{array}$ \\
\hline & & $\begin{array}{l}\text { "Are you wearing [your hearing } \\
\text { aids]?" }\end{array}$ \\
\hline \multirow[t]{2}{*}{ Loss-framing } & \multirow{2}{*}{$\begin{array}{l}\text { Adult child caregiver emphasizes } \\
\text { the cons, disadvantages, or } \\
\text { adverse effects of a negative } \\
\text { health behavior. }\end{array}$} & "You're liable to fall." \\
\hline & & $\begin{array}{l}\text { "Don't you think you better } \\
\text { protect against this?" }\end{array}$ \\
\hline \multirow{2}{*}{$\begin{array}{l}\text { None: Autonomy- } \\
\text { supporting }\end{array}$} & \multirow[b]{2}{*}{$\begin{array}{l}\text { Adult child caregiver messages } \\
\text { are not perceived as freedom } \\
\text { threatening because the child } \\
\text { encourages their older adult } \\
\text { parent to be independent, make } \\
\text { their own decisions, and/or } \\
\text { promotes open discussion about } \\
\text { health-related decisions that need } \\
\text { to be made. }\end{array}$} & "They let me be my own boss." \\
\hline & & $\begin{array}{l}\text { "We always sit down and } \\
\text { discuss things." }\end{array}$ \\
\hline \multirow[t]{2}{*}{ None: Paternalism } & \multirow{2}{*}{$\begin{array}{l}\text { Adult child caregiver messages } \\
\text { are not perceived as freedom } \\
\text { threatening because the child } \\
\text { knows what is best for their older } \\
\text { adult parent or has their best } \\
\text { interests in mind. }\end{array}$} & $\begin{array}{l}\text { "Usually I agree with whatever } \\
\text { she says. I know she's right, } \\
\text { 'cause she's the nurse." }\end{array}$ \\
\hline & & $\begin{array}{l}\text { "[Your children] are trying to } \\
\text { help you." }\end{array}$ \\
\hline
\end{tabular}


his son in regard to getting a new wheelchair that better supports his posture: "Dad, you're holding your head too low for the television. You have to get something to hold it up. Get your head up." Along these same lines, a member of the senior center, Blanche, noted that her son offers directives when trying to get her to visit the senior center on a regular basis: "Mom, don't forget. You gotta get up in the morning. Early." In these examples from Richard and Blanche, in addition to others, the adult child caregiver's directive entails a very specific description of the behavior in which they want their older adult parent to engage.

In addition to being unambiguous in nature, messages in which the adult child caregiver offered directives were characterized by the use of certain linguistic features. Specifically, the language that older adults reported their adult children use when offering directives was consistent with Miller et al.'s (2007) description of forceful language, which entails the use of forceful terms such as "must," "should," and "need." For example, a member of the senior center, Barbara, detailed a freedom-threatening message she has received on multiple occasions from her daughter:

I have a little stool that I have to step up on to step over the side of the tub to get into the shower. And [my daughter] is always telling me, “Don't put a towel on it! Don't put a towel under it!" [...] She's always telling me, "Don't put this here" and "don't put that there."

Similar to Barbara's response, another member of the senior center, Joan, summarized a typical caregiving message she received from her daughter: "You need to do this, you need to do that." Alternately, the low-controlling counterpart to the high-controlling language evident in these examples from Barbara and Joan was mentioned as an example 
of a message that older adults preferred. For instance, Blanche noted she would prefer and be more compliant if her son used phrases such as "how about" or "why don't you," consistent with depictions of low-controlling messages in existing literature (Miller et al., 2007; Quick \& Considine, 2008).

Second, older adults perceive caregiving messages as freedom threatening when they sense that their adult child is expressing doubt. Specifically, these messages tended to be interrogative sentences (i.e., in the form of a question) in which the adult child caregiver conveys their skepticism that the older adult is actually engaging in a desired health behavior. For example, when discussing what her son says to try to get her to wear her hearing aid, Phyllis mentioned, "Sometimes he'll say, 'Well, mom, are you wearing them?'” In another instance, Barbara revealed that her daughter expressed doubt through a series of questions in what Barbara agreed felt like an interrogation:

Sometimes she'll call and say, "How are you feeling?" And if I say, "well I'm a bit tired" or "I don't feel good," [she'll say] "Well, did you take your medicine this morning? What time did you take your medicine this morning?"

Interestingly, there was evidence from the Study Two interviews with adult child caregivers that some caregivers were in fact skeptical about whether their older adult parents are compliant with health behavior recommendations. For example, when asked about whether her mother ever does the opposite of what she recommends, Susan responded, "Well, it's probably taking place when we're not there." Although caregivers did not explicitly mention that they expressed this doubt to their parent, it seems likely that they would at some point communicate in a way that conveys their disbelief, which older adults perceive as freedom threatening. 
Third, older adults perceive their adult child caregivers' use of loss-framing as freedom threatening. In these types of messages, the adult child caregiver emphasizes the negative consequences of noncompliance with their health behavior recommendation. Barbara provided an example of a loss-framed caregiving message she received from her daughter, who warned her about not using grab bars when getting in and out of the shower by saying, "You're gonna slip! You're liable to fall." Important to note is that this message type overlaps with the loss-framing dimension of caregivers' provision of justification to persuade their older adult parents to engage in prosocial health behavior.

Non-freedom threatening messages. When asked what freedom-threatening messages they have received from their adult child caregivers, several older adults noted at some point during their respective interviews that the messages that their adult children typically provide when offering assistance are not freedom threatening. Results revealed two underlying reasons for older adults' perceptions of low freedom threat. On one hand, a number of participants disagreed that their adult child caregivers make decisions on their behalf, and instead of threatening their freedom communicate in a way that supports their ability to make their own decisions (i.e., autonomy-supporting). On the other hand, some participants did acknowledge that their adult child caregivers communicate in a way in which they appear to be making decisions for the older adult parent; however, these older adults did not perceive the communication as freedom threatening because they believed that their adult child caregiver "knows what is best" (i.e., paternalism beliefs).

The majority of cases in which older adults did not perceive their adult child caregivers' messages as freedom threatening reflected a theme of autonomy-supporting, 
such that older adults acknowledged that their children encouraged autonomous decisionmaking. For example, when asked whether she feels that her children make decisions on her behalf, Barbara responded, “Mine don't do that. Mine encourage me to be independent. I make my own decisions and everything." In the same focus group, Martha mentioned, “I'm my own boss" and "I'm independent." Perceptions of caregivers' use of autonomy-supporting messages also transpired when the older adult felt that even though their adult child caregiver may provide input during the decision-making process, the older adult themselves has the final say. As Wanda detailed about her family's decision to redo her bathroom to prevent her from falling, "We sat down that morning and they came out and...discussed things. And [my children] said they were just waiting for me to make a decision."

The second overarching reason for older adults' perceptions that their adult child caregivers do not use freedom-threatening messages was consistent with a theme of paternalism beliefs. Specifically, multiple participants implied that they would adhere to any health behavior their child recommended regardless of how the recommendation was communicated, for a variety of reasons that ultimately reflect their beliefs that their child knows what is best in terms of their health. As Mildred explained:

I try to agree with [my daughter] about everything to make her life easier. And go along with her no matter what the circumstance is because I know she has put me in here specifically for a reason. [...] [My daughter could say] 'Well, this is the way it is, mom, this is the way you're gonna do it' and that'd be ok with me.

Other participants provided more detail as to why they tend to comply with their adult child caregivers regardless of the nature of their communication. As Maxie stated, 
“Usually I agree with whatever she says. I know she's right, 'cause she's the nurse." Additionally, Richard responded, “Listen to them. They're handling all the financials and Medicaid.” In other words, some older adults did not perceive their caregivers' decisionmaking on their behalf as freedom threatening for reasons attributed to their child's medical expertise or level of control over the older adult's affairs.

Caregiver ratings of Study One messages. Caregivers were asked to rate a variety of examples of freedom-threatening and non-freedom threatening caregiving messages that were created based on results of Study One (RQ2). Ratings were based on caregivers' perceptions of how realistic it is that they would use that caregiving message with their older adult parent and how effective they think that caregiving message would be for gaining compliance from their older adult parent. Means and standard deviations for ratings are provided in Table 4. Notably, ratings of realism were all at a 4.0 or higher (i.e., at the midpoint of the scale or above), indicating that caregivers perceived all messages to be relatively realistic.

\section{Research Question Three}

The third research question asked about the health behaviors linked to freedomthreatening messages used by adult child caregivers. When older adults were asked about the health behaviors that freedom-threatening messages are usually about, participants' responses reflected five categories of health behavior (see Table 5). First, injury prevention was the most frequently reported health behavior topic of freedom-threatening messages $(n=15,32.61 \%)$; these behaviors concerned the safety of the older adult, including but not limited to preventing falls. One specific recurring example for Barbara, a member of the senior center, was receiving freedom-threatening messages from her 
Table 4

Means and Standard Deviations for Caregiver Ratings of Realism and Effectiveness of Study One Messages

\begin{tabular}{|c|c|c|}
\hline Message Type & Message & $M(S D)$ \\
\hline \multicolumn{3}{|l|}{ Freedom-threatening } \\
\hline Offering directives & $\begin{array}{l}\text { "You need to get up early in the morning. Don't } \\
\text { forget." }\end{array}$ & $\begin{array}{l}4.00(2.50) \\
2.78(2.17)\end{array}$ \\
\hline Expressing doubt & $\begin{array}{l}\text { "Are you taking your medication? I need you to } \\
\text { take your medication." }\end{array}$ & $\begin{array}{l}4.44(2.07) \\
3.11(1.97)\end{array}$ \\
\hline Loss-framing & $\begin{array}{l}\text { "Don't go outside by yourself! You're likely to } \\
\text { fall." }\end{array}$ & $\begin{array}{l}5.62(2.00) \\
4.88(1.81)\end{array}$ \\
\hline \multirow[t]{2}{*}{ Autonomy-supporting } & "How about you take your medication?" & $\begin{array}{l}4.50(2.45) \\
3.63(2.45)\end{array}$ \\
\hline & $\begin{array}{l}\text { "Should we move this towel so that you don't } \\
\text { fall?" }\end{array}$ & $\begin{array}{l}5.00(2.07) \\
4.63(2.50)\end{array}$ \\
\hline
\end{tabular}

Note. For each message type, means and standard deviations for realism appear first, followed by means and standard deviations for effectiveness. 
Table 5

Study One Results for Health Behaviors Related to Freedom-Threating Messages

\begin{tabular}{|c|c|c|}
\hline Category & Definition & Examples \\
\hline Injury prevention & $\begin{array}{l}\text { Behaviors related to safety and } \\
\text { avoiding unintentional injury. }\end{array}$ & $\begin{array}{l}\text { Refraining from using the } \\
\text { stove } \\
\text { Preventing falls }\end{array}$ \\
\hline Nutrition & $\begin{array}{l}\text { Behaviors related to maintaining a } \\
\text { healthy and balanced diet. }\end{array}$ & $\begin{array}{l}\text { Refraining from drinking soda } \\
\text { Limiting sodium intake }\end{array}$ \\
\hline Health monitoring & $\begin{array}{l}\text { Behaviors related to tracking or } \\
\text { receiving assessments of one's } \\
\text { health status. }\end{array}$ & $\begin{array}{l}\text { Attending doctor visits } \\
\text { Wearing an oxygen monitor }\end{array}$ \\
\hline Medical adherence & $\begin{array}{l}\text { Behaviors related to correctly } \\
\text { following medical } \\
\text { recommendations, including } \\
\text { medicine prescriptions and medical } \\
\text { devices. }\end{array}$ & $\begin{array}{l}\text { Taking medication as } \\
\text { prescribed } \\
\text { Wearing a hearing aid }\end{array}$ \\
\hline Social engagement & $\begin{array}{l}\text { Behaviors that facilitate socialization } \\
\text { and interaction with others. }\end{array}$ & $\begin{array}{l}\text { Attending bingo } \\
\text { Going to a senior center }\end{array}$ \\
\hline
\end{tabular}


adult child about not stepping on a towel in her bathroom when she gets in and out of the shower. Second, nutrition ( $n=9,19.57 \%)$, included any health behaviors linked to maintaining a balanced diet. Third, health monitoring $(n=8,17.39 \%)$ included any behavior that provides evaluative information about an older adult's health status, including visiting the doctor or wearing remote monitoring devices (e.g., oxygen monitor, blood pressure monitor). Fourth, medical adherence $(n=8,17.39 \%)$ encompassed behaviors medically prescribed to improve one's health, such as taking medication or wearing a hearing aid. Fifth, social engagement $(n=6,13.04 \%)$ included behaviors meant to facilitate older adults' socialization and interaction with others.

\section{Research Question Four}

The fourth research question asked about the behaviors that older adults engage in to restore their autonomy in response to freedom-threatening caregiving messages received from their adult children. Older adult participants in Study One as well as adult child caregivers in Study Two were asked about the types of behavior that represent older adults' nonadherence to health behavior requests or recommendations from adult child caregivers.

Older adult self-reports of nonadherence. Three types of nonadherence emerged from older adults' responses about the behaviors in which they engage following a freedom-threatening message from an adult child caregiver (see Table 6). The first freedom restoration behavior type was direct resistance, which included any example of older adults engaging in the opposite behavior of what their adult child advocated. Older adults describing an instance of their direct resistance sometimes elaborated that the resistance took the form of an overt behavior that the adult child 
Table 6

Study One Results for Older Adult Self-Reports of Nonadherence to Caregiving Messages

\begin{tabular}{lll}
\hline Category & Definition & Examples \\
\hline Direct resistance & $\begin{array}{l}\text { Engaging in the opposite } \\
\text { behavior of what was } \\
\text { recommended, either overtly } \\
\text { or covertly. }\end{array}$ & $\begin{array}{l}\text { "They don't want me to drink } \\
\text { pop, so I sneak it in!" } \\
\text { "I said I wasn't gonna do it." }\end{array}$ \\
$\begin{array}{ll}\text { Expressing } \\
\text { disagreement }\end{array}$ & $\begin{array}{l}\text { Communicative responses that } \\
\text { establish concern about or } \\
\text { disagreement with the } \\
\text { recommended health behavior. }\end{array}$ & $\begin{array}{l}\text { "I'll express to her, 'I don't } \\
\text { think that's right." } \\
\text { "You can let them know that } \\
\text { you're concerned about the } \\
\text { problem." }\end{array}$ \\
$\begin{array}{ll}\text { Age-related } \\
\text { excuse-making }\end{array}$ & $\begin{array}{l}\text { Communicative responses that } \\
\text { attribute resistance behavior to } \\
\text { older age. }\end{array}$ & $\begin{array}{l}\text { "I said, 'at my age, I'm not." } \\
\text { "If I don't do something I'll } \\
\text { say, 'it's old age." }\end{array}$ \\
\hline
\end{tabular}


witnessed. For example, Anna, a member of the senior center, noted that in response to her children telling her not to carry the groceries up the stairs, "I don't listen to them. I go ahead and carry [the groceries up the steps] while they're there." In other instances, older adults described their direct resistance as a covert behavior that the adult child may not know about. For example, as another senior center member Rada explained, "[My children] don't want me to drink pop, so I sneak it in!”

The second response to freedom-threatening messages identified by older adults was expressing disagreement. These instances were communicative in nature and permitted older adults to voice their concerns with or disapproval of the health behavior recommended by their adult child caregiver. For example, Joan noted in regard to freedom-threatening messages she receives from her daughter, "I'll express to [my daughter], 'I don't think that's right."” A similar approach was reported by Richard, who mentioned that if he doesn't agree with a health recommendation, he will communicate this to his son.

The third and final type of response that older adults reported engaging in following freedom-threatening messages from their adult child caregivers was agerelated excuse-making. Similar to instances in which older adults expressed disagreement to restore their sense of freedom, age-related excuses were communicative in nature; however, this type of communicative response was typically coupled with an instance of behavioral resistance, such that older adults provided older age as justification for not adhering to a behavioral recommendation from their adult child caregiver. For example, older adults recalled instances in which they did not engage in a recommended behavior and communicated to their adult child "at my age I'm not [doing that]" or "it's just old 
age, don't worry about it.” As Joan explained, “If I don’t do something I'll say, 'it's old age.' I gotta blame it on something. I'm not taking the blame." Interestingly, Joan's explanation implies a face-saving function of these age excuses.

Caregiver reports of older adult nonadherence. To corroborate older adult participants' accounts of nonadherence, caregivers were asked about the types of behaviors in which their parents engage that exhibit resistance to health behaviors they advocate in their caregiving messages. Four types of nonadherence emerged from caregivers' reports (see Table 7).

The first type of nonadherence that emerged from caregiver reports of their older adult parents' nonadherence to health behavior recommendations, direct resistance, overlapped with a type of freedom restoration behavior reported by older adults in Study One. Similar to older adults' accounts, adult child caregivers described instances in which their older adult parents engaged in behavior opposite of what was recommended, noting that their parents "won't do it" or "it hasn't happened." Caregivers recounted a variety of situations in which they observed their parents engaging in the opposite of a health behavior recommendation. For example, Jay discussed his mother's direct resistance to her recommended diet: "She's not supposed to be using salt because she's got high blood pressure. [Yet] she's got the salt shaker and she's shaking salt all over her food." Joanne also received nutrition-related resistance from her mom: "I try to put apples, bananas, peanut butter, something with protein in her room, but she will still go for, you know, her cinnamon sugar squares."

In addition to these instances of caregivers observing direct resistance first-hand, some adult child caregivers speculated that the direct resistance behaviors were "taking 
Table 7

Study Two Results for Caregiver Reports of Older Adult Nonadherence to Caregiving Messages

\begin{tabular}{|c|c|c|}
\hline Category & Definition & Examples \\
\hline $\begin{array}{l}\text { Direct } \\
\text { resistance }\end{array}$ & $\begin{array}{l}\text { Engaging in the opposite } \\
\text { behavior of what was } \\
\text { recommended, either overtly } \\
\text { or covertly. }\end{array}$ & $\begin{array}{l}\text { "I've put away all her underwear, } \\
\text { hid them, so she has to wear } \\
\text { Depends, but yet she won't." } \\
\text { "She's not supposed to be using salt } \\
\text { because she's got high blood } \\
\text { pressure. [Yet] she's got the salt } \\
\text { shaker and she's shaking salt all } \\
\text { over her food." }\end{array}$ \\
\hline $\begin{array}{l}\text { Expressing } \\
\text { disagreement }\end{array}$ & $\begin{array}{l}\text { Communicative responses } \\
\text { that establish concern about or } \\
\text { disagreement with the } \\
\text { recommended health } \\
\text { behavior. }\end{array}$ & $\begin{array}{l}\text { "She'll be very adamant that she had } \\
\text { already taken them." } \\
\text { "[She will tell me] 'I don't need to } \\
\text { use a walker.", }\end{array}$ \\
\hline $\begin{array}{l}\text { Source } \\
\text { derogation }\end{array}$ & $\begin{array}{l}\text { Attacks or threats directed at } \\
\text { the message source (i.e., the } \\
\text { adult child caregiver) that are } \\
\text { not related to the } \\
\text { recommended behavior. }\end{array}$ & $\begin{array}{l}\text { "She went ballistic and became very } \\
\text { aggressive towards me." } \\
\text { "She's a bear, she's nasty. She's } \\
\text { nasty, rude." }\end{array}$ \\
\hline $\begin{array}{l}\text { Passive } \\
\text { resistance }\end{array}$ & $\begin{array}{l}\text { Engaging in behaviors not } \\
\text { related to the recommended } \\
\text { behavior, but which represent } \\
\text { passive noncompliance (e.g., } \\
\text { ignoring, changing the } \\
\text { subject). }\end{array}$ & $\begin{array}{l}\text { "She'll pretend like she doesn't hear } \\
\text { you if she doesn't like what you're } \\
\text { saying." } \\
\text { "He just clams up. He won't answer } \\
\text { questions." }\end{array}$ \\
\hline
\end{tabular}


place when we're not there." As Jay explained in regard to his mother's diet, "you don't know if there's compliance. You're not there, you know, you're not there all the time. You don't know what's going on. You don't know how much she's eating or not eating." Similarly, Lori questioned whether her mother actually adheres to her hygiene recommendations: "Does she do it? I don't know, she's behind closed doors." This finding is particularly interesting in light of the result from Study One indicating that older adults sometimes engage in direct resistance behavior when their adult child caregiver is not present.

The second type of nonadherence behavior reported by caregivers included instances of their older adult parents expressing disagreement toward a recommended behavior. Similar to results from Study One, this type of resistance involved communicative responses in which the older adult parent disagrees or argues with the content of this message. General examples included responses such as "There's nothing wrong with me" and "I don't need to." Lori described an instance in which her mother provided a counterargument to a hygiene-related recommendation by saying "Who am I gonna kiss? Why do I have to brush my teeth?” Interestingly, multiple caregivers implied that there may be a memory issue underlying this particular type of resistance. As Joanne speculated,

[My mom] will say "I've never had to do that before" or "this has never happened before." But yet it has happened every day, and I truly think she doesn't remember. So maybe her resistance then is because her memory is so bad, maybe she truly doesn't remember.

Regardless of speculation about memory, however, these communicative responses of 
resistance served to challenge or disparage the content of the caregiver's message.

Whereas direct resistance and expressing disagreement were resistance attempts directed at the recommended behavior, the third type of nonadherence identified by adult child caregivers, source derogation, was directed at the message source (i.e., the adult child caregiver). When describing this type of resistance, caregivers noted aggressive changes in their older adult parents' demeanor, vocal intonation, and message content. For example, Donna explained that there are times when she and her mom "have a war of words" in which her mother "rips me a new one." Similarly, Maria described that her mother will "get really mad and nasty" and "fuming," almost like "another person emerges." Jane provided a more severe example of source derogation, describing her mother in these instances as "a bear" and "rude," and elaborating that her mother "has been very nasty where a lot of times she says she wishes she never had me or would have drowned me when I was small." Not only do these instances represent nonadherence to a prosocial health behavior, but they also prompt caregivers to convey the hurt that they experienced as the recipient of these attacks.

In contrast to direct resistance, expressing disagreement, and source derogation, each of which displayed active types of resistance that oppose or challenge either the health behavior or message source (i.e., adult child caregiver), caregiver reports of their older adult parents' passive resistance encompassed behaviors related to avoidance and withdrawal. Jane discussed how her mother often ignores her health behavior recommendations:

She'll pretend like she doesn't hear you if she doesn't like what you're saying. Like, going to bed is a good one all the time. She'll continue staring off at 
something, or she'll start brushing herself like she's got crumbs on her and she'll pick off the crumbs, but she's busy doing something else where she's not listening to me.

Similarly, Joanne shared that the "subtle" way her mother resists health behavior recommendations is by changing the subject, and Joyce explained that her father "just clams up. He won't answer questions. If it's something he doesn't want to do, or feels you are being antagonistic towards him because you're pushing an issue, he shuts down, he stops communicating." Particularly apparent in the responses of Jane and Joyce is that these passive behaviors come in response to a behavioral recommendation that an older adult parent "doesn't want to do" or if the older adult "doesn't like what you're saying"; thus, although these responses are unrelated to the behavior advocated by the caregiver, it is clear that they are instances of resistance.

\section{Hypotheses}

Pearson correlations among all Study Three variables can be found in Table 8 . H1-H4 were analyzed using serial mediation analyses accounting for the multicategorical independent variable and controlling for realism and communication quality (see Figure 1). Because a separate model was tested for each of the five types of freedom restoration behavior, casewise deletion was used in these analyses for consistency of the path coefficients, resulting in a sample of $N=203$.

H1 posited that freedom-threatening caregiving messages (i.e., offering directives, expressing doubt) would elicit greater perceived freedom threat than autonomysupporting caregiving messages. Controlling for perceived realism of the caregiving message $\left(a_{5}=-0.19, S E=.06, t=-3.19, p<.01,95 \% \mathrm{CI}[-0.30,-0.70]\right)$ and quality of 
Table 8

Pearson Correlations among Study Three Variables $(N=288)$

\begin{tabular}{|c|c|c|c|c|c|c|c|c|c|c|c|}
\hline Variable & 1 & 2 & 3 & 4 & 5 & 6 & 7 & 8 & 9 & 10 & 11 \\
\hline 1. Realism & - & & & & & & & & & & \\
\hline 2. Comm. quality & -.03 & - & & & & & & & & & \\
\hline 3. Trait reactance & -.02 & $-.17 * *$ & - & & & & & & & & \\
\hline 4. Paternalism & .09 & -.03 & $-.13^{*}$ & - & & & & & & & \\
\hline 5. Freedom threat & $-.27^{\dagger}$ & $-.34^{\dagger}$ & $.28^{\dagger}$ & -.04 & - & & & & & & \\
\hline 6. State reactance & $-.40^{\dagger}$ & $-.31^{\dagger}$ & $.26^{\dagger}$ & $-.16^{* *}$ & $.77^{\dagger}$ & - & & & & & \\
\hline 7. Attitudes & $.33^{\dagger}$ & $.19 * *$ & $-.14 *$ & $.18^{* *}$ & $-.55^{\dagger}$ & $-.64^{\dagger}$ & - & & & & \\
\hline 8. BI & $.36^{\dagger}$ & $.14^{*}$ & -.09 & $.25^{\dagger}$ & $-.47^{\dagger}$ & $-.59^{\dagger}$ & $.79^{\dagger}$ & - & & & \\
\hline 9. FRM: Direct & $-.31^{\dagger}$ & $-.31^{\dagger}$ & $.27^{\dagger}$ & $-.21 * *$ & $.60^{\dagger}$ & $.69^{\dagger}$ & $-.71^{\dagger}$ & $-.72^{\dagger}$ & - & & \\
\hline 10. FRM: Indirect & $-.15^{*}$ & $-.36^{\dagger}$ & $.31^{\dagger}$ & -.02 & $.60^{\dagger}$ & $.60^{\dagger}$ & $-.41^{\dagger}$ & $-.36^{\dagger}$ & $.63^{\dagger}$ & - & \\
\hline $\begin{array}{l}\text { 11. FRM: Message } \\
\text { derogation }\end{array}$ & $-.36^{\dagger}$ & $-.24^{\dagger}$ & $.21^{\dagger}$ & $-.26^{\dagger}$ & $.65^{\dagger}$ & $.77^{\dagger}$ & $-.72^{\dagger}$ & $-.68^{\dagger}$ & $.80^{\dagger}$ & $.57^{\dagger}$ & - \\
\hline
\end{tabular}

Note. $\mathrm{BI}=$ Behavioral intention. $\mathrm{FRM}=$ Freedom Restoration Measure. ${ }^{*} p<.05 .{ }^{*} * p<.01 .{ }^{\dagger} p<.001$. 
communication received from one's own adult child caregiver $\left(a_{6}=-0.36, S E=.06, t=\right.$ $-5.88, p<.001,95 \%$ CI $[-0.48,-0.24])$, results of a serial mediation analysis indicated that older adults exposed to the offering directives caregiving message, relative to those who were exposed to the autonomy-supporting message, reported greater perceived freedom threat, $a_{1}=0.68, S E=.14, t=4.70, p<.001,95 \%$ CI $[0.40,0.97]$. Likewise, controlling for realism and communication quality, older adults exposed to the expressing doubt caregiving message, relative to those who were exposed to the autonomysupporting message, reported greater perceived freedom threat, $a_{2}=0.50, S E=.14, t=$ $3.51, p<.001,95 \% \mathrm{CI}[0.22,0.78]$. These results indicate that older adults exposed to either of the freedom-threatening caregiving messages perceived a significantly greater freedom threat than those exposed to the autonomy-supporting caregiving message. $\mathrm{H} 1$ was fully supported.

$\mathrm{H} 2$ posited that perceived freedom threat would be related positively to state reactance. Results indicated that controlling for realism $\left(a_{7}=-0.22, S E=.04, t=-5.11, p\right.$ $<.001,95 \% \mathrm{CI}[-0.30,-0.13])$ and communication quality $\left(a_{8}=-0.06, S E=.05, t=-1.26\right.$, $p=.21,95 \%$ CI $[-0.15,0.03])$, perceived freedom threat was related positively to state reactance, $d_{1}=0.62, S E=.05, t=12.23, p<.001,95 \% \mathrm{CI}[0.52,0.72]$. In other words, the more that older adults perceived the caregiving message to be freedom threatening, the more reactance they experienced toward the message, regardless of how realistic they perceived the scenario to be and the quality of communication they receive from their actual adult child caregiver. Thus, H2 was supported.

$\mathrm{H} 3$ posited that state reactance would be related positively to freedom restoration behavior. A separate serial mediation model was tested for each freedom restoration 
behavior. Controlling for realism and communication quality, results revealed that state reactance was related negatively to attitudes $\left(b_{2}=-0.55, S E=.10, t=-5.65, p<.001\right.$, $95 \% \mathrm{CI}[-0.74,-0.36])$ as well as behavioral intentions $\left(b_{3}=-0.56, S E=.10, t=-5.34, p\right.$ $<.001,95 \%$ CI $[-0.76,-0.35])$. Additionally, controlling for realism and communication quality, state reactance was related positively to direct freedom restoration $\left(b_{4}=0.57, S E\right.$ $=.09, t=6.61, p<.001,95 \% \mathrm{CI}[0.40,0.74])$, indirect freedom restoration $\left(b_{5}=0.34, S E\right.$ $=.10, t=3.46, p<.001,95 \% \mathrm{CI}[0.15,0.53])$, and message derogation $\left(b_{6}=0.67, S E=\right.$ $.08, t=8.39, p<.001,95 \% \mathrm{CI}[0.51,0.82])$. In other words, the more reactance that older adults experienced in response to the caregiving message, the less likely they were to hold positive attitudes toward using a non-slip bathmat and intend to use a non-slip bathmat within the next week. In addition, older adult participants who experienced heightened reactance were more likely than others to engage in a variety of behaviors to restore their freedom, including direct and indirect freedom restoration as well as message derogation. Moreover, these results held when taking to account the effects of how realistic participants perceived the caregiving message to be as well as the quality of communication they receive from their actual adult child caregiver. Therefore, H3 was fully supported.

H4 posited that there would be a significant indirect effect of freedom-threatening caregiving messages (relative to the autonomy-supporting message) on freedom restoration behavior through sequential mediators of perceived freedom threat and state reactance. A separate model was tested for each freedom restoration behavior. Results revealed that controlling for realism and communication quality, the relative indirect effect of offering directives (versus autonomy-support) through perceived freedom threat 
and state reactance was significant on all five types of freedom restoration behavior: attitudes $\left(a_{1} d_{1} b_{2}=-0.23, S E=0.08,95 \%\right.$ bootstrapped CI [-0.41, -0.10]; ratio of indirect to direct effect $\mathrm{R}_{\mathrm{M}}=-1.00,95 \%$ bootstrapped CI $\left.[-8.66,5.86]\right)$, behavioral intentions $\left(a_{1} d_{1} b_{3}=-0.23, S E=0.08,95 \%\right.$ bootstrapped CI $[-0.42,-0.10] ; \mathrm{R}_{\mathrm{M}}=-2.15,95 \%$ bootstrapped CI $[-21.80,14.43])$, direct restoration $\left(a_{1} d_{1} b_{4}=0.24, S E=0.08,95 \%\right.$ bootstrapped CI $[0.11,0.41] ; \mathrm{R}_{\mathrm{M}}=-1.46,95 \%$ bootstrapped CI $\left.[-13.06,13.61]\right)$, indirect restoration $\left(a_{1} d_{1} b_{5}=0.14, S E=0.06,95 \%\right.$ bootstrapped CI $[0.05,0.28] ; \mathrm{R}_{\mathrm{M}}=-0.90,95 \%$ bootstrapped CI $[-7.73,6.65])$, and message derogation $\left(a_{1} d_{1} b_{6}=0.28, S E=0.09,95 \%\right.$ bootstrapped CI [0.14, 0.47]; $\mathrm{R}_{\mathrm{M}}=-19.67,95 \%$ bootstrapped CI [-40.87, 34.41]). Likewise, results revealed that controlling for realism and communication quality, the relative indirect effect of expressing doubt (versus autonomy-support) through perceived freedom threat and state reactance was significant on all five types of freedom restoration behavior: attitudes $\left(a_{2} d_{1} b_{2}=-0.17, S E=0.07,95 \%\right.$ bootstrapped CI $[-0.32,-0.06] ; \mathrm{R}_{\mathrm{M}}=$ $-0.62,95 \%$ bootstrapped CI $[-3.79,1.97])$, behavioral intentions $\left(a_{2} d_{1} b_{3}=-0.17, S E=\right.$ $0.07,95 \%$ bootstrapped CI $[-0.32,-0.06] ; \mathrm{R}_{\mathrm{M}}=-0.63,95 \%$ bootstrapped CI [-4.40, 3.41]), direct restoration $\left(a_{2} d_{1} b_{4}=0.17, S E=0.07,95 \%\right.$ bootstrapped CI $[0.06,0.33] ; \mathrm{R}_{\mathrm{M}}$ $=-0.45,95 \%$ bootstrapped CI $[-1.40,-0.16])$, indirect restoration $\left(a_{2} d_{1} b_{5}=0.10, S E=\right.$ $0.05,95 \%$ bootstrapped CI $[0.03,0.21] ; \mathrm{R}_{\mathrm{M}}=-1.03,95 \%$ bootstrapped CI $\left.[-7.76,7.32]\right)$, and message derogation $\left(a_{2} d_{1} b_{6}=0.21, S E=0.07,95 \%\right.$ bootstrapped CI $[0.08,0.37] ; \mathrm{R}_{\mathrm{M}}$ $=-4.58,95 \%$ bootstrapped CI $[-27.35,26.87])$. In other words, perceived freedom threat and state reactance sequentially mediated the effects of the caregiving message on all five freedom restoration behaviors. Specifically, relative to those who were exposed to the autonomy-supporting message, older adults who were exposed to either of the two 
freedom-threatening caregiving messages perceived a greater freedom threat, which in turn was associated with a greater experience of state reactance, and this greater experience of reactance was associated with greater intentions to restore freedom directly, indirectly, and through message derogation, as well as in lower attitudes toward using a non-slip bathmat and intentions to use a non-slip bathmat within the next week. Thus, H4 was fully supported.

H5-H6 were analyzed using moderated mediation (see Figures 2 and 3). In addition to examining interaction effects, the index of moderated mediation (IMM) was examined as a formal test of moderation of the indirect effect (Hayes, 2015), such that 95\% bootstrapped confidence intervals for the IMM that did not include zero were interpreted as evidence of moderation of an indirect effect. H5a posited that trait reactance would moderate the indirect effect of freedom-threatening messages (relative to autonomy-supporting messages) on state reactance through perceived freedom threat, such that the indirect effect is strengthened as trait reactance increases. Controlling for realism and communication quality, results revealed that the overall model was significant for the offering directives message, $F(6,194)=17.51, p<.001, R^{2}=.35$, as well as for the expressing doubt message, $F(6,194)=17.53, p<.001, R^{2}=.35$. However, examination of the interaction effects revealed that the two-way interaction between offering directives (relative to autonomy-supporting) and trait reactance on state reactance through perceived freedom threat while controlling for the covariates was not statistically significant $\left(a_{5}=.01, S E=.12, t=.09, p=.93,95 \%\right.$ CI $\left.[-0.23,0.25]\right)$, with an IMM of .01 (95\% bootstrapped CI [-0.13, 0.14]). Similarly, the two-way interaction between expressing doubt (relative to autonomy-supporting) and trait reactance on state 
reactance through perceived freedom threat while controlling for the covariates was not significant $\left(a_{7}=.04, S E=.13, t=.29, p=.77,95 \%\right.$ CI $\left.[-0.22,0.29]\right)$, with an IMM of .02 (95\% bootstrapped CI $[-0.14,0.19])$. In other words, trait reactance did not moderate the indirect effect of freedom-threatening messages, relative to autonomy-support messages, on state reactance through perceived freedom threat. Thus, H5a was not supported.

Hypothesis $5 \mathrm{~b}$ posited that trait reactance would moderate the indirect effect of perceived freedom threat on freedom restoration behavior through state reactance such that the indirect effect is strengthened as trait reactance increases. A separate moderated mediation model was tested for each freedom restoration behavior. Controlling for realism and communication quality, results revealed that the overall model was significant for all five freedom restoration behaviors: attitudes, $F(6,192)=22.65, p<$ $.001, R^{2}=.41$; behavioral intention, $F(6,194)=18.52, p<.001, R^{2}=.36$; direct restoration, $F(6,193)=32.69, p<.001, R^{2}=.50$; indirect restoration, $F(6,193)=20.98$, $p<.001, R^{2}=.39$; and message derogation, $F(6,194)=46.27, p<.001, R^{2}=.59$. However, examination of the interaction effects revealed that the two-way interactions between state reactance and trait reactance were not significant on all five freedom restoration behaviors: attitudes $\left(b_{16}=.03, S E=.05, \mathrm{t}=.66, p=.51,95 \%\right.$ CI $[-0.07,0.14]$; $\mathrm{IMM}=.02,95 \%$ bootstrapped CI $[-0.05,0.13])$, behavioral intentions $\left(b_{17}=.01, S E=\right.$ $.06, t=.24, p=.81,95 \%$ CI [-0.10, 0.12]; IMM $=.01,95 \%$ bootstrapped CI [-0.06, $0.10])$, direct restoration $\left(b_{18}=.08, S E=.05, t=1.81, p=.07,95 \%\right.$ CI $[-0.01,0.17]$; $\mathrm{IMM}=.06,95 \%$ bootstrapped CI $[-0.01,0.12])$, indirect restoration $\left(b_{19}=.04, S E=.05, t\right.$ $=.78, p=.44,95 \%$ CI $[-0.06,0.14] ; \mathrm{IMM}=.03,95 \%$ bootstrapped CI [-0.05, 0.11]), and message derogation $\left(b_{20}=.01, S E=.04, t=.31, p=.75,95 \%\right.$ CI $[-0.07,0.10] ; \mathrm{IMM}=$ 
$.01,95 \%$ bootstrapped CI [-0.08, 0.08]). Thus, H5b was not supported.

H6a posited that older adults' perceptions of paternalism would moderate the indirect effect of freedom-threatening messages (relative to autonomy-supporting messages) on state reactance through perceived freedom threat such that the indirect effect is weakened as paternalism increases. Controlling for realism and communication quality, results revealed that the overall model was significant for the offering directives message, $F(6,198)=16.68, p<.001, R^{2}=.34$, as well as for the expressing doubt message, $F(6,198)=15.88, p<.001, R^{2}=.32$. Examination of the interaction effects revealed that the two-way interaction between expressing doubt (relative to autonomysupporting) and paternalism on state reactance through perceived freedom threat while controlling for the covariates was not significant $\left(a_{8}=-.13, S E=.13, t=-.99, p=.32\right.$, 95\% CI [-0.38, 0.13]), with an IMM of -.08 (95\% bootstrapped CI [-0.23, 0.11$])$. However, the two-way interaction between offering directives (relative to autonomysupporting) and paternalism beliefs on state reactance through perceived freedom threat while controlling for the covariates was significant $\left(a_{6}=-.24, S E=.12, t=-2.05, p=.04\right.$, $95 \%$ CI $[-0.48,-0.01])$.

The IMM was examined as a formal test of moderation of the indirect effect (Hayes, 2015). For the current analysis, the IMM for the conditional process analysis using paternalism beliefs as the moderator was $-.15,95 \%$ CI [-0.33, 0.01]. Although examination of the indirect effect at different values of the moderator (i.e., paternalism beliefs) suggested a trend in favor of the hypothesis (i.e., as scores on paternalism beliefs increased, there was a decrease in the positive effect of offering directives relative to autonomy-support on state reactance through perceived freedom threat), the IMM 
suggests that there was not definitive evidence that the magnitude of this indirect effect depends on the moderator (i.e., the 95\% CI included zero). Therefore, H6a was not supported for either of the freedom-threatening caregiving messages.

Hypothesis $6 \mathrm{~b}$ posited that older adults' paternalism beliefs would moderate the indirect effect of perceived freedom threat on freedom restoration behavior through state reactance such that the indirect effect is weakened as paternalism increases. A separate moderated mediation model was tested for each freedom restoration behavior. Controlling for realism and communication quality, results revealed that the overall model was significant for all five freedom restoration behaviors: attitudes, $F(6,196)=$ $20.80, p<.001, R^{2}=.39$; behavioral intention, $F(6,198)=18.32, p<.001, R^{2}=.36$ direct restoration, $F(6,197)=31.57, p<.001, R^{2}=.49$; indirect restoration, $F(6,197)=$ 22.43, $p<.001, R^{2}=.41$; and message derogation, $F(6,195)=50.46, p<.001, R^{2}=.61$. Examination of the interaction effects revealed that the two-way interactions between state reactance and paternalism beliefs were not significant on the following four freedom restoration behaviors: attitudes $\left(b_{21}=-.01, S E=.05, t=-.23, p=.82,95 \%\right.$ CI [-0.11, $0.08] ; \mathrm{IMM}=-.01,95 \%$ bootstrapped CI $[-0.09,0.06])$, behavioral intentions $\left(b_{22}=.03\right.$, $S E=.05, t=.64, p=.52,95 \% \mathrm{CI}[-0.07,0.13] ; \mathrm{IMM}=.02,95 \%$ bootstrapped CI [-0.05, $0.09])$, direct restoration $\left(b_{23}=-.03, S E=.04, t=-.70, p=.48,95 \%\right.$ CI $[-0.11,0.05]$; $\mathrm{IMM}=-.02,95 \%$ bootstrapped CI $[-0.08,0.05])$, and indirect restoration $\left(b_{24}=.08, S E=\right.$ $.05, t=1.59, p=.11,95 \%$ CI $[-0.02,0.17] ; \mathrm{IMM}=.05,95 \%$ bootstrapped CI [-0.02, 0.15]). However, the two-way interaction between state reactance and paternalism beliefs on message derogation while controlling for the covariates was significant $\left(b_{25}=-.10, S E\right.$ $=.04, t=-2.55, p=.01,95 \% \mathrm{CI}[-0.17,-0.21])$. 
The IMM was examined as a formal test of moderation of the indirect effect (Hayes, 2015). For the current analysis, the IMM for the conditional process analysis using paternalism beliefs as the moderator between state reactance and message derogation was $-.07,95 \% \mathrm{CI}[-0.12,-0.01]$. This result suggests that there is significant moderated mediation, and that the conditional indirect effects at all values of the moderator are significantly different from each other (Hayes, 2015). To probe this moderated mediation, the pick-a-point approach was used with values of the moderator (i.e., paternalism beliefs) at the mean and \pm 1 standard deviation from the mean. Results of the pick-a-point approach revealed that the indirect effect of perceived freedom threat on message derogation through state reactance is positive among individuals with paternalism beliefs that are relatively low, $\theta_{(a b) \mid V=-0.97}=.52,95 \%$ bootstrapped CI $[0.36$, 0.69], relatively moderate, $\theta_{(a b) \mid V=0.05}=.45,95 \%$ bootstrapped CI $[0.31,0.61]$, and relatively high, $\theta_{(a b) \mid V=1.06}=.38,95 \%$ bootstrapped CI $[0.23,0.54]$. Because the bootstrapped $95 \%$ confidence intervals for each of the three conditional indirect effects does not include zero and the conditional indirect effects are positively valenced, paternalism beliefs moderate the positive indirect effect of perceived freedom threat on message derogation through state reactance. Moreover, taking into consideration the IMM, we can conclude that the positive indirect effect is significantly weakened as paternalism beliefs increase. In other words, the more an older adult perceives a freedom threat, the greater their experience of reactance, and in turn, the more likely they are to restore their freedom by engaging in message derogation; however, as older adults have increasingly stronger paternalism beliefs, they are decreasingly likely to engage in message derogation following their experience of reactance, holding scenario realism and 
communication quality with their actual adult child caregiver constant. Thus, H6b was partially supported, albeit for only one of the five freedom restoration behaviors.

\section{Summary}

This chapter details findings from the three studies that were conducted to investigate the four research questions and six hypotheses of this dissertation. In Study One, older adults who receive care from an adult child caregiver identified three types of messages that they perceive as freedom threatening (i.e., offering directives, expressing doubt, loss-framing), although some older adults did not perceive all caregiving messages to be freedom threatening due to their perceptions of autonomy-support from their caregiver or their paternalism beliefs. Additionally, these older adults noted that the health behaviors at the crux of these freedom-threatening messages tended to fall within the categories of injury prevention, nutrition, health monitoring, medical adherence, and social engagement. Finally, older adults revealed that to restore their sense of autonomy following freedom-threatening messages from their adult child caregiver, they engaged in any of three types of freedom-restoration behavior: direct resistance, expressing disagreement, and age-related excuse-making.

Results from Study Two interviews with adult child caregivers revealed that adult children use a variety of types of messages in attempts to gain compliance from older adult parents, including offering directives, expressing doubt, providing justification, providing emotional support, and appealing to authority. Additionally, adult child caregiver perspectives on their parents' nonadherence to these messages revealed four types of nonadherence: direct resistance, expressing disagreement, source derogation, and passive resistance. 
Results of Study One and Two corroborated three types of freedom-threatening messages (i.e., offering directives, expressing doubt, loss-framing) that adult child caregivers use with older adult parents and which older adults perceive as freedom threatening; these message types informed the three freedom-threatening stimulus messages created and tested relative to an autonomy-supporting caregiving message in Study Three. Results of Study Three provided support for PRT in the context of family caregiving for older adults. Specifically, caregiving messages in which an adult child caregiver was offering directives or expressing doubt, both relative to autonomysupporting caregiving messages, triggered perceptions of freedom threat among older adults, which in turn elicited the experience of reactance and resulted in heightened intentions to engage in a variety of freedom restoration behavior. Trait reactance and paternalism beliefs did not moderate the reactance process, with one exception. The theoretical and practical implications of the collective results are discussed in Chapter IV. 


\section{CHAPTER IV}

\section{Discussion}

Guided by PRT (Brehm, 1966; Brehm \& Brehm, 1981), there were two purposes of this dissertation. The first purpose was to identify the nature of reactance-inducing messages that adult child caregivers use to gain healthcare compliance with their older adult parents. The second purpose was to test PRT and determine which caregiving messages trigger the reactance process. Toward addressing these purposes, three studies were conducted. In Study One, older adults shared the types of caregiving messages that they perceive as freedom threatening and the freedom restoration behaviors in which they engage in response to these messages. In Study Two, caregivers detailed the messages they use to gain compliance with their older adult parents and the ways in which their parents resist these messages. In Study Three, older adults were randomly assigned to read one of four caregiving messages that represented two message conditions, freedomthreatening and autonomy-supporting, to test PRT. The collective results of these three studies are discussed below, followed by the theoretical and practical implications of the findings, the limitations of the three studies, and suggestions for future research exploring the domains of PRT and communication between adult child caregivers and their older adult parents.

\section{Review of Findings}

Persuasive messages used by adult child caregivers. The first and second research questions inquired about the types of messages that adult child caregivers use to gain compliance with their older adult parents and the types of caregiving messages that older adults perceive as freedom threatening, respectively. Results of Study One and 
Study Two demonstrated that there is overlap between these types of caregiving messages. Although the literature suggests that adult children and their older adult parents use communication to negotiate between independence and dependence in caregiving situations (Cicirelli, 1992; Egbert, 2014; Hummert \& Morgan, 2001;

Pecchioni \& Nussbaum, 2000), implying a likelihood that at least some of this caregiving communication is freedom threatening, the current results established that not only do older adult parents perceive certain caregiving messages as freedom threatening, but also that adult children do in fact employ freedom-threatening messages when attempting to persuade their parents to engage in particular health behaviors. As noted in results of Study One, Joan, a member of the senior center, noted that she experiences a freedom threat when her daughter asks her "have you been taking [your medication]?" after Joan vouches that she has been taking her medication as prescribed. In results of Study Two, Valerie reported using a very similar message when she provides care for her mother: "[My mother] will be very adamant that she had already taken [her medication]. So [...] I'll say, 'No, you didn't take 'em."” This close parallel among others between the results of Study One and Study Two established the practicality of exploring freedomthreatening caregiving messages as a trigger of reactance among older adults in Study Three.

Results of Study One and Study Two also yielded multiple types of caregiving messages that older adults perceive as freedom threatening, several of which have parallels in existing PRT research. Offering directives, the first type of message that adult child caregivers reported using to gain compliance with their parents and that older adult reported as freedom threatening, encompassed caregiving messages that were demanding, 
used forceful language terms such as "should" and "need," and explicitly detailed the health behavior that caregivers desired their older adult parents to enact. This finding is consistent with existing research on forceful language messages, which tend to be more explicit and less difficult to understand than low-controlling messages, but also perceived as more freedom threatening (Miller et al., 2007). Existing literature on PRT suggests that high-controlling messages elicit greater perceptions of freedom threat and reactance than low-controlling messages (Dillard \& Shen, 2005; Miller et al., 2007; Quick \& Considine, 2008; Rains \& Turner, 2007), so it is not surprising that messages such as "go to the doctor" and "you should wear your hearing aid more often" comprised an overarching message type that older adults perceived as freedom threatening.

Although several adult child caregivers noted that they no longer use directives after learning of their relative ineffectiveness through "trial-and-error," it is important to note that at one point these caregivers relied on directives. In addition, some caregivers reported that they still use directives with their older adult parents in certain situations. Maria explained that the communication she uses in her attempts to persuade her mother varies based on the importance of the task and the timeframe in which the task must occur, noting that if she is pressed for time or if her mother is engaging in a behavior that threatens her safety, she tends to use "forceful redirection" with her mother. Additionally, Sarah explained that she sometimes uses directives because "it takes a lot longer to [persuade my father] the right way. It takes a lot of time and patience to do it the right way," and Lori noted she is more likely to use forceful language "especially if I worked all day and I'm tired." It appears that caregivers are at increased risk of using this type of freedom-threatening message when they lack experience providing care and/or their 
communication is driven by emotion.

Expressing doubt, the second type of persuasive appeal used by caregivers and perceived as freedom threatening by older adult parents, encompassed messages that questioned whether older adults were actually engaging in a recommended health behavior. Notably, expressions of doubt have not been examined as an antecedent of the reactance process prior to this study; however, the finding that a caregiver's expression of doubt is perceived as freedom threatening is echoed in the literature on caregiver distrust of patients. Patients may experience anger and hostility when faced with skepticism from their healthcare providers because they feel a lack of control over their ability to convey their health situation (Newton, Southall, Raphael, Ashford, \& LeMarchand, 2013; Reid, Ewan, \& Lowy, 1991). Perhaps older adults who are faced with expressions of doubt from their adult child caregivers experience a similar autonomy threat because their caregiver has already made up his/her mind regardless of the older adult's actual behavior.

As mentioned in Chapter III, providing justification, another type of compliancegaining tactic used by caregivers, was largely consistent with the definitions for gainframing (i.e., messages are framed in terms of the gains of complying) and loss-framing (i.e., messages are framed in terms of the losses of noncompliance) from Kahneman and Tversky’s (1981) prospect theory. Interestingly, older adults identified loss-framed messages, only, as freedom threating (i.e., versus both loss- and gain-framed), which is consistent with previous findings that loss-framing is more freedom-threatening and reactance-inducing than its counterpart of gain-framing (Cho \& Sands, 2011; Reinhart et al., 2007; Shen, 2015), particularly when one’s perceived risk is low (Quick \& Bates, 
2010) or when the message also uses controlling language (Shen, 2015). Indeed, as Cho and Sands (2011) summarized, language used in loss-framed messages tends to be "perceived as an argument or a command that must be answered, obeyed, or rebelled against" (p. 314), which is likely why older adults identified this type of caregiving message as freedom threatening.

Beyond the three types of caregiving messages that older adults identified as freedom threatening, results of Study Two revealed two additional types of messages that adult child caregivers use in attempts to gain compliance with their older adult parents: providing emotional support and appealing to authority. Because the current study sought to test freedom-threatening messages, these two particular messages were not tested in Study Three; however, it is important to discuss two ways in which these two message types fit within the wider body of persuasion literature. First, the literature on supportive messages that convey a source's concern toward a receiver's well-being has several intersections with the persuasion literature (Bodie, 2013). For example, advice-giving, which draws parallels to compliance-gaining (Bodie, 2013), tends to be evaluated more positively when preceded by person-centered emotional support (Feng, 2009) and when perceived relational closeness with the message source is high (Feng \& MacGeorge, 2006). Second, the influence of an authority figure, physicians included, is associated with persuasive effectiveness (Cialdini, 2009). In particular, individuals tend to be more receptive to advice when they perceive that the advice-giver's knowledge and experience relevant to a recommended behavior (i.e., expertise) is high (Feng \& MacGeorge, 2006). Given these parallels with existing persuasion literature, it appears that caregiver strategies of providing emotional support and appealing to authority may effectively 
mask the persuasive intent behind a health behavior recommendation; the former by embedding the behavioral recommendation in a person-centered emotional appeal and the latter by displacing the message source from the caregiver to a healthcare provider. Future research should examine whether caregiving messages that appeal to authority or provide emotional support mitigate the reactance process.

Older adult nonadherence to caregiving messages. The fourth research question inquired about the types of freedom restoration behaviors older adults enact in response to freedom-threatening caregiving messages. Results from Study One and Study Two yielded a host of responses to these messages that represent nonadherence, possibly due to the experience of reactance. Notably, several types of nonadherence draw parallels to types of reactance restoration behavior previously identified within the PRT literature, which further strengthens the argument for the appropriateness of studying communication between adult child caregivers and their older adult parents using a PRT lens. For example, three types of nonadherence behavior, including direct resistance, agerelated excuse-making, and passive resistance, parallel direct freedom restoration. Specifically, direct freedom restoration entails individuals attempting to regain their threatened freedom by adopting attitudes or behaviors that are the exact opposite of a recommendation (Burgoon et al., 2002; Quick \& Stephenson, 2007b; Worchel \& Brehm, 1970) and each of these three types of nonadherence behavior involve resistance to the recommended behavior.

Although providing age-related excuses as justification for engaging in direct freedom restoration does not have explicit parallels in existing PRT research, using such a stereotyped excuse may serve an impression-management function for older adults. 
That is, perhaps older adults who are motivated to resist a freedom-threatening recommendation but also want to save face with their adult child caregiver provide an age excuse for their nonadherence. Consistent with this notion, existing literature suggests that age excuses tend to be perceived as more believable as well as more socially skillful (e.g., polite, competent) than other types of excuses (e.g., situation, ability; Ryan, Bieman-Copland, See, Ellis, \& Anas, 2002). Also, given that age excuses are a stereotype-reinforcing communication behavior (Ryan et al., 2002), older adults' provision of an age-related excuse for enacting an opposing health behavior may facilitate caregivers' beliefs that age is the barrier to their older adult parent's ability to comply rather than the older adult's rebelliousness.

The remaining two types of nonadherence, expressing disagreement and source derogation, fall within the category of indirect freedom restoration, as they each involve attitudes or behaviors tangentially related to engaging in the opposite of the recommended behavior (Burgoon et al., 2002). Specifically, expressing disagreement involves attacking the content of the message and source derogation involves attacking the source of the message. The emergence of categories related to attacks on the content of a persuasive message is not surprising given that individuals who experience high levels of reactance are known to disparage the content of the message; reactance-inducing messages tend to be deemed not persuasive or convincing (Quick \& Stephenson, 2007a) and unfair (Miller et al., 2007), among other negative appraisals (Grandpre et al., 2003). Moreover, expressing disagreements and complaints have been identified as an outcome of the reactance process (Ball \& Goodboy, 2014; Olison \& Roloff, 2012). Similarly, the finding related to attacks on the source of the persuasive message is also consistent with 
existing literature, as individuals who experience high levels of reactance tend to rate the source of the reactance-inducing message as low in source credibility (Grandpre et al., 2003; Quick, 2012), including individual dimensions of domineeringness (LaVoie et al., 2015), sociability, trustworthiness, and expertise (Miller et al., 2007; Quick \& Bates, 2010).

Caregiving messages as triggers of the reactance process. The first four hypotheses predicted that relative to an autonomy-supporting message, freedomthreatening caregiving messages would elicit greater perceived freedom threat, which would trigger a greater experience of state reactance, which in turn would promote intentions to engage in a variety of freedom restoration behaviors. Of the three different freedom-threatening caregiving messages created for Study Three based on results of Study One and Study Two (i.e., offering directives, expressing doubt, loss-framing), offering directives and expressing doubt elicited significantly greater perceptions of freedom threat among older adults than the autonomy-supporting message. Moreover, for each of these freedom-threatening messages (versus autonomy-supporting), perceived freedom threat and state reactance sequentially mediated the relationship between caregiving message type and freedom restoration behavior. Specifically, higher levels of perceived freedom threat were related to higher levels of state reactance, which in turn was related to more negative attitudes and lower behavioral intentions toward the behavior recommended in the caregiving message (i.e., using a non-slip bathmat), as well as higher intentions to engage in direct freedom restoration, indirect freedom restoration, and message derogation. Notably, these findings held even when accounting for the quality of communication that the older adult participants actually receive from an adult 
child caregiver, as well as the perceived realism of the caregiving messages.

These results yield overwhelming support for PRT as an explanatory mechanism for older adult noncompliance with caregiving messages. Moreover, the two types of caregiving messages identified as triggers of the reactance process add to the voluminous body of literature on message features of reactance-inducing messages. Specifically, the finding that offering directives is an antecedent to the reactance process verifies that even in the context of caregiving for older adult parents, messages that feature commands and forceful, controlling language are not likely to be persuasive due to the recipient's experience of reactance (Ball \& Goodboy, 2014; Dillard \& Shen, 2005; Grandpre et al., 2003; Miller et al., 2007, 2013; Quick, 2012; Quick et al., 2011; Quick \& Stephenson, 2007a, 2008; Scott \& Quick, 2012; Shen, 2015; Xu, 2015). Additionally, the finding that the reactance process is induced by messages in which the persuader expresses doubt toward the recipient's compliance is a new contribution to the PRT literature that warrants further exploration as a type of message to avoid. Future PRT research should continue to examine message features that emphasize doubt and skepticism about a message receivers' behavior as antecedents of the reactance process.

Notably, although scores for perceived freedom threat were higher on average for the loss-framing message than the autonomy-supporting message created for Study Three, the difference between these means was not statistically significant and the lossframing message was excluded from subsequent analysis. Despite the unexpectedness of this finding and its inconsistency with literature suggesting that loss-frame messages evoke perceptions of freedom threat (e.g., Reinhart et al., 2007), there are multiple explanations for why the loss-framed message was not perceived as significantly more 
freedom threatening than the autonomy-supporting message. First, the literature on explaining why someone should enact a behavior advocated in a persuasive request suggests that providing justification lessens perceptions of dominance (Dillard, Wilson, Tusing, \& Kinney, 1997), therefore mitigating the experience of reactance (Dillard \& Shen, 2005). In Study One, when older adults were asked about their preferences for how their adult child caregivers ask them to engage in a health behavior, multiple participants noted they preferred and would be more likely to adhere if their caregiver provided them with the "pros and cons." Perhaps older adults perceive that they are making at least somewhat of an autonomous decision (i.e., versus being completely controlled) when their caregiver provides them with the consequences of noncompliance, therefore yielding slightly but not significantly higher scores in perceived freedom threat relative to the autonomy-supporting message.

Second, there are notable inconsistencies in the message framing literature (O'Keefe \& Jensen, 2006, 2007, 2009), including at the nexus of message framing and reactance, that may provide insight into this discrepant finding. Specifically, the finding that loss-framed messages yield greater perceived freedom threat than gain-framed messages has not held up across all studies testing PRT with message framing as an antecedent. For example, Quick and Bates (2010) found that message frame was not associated with perceived freedom threat. Additionally, Quick et al. (2014) found that gain-framed messages elicited greater perceived freedom threat than loss-framed messages when these messages were presented in the format of a narrative. Given that there have been calls to identify moderating and mediating variables that account for the effectiveness of gain- and loss-framed messages, both in general (Shen \& Bigsby, 2013) 
and within the reactance domain (Quick et al., 2014), perhaps moderating or mediating factors in the context of caregiver communication need to be taken into account.

Lack of moderation of the reactance process. The fifth and sixth hypotheses posited that trait reactance and paternalism beliefs would each moderate the reactance process; specifically, that these variable would moderate the relative indirect effect of message type on state reactance through perceived threat, as well as the indirect effect of perceived threat on freedom restoration behavior through state reactance. Results provided no evidence that trait reactance moderated the reactance process. Although this finding contradicts previous results that individuals experience the reactance process differentially depending on their level of reactance proneness (e.g., Dillard \& Shen, 2005; Quick \& Stephenson, 2008; Shen \& Dillard, 2005), there are mixed results regarding trait reactance as a moderator of perceived threat and freedom restoration behavior that may provide insight into this statistically nonsignificant result. Similar to the current results, Quick and Stephenson (2008) found that message features (specifically, dogmatic language and vivid language) were perceived as freedom threatening regardless of one's level of trait reactance. Perhaps the role of trait reactance as a moderator depends on the context; for example, Dillard and Shen (2005) found significant moderation in the context of flossing but not binge drinking, and Quick and Stephenson reported similar discrepancies between messages about sunscreen use and exercise. Based on the scope of the current study, however, this lack of moderation suggests that the message features and the extent to which they are freedom-threatening versus autonomy-supporting outweigh individuals' levels of reactance proneness.

In addition to the lack of support for trait reactance as a moderator, results 
provided almost no statistical support for moderating effects of paternalism beliefs. Although there were several trends in the hypothesized direction, paternalism beliefs did not emerge as a significant moderator, with one exception. Paternalism beliefs moderated the positive indirect effect of perceived freedom threat on message derogation through state reactance. Specifically, the stronger an older adult's paternalism beliefs, the less likely they were to engage in message derogation following the experience of reactance. It is unclear why paternalism emerged as a moderator for message derogation and not the other types of freedom restoration behavior; perhaps older adults who strongly believe that an adult child should make decisions on behalf of their older adult parent if those decisions benefit the parent's well-being have less to attack or critique about a persuasive caregiving message than older adults who are against paternalistic decision making.

Taken together, however, this set of results indicate that although paternalism may contribute slightly to individuals' experience of the reactance process, it appears that message type in this context outweighs the contribution of this set of beliefs - similar to the findings for trait reactance.

\section{Theoretical Implications}

The results of this dissertation serve to extend existing literature on PRT in three important ways. First, the current study fills a gap in a body of literature plagued by reliance on college student samples by exploring how older adults experience the reactance process. PRT researchers have speculated that individuals are particularly prone to resisting freedom-threatening persuasive appeals during transitional stages, including the transition into older adulthood (Burgoon et al., 2002; Miller, 2015; Miller et al., 2007; Voyer et al., 2005). However, older adults' experience of the reactance process 
has been excluded up to this point from the literature, despite how the transition into older adulthood is a context filled with conflicting needs to maintain one's autonomy and also depend on others for care (Egbert, 2014). Taken together, the qualitative and quantitative results of this dissertation confirm that reactance is salient among older adults in the context of health-related messages received from adult child caregivers. Specifically, PRT explains older adults' aversion to freedom-threatening caregiving messages and receptivity to autonomy-supporting caregiving messages delivered from their adult child. Moreover, in support of PRT, results illustrate that experiencing reactance in response to caregiving messages has deleterious effects on older adults' health attitudes and behavior. In the future, more research attention should be paid to how PRT functions within older adulthood.

Second, the current study takes a unique methodological approach to testing PRT by utilizing an experimental condition with more than two levels. One noticeable limitation of existing tests of PRT is that many of these studies rely on treatment conditions with only two levels (e.g., Dillard \& Shen, 2005; Quick, 2012; Shen, 2014; $\mathrm{Xu}, 2014)$. In contrast to these previous studies, the current study compares multiple types of freedom-threatening caregiving messages (i.e., offering directives, expressing doubt) to a reference message (i.e., autonomy-supporting) and examines each message's indirect effect on freedom restoration through the sequential mediators, all relative to the reference group. Using a similar methodological approach going forward will allow PRT researchers to not only obtain evidence about whether perceived freedom threat and state reactance serially mediate the effect of a message feature on freedom restoration behavior (i.e., whether there is an indirect effect), but also conclude for which levels of that 
message feature this indirect effect holds. Along these lines, researchers should take advantage of existing statistical tools that have the capacity to examine experimental conditions with high, moderate, and low levels of reactance-inducing or mitigating message features, such as the serial mediation analysis with a multicategorical independent variable used in the current study. Conducting mediation analyses involving two or more experimental groups relative to a reference group is advantageous because it allows researchers to examine the relative direct and relative indirect effects of each experimental group without having to collapse the treatment groups, among other less appropriate alternatives (Hayes \& Preacher, 2014).

Third, results from moderation analysis in Study Three revealed that the experience of reactance by older adults in the caregiving communication context was not conditional upon dispositions related to communication and control. Specifically, the freedom-threatening messages triggered the reactance process uniformly for all participants, such that neither trait reactance nor paternalism beliefs affected the efficacy of these messages to induce a perceived freedom threat. Although previous literature suggests that individuals high in trait reactance "respond more strongly to the same stimuli than do persons low in trait proneness" (Dillard \& Shen, 2005, p. 162), the current results suggest that the reactance process is more strongly associated with situational factors than with individual traits. Important for PRT, this conclusion reinforces Brehm's (1966) initial conceptualization of reactance as a situational attribute and the notion that all individuals strongly value their sense of autonomy. Moreover, the current results highlight how exploring communication-based antecedents of the reactance process holds more potential than examining individual differences in message processing. 


\section{Practical Implications}

Beyond the theoretical implications for PRT, these results take into account the care receiver's perspective, which is largely ignored in existing research (Egbert, 2014; Lyons et al., 2002), to offer practical implications for communication within the aging parent-child relationship. Specifically, results reveal the relative effectiveness and ineffectiveness of messages that caregivers use in attempts to gain compliance with their older adult parents. Simply put, to reduce the chance that older adults will experience reactance and subsequently adopt unhealthy or unsafe attitudes and behaviors, adult child caregivers should use persuasive messages that optimize the older adult's autonomy. Following Miller et al. (2007), these messages should emphasize choice and include autonomy-supporting language such as "perhaps," "possibly," "could," and "might want to." Moreover, caregivers should avoid messages that are likely to threaten older adults' freedom. The current results suggest that these types of messages include those that offer directives using controlling, forceful language, or those that imply to the older adult that the caregiver doubts whether they have been compliant.

Statistically nonsignificant findings for trait reactance and paternalism beliefs as moderators of the reactance process also provide practical implications for adult child caregivers of older adult parents. Caregivers should consider that the reactance process occurs uniformly among older adult care receivers, regardless of how receptive they think their parents are to advice or recommendations or the level of appropriateness that they think their parents assign to paternalistic interventions. In other words, caregivers are advised to find opportunities to use autonomy-supporting caregiving messages with their older adult parents, regardless of their parents' individual tendencies, in order to 
circumvent triggering the reactance process.

These results could be used to inform communication training for adult children planning to transition into the role of caregiver for an older adult parent. Important to note is that few informal caregivers receive adequate training (NAC and AARP, 2015a). In fact, among adult child caregivers interviewed for Study Two, only one caregiver reported receiving formal training about how to assist older adults. Instead, adult child caregivers reported learning "through trial-and-error" or "as you go," noting the mistakes and frustration they faced as they uncovered which messages are most persuasive. Moreover, during their interviews, caregivers seemed receptive to receiving communication training and guidance about what to expect in this new role and how to communicate with an aging parent. Although existing communication training programs for informal caregivers are largely geared toward caregivers of older adults with a progressive disease (e.g., cancer) or a diminished capacity to communicate (e.g., due to dementia), there is evidence that these programs are effective in improving informal caregivers' communication skills (e.g., Eggenberger, Heimerl, \& Bennett, 2012; Haberstroh, Neumeyer, Krause, Franzmann, \& Pantel, 2011; Liddle et al., 2012) and the quality of life of care recipients (Haberstroh et al., 2011). Additionally, training that advocates for autonomy-supporting communication may reduce conflict in the aging parent-child relationship considering that much of the conflict in this relationship stems from the adult child's attempts to control their parent's behavior (Cicirelli, 1981, 1992). Potentially, communication training programs that draw from the current findings could be implemented at independent living communities with adult children who are considering becoming a caregiver for an older adult parent. 


\section{Limitations}

Despite the theoretical and practical implications offered by the current findings, the three studies were not without limitations. The first limitation is that the perceived freedom threat induction check for the loss-framing caregiving message was unsuccessful. As Quick et al. (2013) asserted, “Inclusion of the threat induction check creates a more demanding and theoretically precise test of the theoretical process under scrutiny" (p. 173). Therefore, to retain the rigor of the theoretical test, the loss-framing message was dropped from subsequent analyses. Although existing PRT research suggests that loss-framed messages tend to be perceived as commandeering (Cho \& Sands, 2011) and guilt-inducing (Quick et al., 2014), features which should inherently trigger a greater perceived freedom threat, future research should consider adding other message features to loss-framed message conditions to ensure that they elicit an appropriate level of perceived freedom threat. For example, Lee and Cameron (2016) added controlling language to loss-framed messages previously used to test PRT to ensure that reactance was induced.

The second limitation is that one sole behavior (i.e., using a non-slip bathmat) was chosen as the focus for the caregiving messages in Study Three. Although this decision was made for consistency of the experimental manipulation and informed by a combination of the results from Study One and statistics indicating that falling is a common risk among older adults, using multiple behaviors would have strengthened the validity of the experimental design. Other PRT studies have tested the efficacy of certain message features to trigger the reactance process across multiple health contexts (e.g., Dillard \& Shen, 2005; Quick \& Considine, 2008). Most recently, Gardner and Leshner 
(2015) tested message features applied to recommendations about diet as well as recommendations about exercise. To further validate the current findings, future studies should examine health-related behaviors other than those related to fall prevention that may be more or less tied to older adults' autonomy, as the magnitude of reactance experienced tends to depend on the importance an individual places upon a threatened behavior (Brehm \& Brehm, 1981; Buller et al., 1998; Burgoon et al., 2002).

The third limitation was that the stimuli used in Study Three were print messages read online by older adults who were aware that they were partaking in a research study. Notably, the use of written scenarios is common in PRT research (e.g., Ball \& Goodboy, 2014; Bessarabova et al., 2013; Dillard \& Shen, 2005; Olison \& Roloff, 2012; Miller et al., 2007; Reinhart et al., 2007; Zhang \& Sapp, 2013) as this method strengthens the internal validity of stimulus material by affording researchers greater control over the experimental manipulation (Quick \& Considine, 2008). At the same time, however, reliance on written messages for the current study sacrifices external validity (Shadish, Cook, \& Campbell, 2002) because the messages are unlikely to represent typical conversational exchanges between older adults and their adult child caregivers. Although the current study controlled for perceived realism of the caregiving message and perceived communication quality received from one's actual adult child caregiver, it remains to be seen whether these messages would elicit the same effects if they were actually being said to older adults by their adult child caregivers. In future research, it would be fruitful to examine how caregiver messages or older adult responses vary based on the context of a conversation.

The fourth limitation is that participants for Study Three were recruited through 
convenience sampling via MTurk, decreasing the likelihood that results are representative of the overarching population of older adults who receive care from an adult child caregiver. Notably, older adult participants from Study Three were relatively educated and received significantly fewer hours of care per week from their adult child caregiver than recent reports of the population mean (17.1 vs. 23.9 hours per week, $t(286)=-12.92$, $p<.001, d=0.76)$. However, there is evidence that older adult samples from MTurk are not significantly different than those from community samples (Lemaster et al., 2015). Additionally, there was consistency with other demographic information on the aging parent-child caregiving relationship. For example, more than half of participants in Study Three received care from their biological daughter (50.7\%) and the largest proportion (36.1\%) of these relationships was biological mother-daughter, which is consistent with existing figures (Cicirelli, 1992; NAC and AARP, 2015a). Additionally, all participants met the recommended inclusion criteria for research on the aging parent-child relationship (i.e., older adults who receive at least 10 hours per week of care; Cicirelli, 2003, 2006). Despite these similarities, the results should be interpreted in light of the narrow sample, and researchers should aim to replicate the current findings in other older adult samples in the future.

The fifth limitation is that although the order of the paths for the serial mediation model used in Study Three was driven by PRT, the model was analyzed based on crosssectional self-report data; as such, causality claims cannot be made. Future research employing longitudinal data collection would be a welcome addition to the PRT literature, as reactance research up to this point has relied heavily on cross-sectional selfreport measures of the reactance process (for an exception, see Smith, Cornacchione, 
Morash, Kashy, \& Cobbina, 2016). Moreover, data collected such that causality claims can be made would be more appropriate to test using a serial mediation, as the analysis would not merely assume a causal chain (Hayes, 2013).

\section{Future Directions}

Results of the current study lend themselves to several avenues for future inquiry. One direction for additional research at the crux of PRT and caregiving communication between older adults and their adult children is to conduct research with these populations earlier in the transition into caregiver-care recipient roles. Results from interviews with caregivers in Study Two revealed that many caregivers reported not currently using controlling language or directives after learning that those types of messages are not effective in gaining compliance with their older adult parents, perhaps indicating that adult children's use of freedom-threatening language changes as they adjust to and gain more experience in the caregiving role. Therefore, examining caregiver communication earlier in the transition stages of this caregiving relationship may establish the extent to which new caregivers are prone to using reactance-inducing messages and may reveal other types of freedom-threatening messages that are common during these earlier stages. Ultimately, such research could help establish a need for communication training during the transition into this role.

Another future direction is to examine connections between reactance-inducing language and the Communication Predicament of Aging Model (CPA; Ryan et al., 1986). In combination with the parallels between the two frameworks detailed in Chapter I, the current results inform two lines of future research regarding PRT and the CPA. First, certain types of older adults' freedom restoration behaviors may serve to perpetuate 
negative age stereotypes among adult child caregivers and older adults alike. For instance, age-related excuse-making, which older adults from Study One reported as a response to freedom-threatening messages, is a type of stereotype-reinforcing communication behavior that prompts the negative feedback cycle of the CPA (Ryan et al., 2002). Specifically, individuals who provide an age excuse as justification for why they did not engage in a recommended health behavior may reinforce the adult child caregiver's negative age stereotypes and contribute to their own beliefs that they cannot engage in a recommended behavior because of "old age" (Hummert et al., 2004). Along these lines, Ryan et al. (2002) found that older adults who used an age excuse to rationalize why they forgot something were rated by older adult and younger adult participants as more likely to forget something again in the future and elicit worry and frustration from others, versus older adults who used excuses unrelated to age.

Second, it may be possible that old age cues and stereotyped beliefs about older adulthood prompt adult child caregivers' use of freedom-threatening caregiving messages. Existing research indicates that various types of overaccommodation used by caregivers, such as elderspeak, baby talk, control strategies, and dependence-support scripts, are prompted by negative stereotypes of old age (Ryan et al., 1986). Similarly, freedom-threatening messages may be a type of overaccommodation triggered by adult child caregivers' negative age stereotypes. Future research should formally examine how PRT may fit within the CPA framework.

In addition to old age cues and age-stereotyped beliefs as prompts of freedomthreatening messages, future research should explore reasons why adult child caregivers resort to the use of freedom-threatening caregiving messages with their older adult 
parents. As previously mentioned in the results of Study Two, caregivers who reported using freedom-threatening messages, particularly directives, with their older adult parents usually noted that they used these messages when feeling frustrated with or overwhelmed by their role as caregiver. Taking this into consideration, researchers should explore whether adult children's perceptions of caregiver strain and burden transpire through the use of forceful caregiving messages with their older adult parents.

Given that the current study confirms prior suggestions that reactance is prevalent among older adults (Burgoon et al., 2002; Miller, 2015; Voyer et al., 2005), future PRT research should continue to examine older adults' experience of the reactance process. One such avenue is related to how reactance has traditionally been examined as an undesired effect of persuasive communication (i.e., "aversive state"; Quick et al., 2013, p. 179); yet, PRT does not require the freedom restoration behavior to be antisocial. Instead, the theory posits that upon experiencing reactance, an individual is simply more aware of and motivated to restore their threatened or eliminated autonomy (Brehm, 1966), regardless of the valence of that restoration behavior. Thus, there are other potentially more productive ways to apply PRT such that reactance itself is a vehicle for prosocial behavior change. One such avenue that has been underexplored is the utility of reactance as a "strategy of empowerment" (Quick et al., 2013, p. 179) that motivates individuals to engage in prosocial behavior change (for exceptions, see Miller et al., 2013; Quick, Bates, \& Quinlan, 2009). In other words, to capitalize on the motivation to restore freedom as a result of experiencing reactance, studies could explore how to depict negative behaviors themselves - as opposed to persuasive messages about negative behaviors - as freedom threatening, so that the experience of reactance is directed toward 
these deleterious health behaviors rather than the prosocial persuasive health message. This approach may be particularly valuable in promoting aging with agency and motivating older adults to prolong the onset of ill-health and autonomy-restricting conditions associated with later life (e.g., hip fractures; Stevens et al., 2006). In sum, research that examines the utility of reactance itself as a basis for change would provide persuasive health message designers with valuable strategies to implement rather than simply what to avoid (e.g., freedom-threatening language) in their messaging, especially with regard to aging-related health behaviors.

\section{Conclusion}

One major challenge faced by individuals in the aging parent-child relationship is the older adult's transition from being completely independent to being dependent on a care provider (Egbert, 2014). The collective results of this dissertation reinforce how communication is crucial in negotiations between autonomy and control during older adulthood, particularly as adult children's persuasive caregiving messages relate to their older adult parents' experience of reactance. Specifically, adult child caregivers should avoid freedom-threatening caregiving messages and instead use autonomy-supporting messages in attempts to persuade their older adult parents to engage in healthy behavior. Ultimately, autonomy-supporting messages offer older adults some semblance of control, whereas older adults may adopt unhealthy or unsafe attitudes and behaviors in response to freedom-threatening messages to preserve their independence. Importantly, this dissertation highlights how PRT accounts for some of the regularities in negotiations between independence and dependence among older adults and their adult child caregivers. 


\section{References}

Administration on Aging. (2014). A profile of older Americans: 2014. Retrieved from http://www.aoa.acl.gov/Aging_Statistics/Profile/2014/docs/2014-Profile.pdf

Allen, D. N., Sprenkel, D. G., \& Vitale, P. A. (1994). Reactance theory and alcohol consumption laws: Further confirmation among collegiate alcohol consumers. Journal of Studies on Alcohol, 55, 34-40. doi:10.15288/jsa.1994.55.34

Ball, H. (2015, November). Toward the development and initial validation of a Freedom Restoration Measure. Paper presented at the annual meeting of the National Communication Association, Las Vegas, NV.

Ball, H., \& Goodboy, A. K. (2014). An experimental investigation of the antecedents and consequences of psychological reactance theory in the college classroom. Communication Education, 63, 192-209. doi:10.1080/03634523.2014.918634

Baltes, M. M. (1996). The many faces of dependency in old age. New York, NY: Cambridge University Press.

Baltes, M. M., \& Wahl, H.-W. (1996). Patterns of communication in old age: The dependence-support and independence-ignore script. Health Communication, 8, 217-231. doi:10.1207/s15327027hc0803_3

Bell, R. A., McGlone, M. S., \& Dragojevic, M. (2014). Bacteria as bullies: Effects of linguistic agency assignment in health message. Journal of Health Communication, 19, 340-358. doi:10.1080/10810730.2013.798383

Bessarabova, E., Fink, E. L., \& Turner, M. (2013). Reactance, restoration, and cognitive structures: Comparative statics. Human Communication Research, 39, 339-364. doi:10.1111/hcre.12007 
Bodie, G. D. (2013). Supportive and persuasive communication: Theoretical intersections. In J. P. Dillard \& L. Shen (Eds.), The SAGE handbook of persuasion (2nd ed., pp. 237-255). Thousand Oaks, CA: Sage.

Brehm, J. W. (1966). A theory of psychological reactance. New York, NY: Academic Press.

Brehm, S. S., \& Brehm, J. W. (1981). Psychological reactance: A theory of freedom and control. New York, NY: Academic Press.

Buboltz, W. C., Jr., Johnson, P., \& Woller, K. M. P. (2003). Psychological reactance in college students: Family-of-origin predictors. Journal of Counseling \& Development, 81, 311-317. doi:10.1002/j.1556-6678.2003.tb00258.x

Buhrmester, M., Kwang, T., \& Gosling, S. D. (2011). Amazon's Mechanical Turk: A new source of inexpensive, yet high-quality, data? Perspectives on Psychological Science, 6, 3-5. doi:10.1177/1745691610393980

Buller, D. B., Borland, R., \& Burgoon, M. (1998). Impact of behavioral intention on effectiveness of message features: Evidence from the family sun safety project. Human Communication Research, 24, 433-453. doi:10.1111/j.14682958.1998.tb00424.x

Burgoon, M., Alvaro, E., Grandpre, J., \& Voulodakis, M. (2002). Revisiting the theory of psychological reactance: Communicating threats to attitudinal freedom. In J. P. Dillard \& M. Pfau (Eds.), The persuasion handbook: Developments in theory and practice (pp. 213-232). Thousand Oaks, CA: Sage.

Caporael, L. R. (1981). The paralanguage of caregiving: Baby talk to the institutionalized aged. Journal of Personality and Social Psychology, 40, 876-884. 
doi:10.1037/0022-3514.40.5.876

Centers for Disease Control and Prevention (CDC). (2009). Limitations in activities of daily living and instrumental activities of daily living, 2003-2007. Retrived from http://www.cdc.gov/nchs/health_policy/ADL_tables.htm

Centers for Disease Control and Prevention (CDC). (2016). Preventing falls among older adults. Retrieved from http://www.cdc.gov/features/olderamericans/

Cho, H., \& Salmon, C. T. (2007). Unintended effects of health communication campaigns. Journal of Communication, 57, 293-317. doi:10.1111/j.14602466.2007.00344.x

Cho, H., \& Sands, L. (2011). Gain- and loss-frame sun safety messages and psychological reactance of adolescents. Communication Research Reports, 28, 308-317. doi:10.1080/08824096.2011.616242

Cialdini, R. B. (2009). Influence: Science and practice (5th ed.). Boston, MA: Pearson.

Cicirelli, V. G. (1992). Family caregiving: Autonomous and paternalistic decision making. Newbury Park, CA: Sage.

Cicirelli, V. G. (2003). Mothers' and daughters' paternalism beliefs and caregiving decision making. Research on Aging, 25, 3-21. doi:10.1177/0164027502238340

Cicirelli, V. G. (2006). Caregiving decision making by older mothers and adult children: Process and expected outcome. Psychology and Aging, 21, 209-221. doi:10.1037/0882-7974.21.2.209

Cohen, J. A. (1960). A coefficient of agreement for nominal scales. Educational and Psychological Measurement, 20, 37-46. doi:10.1177/001316446002000104

Dickson, F. C., Hughes, P. C., \& Walker, K. L. (2005). An exploratory investigation into 
dating among later-life women. Western Journal of Communication, 69, 67-82. doi:10.1080/10570310500034196

Dillard, J. P., Kinney, T. A., \& Cruz, M. G. (1996). Influence, appraisals, and emotions in close relationships. Communication Monographs, 63, 105-130. doi:10.1080/03637759609376382

Dillard, J. P., \& Shen, L. (2005). On the nature of reactance and its role in persuasive health communication. Communication Monographs, 72, 144-168. doi:10.1080/03637750500111815

Dillard, J. P., Wilson, S. R., Tusing, K. J., \& Kinney, T. A. (1997). Politeness judgments in personal relationships. Journal of Language and Social Psychology, 16, 297325. doi:10.1177/0261927x970163003

Edwards, H., \& Noller, P. (1998). Factors influencing caregiver-care receiver communication and its impact on the well-being of older care receivers. Health Communication, 10, 317-341.doi:10.1207/s15327027hc1004_2

Egbert, N. (2014). Integrating intergenerational family caregiving challenges across discipline and culture: Identity, attribution, and relationship. In E. L. Cohen (Ed.), Communication yearbook (Vol. 38, pp. 307-336). New York, NY: Routledge.

Eggenberger, E., Heimerl, K., \& Bennett, M. I. (2012). Communication skills training in dementia care: A systematic review of effectiveness, training content, and didactic methods in different care settings. International Psychogeriatrics, 25, 345-358. doi:10.1017/S1041610212001664

Engs, R., \& Hanson, D. J. (1989). Reactance theory: A test with collegiate drinking. Psychological Reports, 64, 1083-1086. doi:10.2466/pr0.1989.64.3c.1083 
Feinberg, L., Renhard, S. C., Houser, A., \& Choula, R. (2011). Valuing the invaluable: 2011 update: The growing contributions and costs of family caregiving. Washington, DC: AARP Public Policy Institute.

Feng, B. (2009). Testing an integrative model of advice giving in supportive interactions. Human Communication Research, 35, 115-129. doi:10.1111/j.14682958.2008.01340.x

Feng, B., \& MacGeorge, E. L. (2006). Predicting receptiveness to advice: Characteristics of the problem, the advice-giver, and the recipient. Southern Communication Journal, 71, 67-85. doi:10.1080/10417940500503548

Ford, A. B., Haug, M. R., Stange, K. C., Gaines, A. D., Noelker, L. S., \& Jones, P. K. (2000). Sustained personal autonomy: A measure of successful aging. Journal of Aging and Health, 12, 470-489. doi:10.1177/089826430001200402

Fowler, C., \& Fisher, C. L. (2009). Attitudes toward decision making and aging, and preparation for future care needs. Health Communication, 24, 619-630. doi:10.1080/10410230903242226

Fox, S. A. (1999). Communication in families with an aging parent: A review of the literature and agenda for future research. In M. E. Roloff (Ed.), Communication yearbook (Vol. 22, pp. 377-429). Thousand Oaks, CA: Sage.

Gardner, L., \& Leshner, G. (2015). The role of narrative and other-referencing in attenuating psychological reactance to diabetes self-care messages. Health Communication, 31, 738-751. doi:10.1080/10410236.2014.993498

Giles, H., Coupland, N., \& Coupland, J. (1991). Accommodation theory: Communication, context, and consequence. In H. Giles, J. Coupland, \& N. 
Coupland (Eds.), Contexts of accommodation: Developments in applied linguistics (pp. 1-68). Cambridge, UK: Cambridge University Press.

Glaser, B., \& Strauss, A. (1967). The discovery of grounded theory: Strategies for qualitative inquiry. Chicago, IL: Aldine.

Golding, S., Nadorff, M. R., Winer, E. S., \& Ward, K. C. (2015). Unpacking sleep and suicide in older adults in a combined online sample. Journal of Clinical Sleep Medicine, 11, 1385-1392. doi:10.5664/jcsm.5270

Grandpre, J., Alvaro, E. M., Burgoon, M., Miller, C. H., \& Hall, J. R. (2003). Adolescent reactance and anti-smoking campaigns: A theoretical approach. Health Communication, 15, 349-366. doi:10.1207/S15327027HC1503_6

Grasso, K. L., \& Bell, R. A. (2015). Understanding health information seeking: A test of the risk perception attitude framework. Journal of Health Communication, 20, 1406-1414. doi:10.1080/10810730.2015.1018634

Haberstroh, J., Neumeyer, K., Krause, K., Franzmann, J., \& Pantel, J. (2011). TANDEM: Communication training for informal caregivers of people with dementia. Aging \& Mental Health, 15, 405-413. doi:10.1080/13607863.2010.536135

Hammock, T., \& Brehm, J. W. (1966). The attractiveness of choice alternatives when freedom to choose is eliminated by social agent. Journal of Personality, 34, 546554. doi:10.1111/j.1467-6494.1966.tb02370.x

Hayes, A. F. (2013). Introduction to mediation, moderation, and conditional process analysis. New York, NY: Guilford.

Hayes, A. F. (2015). An index and test of linear moderated mediation. Multivariate Behavioral Research, 50, 1-22. doi:10.1080/00273171.2014.962683 
Hayes, A. F., \& Preacher, K. J. (2014). Statistical mediation analysis with a multicategorical independent variable. British Journal of Mathematical and Statistical Psychology, 67, 451-470. doi:10.1111/bmsp.12028

Hofland, B. F. (1988). Autonomy in long term care: Background issues and a programmatic response. The Gerontologist, 28(Suppl.), 3-9. doi:10.1093/geront/28.Suppl.3

Hong, S. M., \& Faedda, S. (1996). Refinement of the Hong Psychological Reactance Scale: A further factor analytic validation. Education and Psychological Measurement, 56, 173-182. doi:10.1177/0013164496056001014

Hong, S.-M., Giannakopoulos, E., Laing, D., \& Williams, N. A. (1994). Psychological reactance: Effects of age and gender. Journal of Social Psychology, 134, 223-228. doi:10.1080/00224545.1994.9711385

Hummert, M. L. (2007). As family members age: A research agenda for family communication. Journal of Family Communication, 7, 3-21. doi:10.1080/15267430709336666

Hummert, M. L., Garstka, T. A., Ryan, E. B., \& Bonneson, J. L. (2004). The role of age stereotypes in interpersonal communication. In J. F. Nussbaum \& J. Coupland (Eds.), Handbook of communication and aging research (2nd ed., pp. 91-114). Mahwah, NJ: Lawrence Erlbaum Associates.

Hummert, M. L., \& Morgan, M. (2001). Negotiating decisions in the aging family. In M. L. Hummert \& J. F. Nussbaum (Eds.), Aging, communication, and health: Linking research and practice for successful aging (pp. 177-202). Mahwah, NJ: Lawrence Erlbaum Associates. 
Hummert, M. L., \& Ryan, E. B. (1996). Toward understanding variations in patronizing talk addressed to older adults: Psycholinguistic features of care and control. International Journal of Psycholinguistics, 12, 149-169.

Johnson, P., \& Buboltz, W. C., Jr. (2000). Differentiation of self and psychological reactance. Contemporary Family Therapy, 22, 91-102. doi:10.1007/s10591-005$4042-6$

Kemper, S. (1994). "Elderspeak": Speech accommodations to older adults. Aging and Cognition, 1, 17-28. doi:10.1080/09289919408251447

Kim, S.-Y., Levine, T. R., \& Allen, M. (2013). Comparing separate process and intertwined models for reactance. Communication Studies, 64, 273-295. doi:10.1080/10510974.2012.755639

Kim, S.-Y., Levine, T. R., \& Allen, M. (2014). The intertwined model of reactance for resistance and persuasive boomerang. Communication Research. Advance online publication. doi:10.1177/0093650214548575

Lanceley, A. (1985). Use of controlling language in the rehabilitation of the elderly. Journal of Advanced Nursing, 10, 125-135. doi:10.1111/j.13652648.1985.tb00502.x

LaVail, K. H., Anker, A. E., Reinhart, A., \& Feeley, T. H. (2010). The persuasive effects of audiovisual PSAs to promote organ donation: The mediating role of psychological reactance. Communication Studies, 61, 46-69. doi:10.1080/10510970903400337

LaVoie, N. R., Quick, B. L., Riles, J. M., \& Lambert, N. J. (2015). Are graphic cigarette warning labels an effective message strategy? A test of psychological reactance 
theory and source appraisal. Communication Research. Advance online publication. doi:10.1177/0093650215609669

Lee, H., \& Cameron, G. T. (2016). Utilizing audiovisual and gain-framed messages to attenuate psychological reactance toward weight management health messages. Health Communication. Advance online publication. doi:10.1080/10410236.2015.1099506

Lee, D.-C. A., McDermott, F., Hoffmann, T., \& Haines, T. P. (2013). 'They will tell me if there is a problem': Limited discussion between health professionals, older adults and their caregivers on fall prevention during and after hospitalization. Health Education Research, 28, 1051-1066. doi:10.1093/her/cyt091

Lemaster, P., Pichayayothin, N., \& Strough, J. (2015). Using Amazon's Mechanical Turk to recruit older adults: Easy and cheap, but is it valid? Gerontologist, 55(Suppl. 2), 469. doi:10.1093/geront/gnv198.08

Leroy, G., Kauchak, D., \& Hogue, A. (2016). Effects on text simplification: Evaluation of splitting up noun phrases. Journal of Health Communication, 21, 18-26. doi:10.1080/10810730.2015.1131775

Levy, B. R. (2003). Mind matters: Cognitive and physical effects of aging selfstereotypes. Journal of Gerontology: Psychological Sciences, 58, 203-211. doi:10.1093/geronb/58.4.P203

Liddle, J., Smith-Conway, E. R., Baker, R., Angwin, A. J., Gallois, C., Copland, D. A., ... Chenery, H. J. (2012). Memory and communication support strategies in dementia: Effect of a training program for informal caregivers. International Psychogeriatrics, 24, 1927-1942. doi:10.1017/S1041610212001366 
Lindlof, T. R., \& Taylor, B. C. (2002). Qualitative communication research methods (3rd ed.). Los Angeles, CA: Sage.

Lindsey, L. L. M. (2005). Anticipated guilt as behavioral motivation: An examination of appeals to help unknown others through bone marrow donation. Human Communication Research, 31, 453-481. doi:10.1093/hcr/31.4.453

Lombard, M., Snyder-Duch, J., \& Bracken, C. C. (2002). Content analysis in mass communication: Assessment and reporting of intercoder reliability. Human Communication Research, 28, 587-604. doi:10.1111/j.1468-2958.2002.tb00826.x

Lyons, K. S., Zarit, S. H., Sayer, A. G., \& Whitlatch, C. J. (2002). Caregiving as a dyadic process: Perspectives from caregiver and receiver. Journal of Gerontology:

Psychological Sciences and Social Sciences, 57, 195-204. doi:10.1093/geronb/57.3.P195

Mason, W., \& Suri, S. (2012). Conducting behavioral research on Amazon's Mechanical Turk. Behavior Research Methods, 44, 1-23. doi:10.3758/s13428-011-0124-6

Mendes, E. (2011, July 28). Most caregivers look after elderly parent; Invest a lot of time. Retrieved from http://www.gallup.com/poll/148682/caregivers-look-elderlyparent-invest-lot-time.aspx

Miller, C. H. (2015). Persuasion and psychological reactance: The effects of explicit, high-controlling language. In R. Schulze \& H. Pishwa (Eds.), The exercise of power in communication (pp. 269-286). New York, NY: Palgrave Macmillan.

Miller, C. H., Burgoon, M., Grandpre, J. R., \& Alvaro, E. M. (2006). Identifying principal risk factors for the initiation of adolescent smoking behaviors: The significance of psychological reactance. Health Communication, 19, 241-252. 
doi:10.1207/s15327027hc1903_6

Miller, C. H., Ivanov, B., Sims, J., Compton, J., Harrison, K. J., Parker, K. A., . . . Averbeck, J. M. (2013). Boosting the potency of resistance: Combining the motivational forces of inoculation and psychological reactance. Human Communication Research, 39, 127-155. doi:10.1111/j.1468-2958.2012.01438.x

Miller, C. H., Lane, L. T., Deatrick, L., M., Young, A. M., \& Potts, K. A. (2007). Psychological reactance and promotional health messages: The effects of controlling language, lexical concreteness, and the restoration of freedom. Human Communication Research, 33, 219-240. doi:10.1111/j.1468-2958.2007.00297.x

Miller, C. H., \& Quick, B. L. (2010). Sensation seeking and psychological reactance as health risk predictors for an emerging adult population. Health Communication, 25, 266-275. doi:10.1080/10410231003698945

Miller, K. I., Shoemaker, M. M., Willyard, J., \& Addison, P. (2008). Providing care for elderly parents: A structurational approach to family caregiver identity. Journal of Family Communication, 8, 19-43. doi:10.1080/15267430701389947

Miron, A. M., \& Brehm, J. W. (2006). Reactance theory - 40 years later. Zeitschrift für Sozialpsychologie, 37, 9-18. doi:10.1024/0044-3514.37.1.3

Mongeau, P. A. (2013). Fear appeals. In J. P. Dillard \& L. Shen (Eds.), The SAGE handbook of persuasion (2nd ed., pp. 184-199). Thousand Oaks, CA: Sage.

Morgan, M., \& Hummert, M. L. (2000). Perceptions of communicative control strategies in mother-daughter dyads across the life span. Journal of Communication, 50, 4864. doi:10.1111/j.1460-2466.2000.tb02852.x

Moyer-Gusé, E. (2008). Toward a theory of entertainment persuasion: Explaining the 
persuasive effects of entertainment-education messages. Communication Theory, 18, 407-425. doi:10.1111/j.1468-2885.2008.00328.x

Moyer-Gusé, E., Jain, P., \& Chung, A. H. (2012). Reinforcement or reactance?

Examining the effect of an explicit persuasive appeal following an entertainmenteducation narrative. Journal of Communication, 62, 1010-1027. doi:10.1111/j.1460-2466.2012.01680.x

Moyer-Gusé, E., \& Nabi, R. L. (2010). Explaining the effects of narrative in an entertainment television program: Overcoming resistance to persuasion. Human Communication Research, 36, 26-52. doi:10.1111/j.1468-2958.2009.01367.x

O’Connor, B. P., \& Rigby, H. (1996). Perceptions of baby talk, frequency of receiving baby talk, and self-esteem among community and nursing home residents. Psychology and Aging, 11, 147-154. doi:10.1037/0882-7974.11.1.147

O'Keefe, D. J., \& Jensen, J. D. (2006).The advantages of compliance or the disadvantages of noncompliance? A meta-analytic review of the relative persuasive effectiveness of gain-framed and loss-framed messages. Communication yearbook (Vol. 30, pp. 1-43). New York, NY: Routledge.

O'Keefe, D. J., \& Jensen, J. D. (2007).The relative persuasiveness of gain-framed and loss-framed message processing for encouraging disease prevention behaviors: A meta-analytic review. Journal of Health Communication, 12, 623-644. doi:10.1080/10810730701615198

O'Keefe, D. J., \& Jensen, J. D. (2009). The relative persuasiveness of gain-framed and loss-framed message processing for encouraging disease detection behaviors: A meta-analytic review. Journal of Communication, 59, 296-316. 
doi:10.1111/j.1460-2466.2009.01417.x

Olison, W. O., \& Roloff, M. E. (2012). Responses to organizational mandates: How voice attenuates psychological reactance and dissent. Communication Research Reports, 29, 204-216. doi:10.1080/08824096.2012.684984

Ouwehand, C., de Ridder, D. T. D., \& Bensing, J. M. (2007). A review of successful aging models: Proposing proactive coping as an important additional strategy. Clinical Psychology Review, 27, 873-884. doi:10.1016/j.cpr.2006.11.003

Owen, W. F. (1984). Interpretive themes in relational communication. Quarterly Journal of Speech, 70, 274-287. doi:10.1080/00335638409383697

Nabi, R. L., Roskos-Ewoldsen, D., \& Carpentier, F. D. (2008). Subjective knowledge and fear appeal effectiveness: Implications for message design. Health Communication, 23, 191-201. doi:10.1080/10410230701808327

National Alliance for Caregiving and AARP Public Policy Institute (NAC and AARP). (2015a). 2015 report: Caregiving in the U.S. Retrieved from http://www.caregiving.org/wpcontent/uploads/2015/05/2015_CaregivingintheUS_Final-Report-June4_WEB.pdf

National Alliance for Caregiving and AARP Public Policy Institute (NAC and AARP). (2015b). Caregivers of older adults: A focused look at those caring for someone age 50+. Retrieved from http://www.aarp.org/content/dam/aarp/ppi/2015/caregivers-of-older-adultsfocused-look.pdf

Newton, B. J., Southall, J. L., Raphael, J. H., Ashford, R. L., \& LeMarchand, K. (2013). 
A narrative review of the impact of disbelief in chronic pain. Pain Management Nursing, 14, 161-171. doi:10.1016/j.pmn.2010.09.001

Palmgreen, P., Donohew, L., \& Harrington, N. G. (2001). Sensation seeking in antidrug campaign and message design. In R. E. Rice \& C. K. Atkin (Eds.), Public communication campaigns (3rd ed., pp. 300-304). Thousand Oaks, CA: Sage.

Pecchioni, L. L., \& Nussbaum, J. F. (2000). The influence of autonomy and paternalism on communicative behaviors in mother-daughter relationships prior to dependency. Health Communication, 12, 317-338. doi:10.1207/S15327027HC1204_1

Pecchioni, L. L., Ota, H., \& Sparks, L. (2004). Cultural issues in communication and aging. In J. F. Nussbaum \& J. Coupland (Eds.), Handbook of communication and aging research (2nd ed., pp. 167-207). Mahwah, NJ: Lawrence Erlbaum Associates.

Piercy, K. W., \& Chapman, J. G. (2001). Adopting the caregiver role: A family legacy. Family Relations, 50, 386-393. doi:10.1111/j.1741-3729.2001.00386.x

Plander, K. L. (2013). Checking accounts: Communication privacy management in familial financial caregiving. Journal of Family Communication, 13, 17-31. doi:10.1080/15267431.2012.742090

Quick, B. L. (2012). What is the best measure of psychological reactance? An empirical test of two measures. Health Communication, 27, 1-9. doi:10.1080/10410236.2011.567446

Quick, B. L. (2013). Perceived message sensation value and psychological reactance: A test of the dominant thought disruption hypothesis. Journal of Health 
Communication, 18, 1024-1038. doi:10.1080/10810730.2013.768728

Quick, B. L., \& Bates, B. R. (2010). The use of gain- or loss-frame messages and efficacy appeals to dissuade excessive alcohol consumption among college students: A test of psychological reactance theory. Journal of Health Communication, 15, 603628. doi:10.1080/10810730.2010.499593

Quick, B. L., Bates, B. R., \& Quinlan, M. R. (2009). The utility of anger in promoting clean indoor air policies. Health Communication, 24, 548-561. doi:10.1080/10410230903104939

Quick, B. L., \& Considine, J. R. (2008). Examining the use of forceful language when designing exercise persuasive messages for adults: A test of conceptualizing reactance arousal as a two-step process. Health Communication, 23, 483-491. doi:10.1080/10410230802342150

Quick, B. L., Kam, J. A., Morgan, S. E., Montero Liberona, C. A., \& Smith, R. A. (2014). Prospect theory, discrete emotions, and freedom threats: An extension of psychological reactance theory. Journal of Communication, 65, 1-22. doi:10.1111/jcom.12134

Quick, B. L., \& Kim, D. K. (2009). Examining reactance and reactance restoration with South Korean adolescents: A test of psychological reactance within a collectivist culture. Communication Research, 36, 765-782. doi:10.1177/009365020346797

Quick, B. L., Scott, A. M., \& Ledbetter, A. M. (2011). A close examination of trait reactance and issue involvement as moderators of psychological reactance theory. Health Communication, 16, 660-679. doi:10.1080/10810730.2011.551989

Quick, B. L., Shen, L., \& Dillard, J. P. (2013). Reactance theory and persuasion. In J. P. 
Dillard \& L. Shen (Eds.), The SAGE handbook of persuasion (2nd ed., pp. 167183). Thousand Oaks, CA: Sage.

Quick, B. L., \& Stephenson, M. T. (2007a). Further evidence that psychological reactance can be modeled as a combination of anger and negative cognitions. Communication Research, 34, 255-276. doi:10.1177/0093650207300427

Quick, B. L., \& Stephenson, M. T. (2007b). The Reactance Restoration Scale (RRS): A measure of direct and indirect restoration. Communication Research Reports, 24, 131-138. doi:10.1080/08824090701304840

Quick, B. L., \& Stephenson, M. T. (2008). Examining the role of trait reactance and sensation seeking on perceived threat, state reactance, and reactance restoration. Human Communication Research, 34, 448-476. doi:10.1111/j.14682958.2008.00328.x

Rains, S. A. (2013). The nature of psychological reactance revisited: A meta-analytic review. Human Communication Research, 39, 47-73. doi:10.1111/j.14682958.2012.01443.x

Rains, S. A., \& Turner, M. M. (2007). Psychological reactance and persuasive health communication: A test and extension of the intertwined model. Human Communication Research, 33, 241-269. doi:10.1111/j.1468-2958.2007.00298.x

Rand, D. G. (2012). The promise of Mechanical Turk: How online labor markets can help theorists run behavioral experiments. Journal of Theoretical Biology, 299, 172179. doi:10.1016/j.jtbi.2011.03.004

Reid, J., Ewan, C., \& Lowy, E. (1991). Pilgrimage of pain: The illness experiences of women with repetition strain injury and the search for credibility. Social Science 
\& Medicine, 32, 601-612. doi:10.1016/0277-9536(91)90295-N

Reinhart, A. M., \& Anker, A. E. (2012). An exploration of transportation and psychological reactance in organ donation PSAs. Communication Research Reports, 29, 274-284. doi:10.1080/08824096.2012.704601

Reinhart, A. M., Marshall, H. M., Feeley, T. H., \& Tutzauer, F. (2007). The persuasive effects of message framing in organ donation: The mediating role of psychological reactance. Communication Monographs, 74, 229-255. doi:10.1080/03637750701397098

Richards, A. S., \& Banas, J. A. (2015). Inoculating against reactance to persuasive health messages. Health Communication, 30, 451-460.

doi:10.1080/10410236.2013.867005

Rook, K. S., Thuras, P. D., \& Lewis, M. A. (1990). Social control, health risk taking, and psychological distress among the elderly. Psychology and Aging, 5, 327-334. doi:10.1037/0882-7974.5.3.327

Rosen, T., Mack, K. A., \& Noonan, R. K. (2013). Slipping and tripping: Fall injuries in adults associated with rugs and carpets. Journal of International Violence Research, 5, 61-69. doi:10.5249/jivr.v5i1.177

Russell, C. A., Russell, D. W., Boland, W. A., \& Grube, J. W. (2014). Television's cultivation of American adolescents' beliefs about alcohol and the moderating role of trait reactance. Journal of Children \& Media, 8, 5-22. doi:10.1080/17482798.2014.863475

Ryan, E. B., Bieman-Copland, S., See, S. T. K., Ellis, C. H., \& Anas, A. P. (2002). Age excuses: Conversational management of memory failures in older adults. The 
Journals of Gerontology Series B: Psychological Sciences and Social Sciences, 57, P256-P267. doi:10.1093/geronb/57.3.P256

Ryan, E. B., Giles, H., Bartolucci, G., \& Henwood, K. (1986). Psycholinguistic and social psychological components of communication by and with the elderly. Language \& Communication, 6, 1-24. doi:10.1016/0271-5309(86)90002-9

Ryan, E. B., Hummert, M. L., \& Boich, L. H. (1995). Communication predicaments of aging: Patronizing behavior toward older adults. Journal of Language and Social Psychology, 14, 144-166. doi:10.1177/0261927X95141008

Ryan, E. B., Meredith, S. D., MacLean, M. J., \& Orange, J. B. (1995). Changing the way we talk with elders: Promoting health using the communication enhancement model. International Journal of Aging and Human Development, 41, 69-107. doi:10.1097/00011363-199502000-00004

Scott, A. M., \& Quick, B. L. (2012). Family communication patterns moderate the relationship between psychological reactance and willingness to talk about organ donation. Health Communication, 27, 702-711.

doi:10.1080/10410236.2011.635135

Shadish, W. R., Cook, T. D., \& Campbell, D. T. (2002). Experimental and quasiexperimental designs for generalized causal inference. Boston, MA: Houghton Mifflin Company.

Shen, L. (2010). Mitigating psychological reactance: The role of message-induced empathy in persuasion. Human Communication Research, 36, 397-422. doi:10.1111/j.1468-2958.2010.01381.x

Shen, L. (2011). The effectiveness of empathy- versus fear-arousing antismoking PSAs. 
Health Communication, 26, 404-415. doi:10.1080/10410236.2011.552480

Shen, L. (2015). Antecedents to psychological reactance: The impact of threat, message frame, and choice. Health communication, 30, 975-985. doi:10.1080/10410236.2014.910882

Shen, L. J., \& Bigsby, E. (2013).The effects of message features: Content, structure, and style. In J. P. Dillard \& L. Shen (Eds.), The SAGE handbook of persuasion: Developments in theory and practice (2nd ed., pp. 20-35). Thousand Oaks, CA: Sage.

Shen, L., \& Dillard, J. P. (2005). Psychometric properties of the Hong Psychological Reactance Scale. Journal of Personality and Assessment, 85, 74-81. doi:10.1207/s15327752jpa8501_07

Silk, K. J., Atkin, C. K., \& Salmon, C. T. (2011). Developing effective media campaigns for health promotion. In T. L. Thompson, R. Parrott, \& J. F. Nussbaum (Eds.), The Routledge handbook of health communication (2nd ed., pp. 203-219). New York, NY: Lawrence Erlbaum Associates.

Smith, S. W., Cornacchione, J. J., Morash, M., Kashy, D., \& Cobbina, J. (2016). Communication style as an antecedent to reactance, self-efficacy, and restoration of freedom for drug- and alcohol-involved women on probation and parole. Journal of Health Communication, 21, 504-511. doi:10.1080/10810730.2015.1103329

Snyder, L. B., \& LaCroix, J. M. (2013). How effective are mediated health campaigns? A synthesis of meta-analyses. In R. E. Rice \& C. K. Atkin (Eds.), Public communication campaigns (4th ed., pp. 113-129). Thousand Oaks, CA: Sage. 
Stevens, J. A., Corso, P. S., Finkelstein, E. A., \& Miller, T. R. (2006). The costs of fatal and non-fatal falls among older adults. Injury Prevention, 12, 290-295. doi:10.1136/ip.2005.011015

Strauss, A., \& Corbin, J. (1998). Basics of qualitative research: Techniques and procedures for developing grounded theory (2nd ed.). Thousand Oaks, CA: Sage.

Tabachnick, B. G., \& Fidell, L. S. (2013). Using multivariate statistics (6th ed.). Boston, MA: Pearson.

Tucker, J. S. (2002). Health-related social control within older adults' relationships. Journal of Gerontology: Psychological Sciences, 57, 387-395. doi:10.1093/geronb/57.5.P387

Tucker, J. S., Orlando, M., Elliott, M. N., \& Klein, D. J. (2006). Affective and behavioral responses to health-related social control. Health Psychology, 25, 715-722. doi:10.1037/0278-6133.25.6.715

Tversky, A., \& Kahneman, D. (1981). The framing of decisions and the psychology of choice. Science, 211, 453-458. doi:10.1126/science.7455683

Voyer, P., Verreault, R., Azizah, G. M., Desrosiers, J., Champoux, N., \& Bédard, A. (2005). Prevalence of physical and verbal aggressive behaviours and associated factors among older adults in long-term care facilities. BMC Geriatrics, 5, 1-13. doi:10.1186/1471-2318-5-13

Wenzel, K. A., \& Poynter, D. (2014). “I'm mother! I can take care of myself!': A contrapuntal analysis of older parents' relational talk with their adult children. Southern Communication Journal, 79, 147-170. doi:10.1080/1041794X.2014.881540 
Williams, K., Kemper, S., \& Hummert, M. L. (2003). Improving nursing home communication: An intervention to reduce elderspeak. Gerontologist, 43, 242247. doi:10.1093/geront/43.2.242

Wimmer, R. D., \& Dominick, J. R. (2014). Mass media research: An introduction (10th ed.). Boston, MA: Wadsworth.

Witte, K. (1994). The manipulative nature of health communication research: Ethical issues and guidelines. American Behavioral Scientist, 38, 285-293. doi:10.1177/0002764294038002009

Woller, K. M. P., Buboltz, W. C., Jr., \& Loveland, J. M. (2007). Psychological reactance: Examination across age, ethnicity, and gender. American Journal of Psychology, 120, 15-24. doi:10.2307/20445379

Worchel, S., \& Brehm, J. (1970). Effect of threats to attitudinal freedom as a function of agreement with the communicator. Journal of Personality and Social Psychology, 14, 18-22. doi:10.1037/h0028620

Worchel, S., \& Brehm, J. (1971). Direct and implied social restoration of freedom. Journal of Personality and Social Psychology, 18, 294-304. doi:10.1037/h0031000

World Health Organization (WHO). (2007). WHO global report on falls prevention in older age. Retrieved from http://www.who.int/ageing/publications/Falls_prevention7March.pdf?ua=1

Xu, J. (2015). Designing messages with high sensation value: When activation meets reactance. Psychology \& Health, 30, 423-440. doi:10.1080/08870446.2014.977280 


\section{NOTES}

${ }^{1}$ The other type of non-freedom threatening category that emerged from Study One (RQ2), paternalism, was not used to create a caregiving message for Study Three because it was hypothesized as a moderator. 


\section{APPENDICES}

\section{Appendix A: Study One Recruitment Script}

Hello! My name is Hannah Ball and I am a Ph.D. Candidate in the Department of Communication Studies at West Virginia University. I am currently working on my doctoral dissertation with Dr. Keith Weber, a Professor in the Department of Communication Studies at WVU. My general research interests are related to ways that family members communicate about their health. My dissertation research specifically focuses on caregiving communication between adults 60 and over and their own kids, which was inspired by my background in gerontology and communication as well as by a caregiving relationship in my own family - between my mom and my grandma.

I am looking for individuals who are age 60 or older to help me with my dissertation research. Participation will take up to one hour and will involve a small focus group discussion about your communication with one of your children who helps take care of you - this could be a son, daughter, son-in-law, or daughter-in-law. By "care," I mean anything from assistance with everyday tasks like taking medication or grocery shopping to help with things like getting dressed or making something to eat. In addition to our small group discussion, participants will be asked to fill out a short questionnaire.

The discussion will be completely voluntary - you may choose to withdraw from the study at any time without fear of penalty and you don't have to answer any questions that you don't want to answer. There are no known risks to participating in this study. Please note that focus group sessions will be audio-recorded and that focus group participants may know one another and may talk about our discussion outside of the study; however, I will not share your answers from the focus group or the questionnaire with anyone outside of the research team.

If you are interested in participating, if you are 60 years of age or older, and if you have an adult child or child-in-law who provides you with assistance at least 10 hours per week, please see me at the end of this guest speaker event so that we can sign you up for a focus group session.

Once again, my name is Hannah Ball, and you can feel free to contact me if you would like more information about this study. My business cards are located by the door.

Thank you in advance for your help - I value your input about this topic! 
Appendix B: Study One Recruitment Flyer

\section{Older Adults Invited to Participate in a Research Study}

Help communication researchers learn how to improve healthrelated communication between older adults and their children!

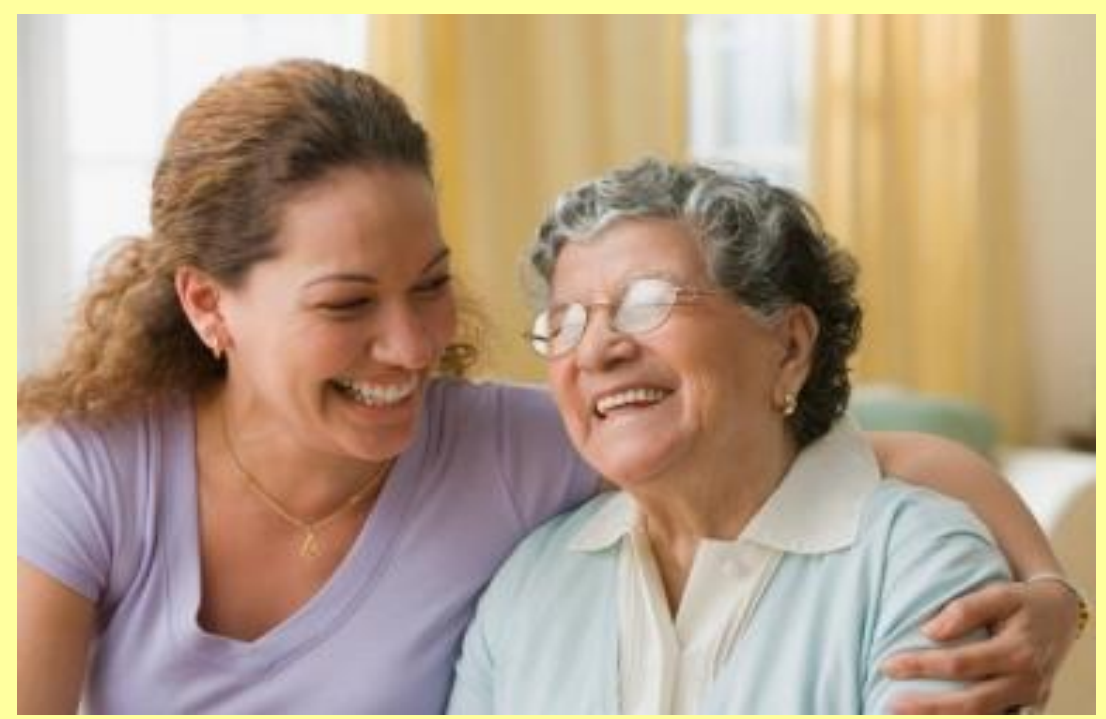

\section{Who can participate?}

- Adults 60 years or older who receive assistance from one of their children (e.g., son/daughter, son/daughter-in-law) for $10+$ hours per week

\section{What's involved?}

- Participants will contribute to one small-group discussion and answer questions about health-related communication with the child who provides assistance

- Discussions will take up to one hour and will take place at Senior Mons

If interested, please call Hannah Ball at (304) 293-3905 or email haball@mix.wvu.edu 


\section{Appendix C: Study One Cover Letter}

\section{We West VirginiaUniversity. EBERLY COLLEGE OF ARTS AND SCIENCES}

February 2016

Dear Participant:

You are being asked to participate in a focus group discussion which is part of research being conducted by Principal Investigator Dr. Keith Weber, Professor of Communication Studies at West Virginia University, and Co-Investigator Hannah Ball, Ph.D. Candidate in the Department of Communication Studies at West Virginia University. This research examines health-related messages exchanged between older adults and their adult child caregivers. The current study will fulfill requirements toward earning a Ph.D. in Communication Studies for the co-investigator.

To participate in this study, you must (a) be at least 60 years of age and (b) receive 10 or more hours per week of assistance from an adult child (e.g., daughter, daughter-in-law, etc.).

Participation in this focus group is voluntary. You do not have to answer any questions that you do not feel comfortable answering. You may refuse to participate or withdraw from participation at any time without penalty or loss of benefits to which you are otherwise entitled.

Please note that focus group sessions will be audio-recorded, and that focus group participants may know one another and may talk about our discussion outside of the study; however, the researchers will keep anything that you say during the focus group strictly confidential. There are no known risks associated with participation in this study. Participation should take about one hour to complete. Remaining in the room indicates that you have agreed to participate in this study.

If you would like more information about this research project, please feel free to contact Hannah Ball at (304) 293-3905 or haball@mix.wvu.edu. If you have any questions about your rights as a research participant, you may contact the West Virginia University Institutional Review Board (IRB) at (304) 293-7073. This study has been acknowledged by West Virginia University's IRB as Protocol \#1602002504.

Thank you for your participation.

Sincerely,

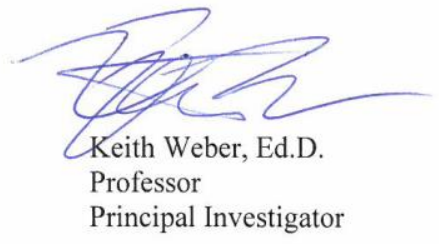

DEPARTMENT OF COMMUNICATION STUDIES

PO Box 6293 | 108 Armstrong Hal

Morgantown, WV 26506-6293

ब 304.293 .3905 田 304.293 .8667

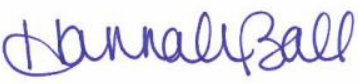

Hannah Ball, M.A.

Ph.D. Candidate

Co-Investigator 


\section{Appendix D: Study One Moderator Guide}

Good morning/afternoon/evening and thank you for attending today. My name is Hannah Ball and I guide our focus group discussion.

The purpose of this focus group is to talk about health-related discussions you have had with a daughter, son, daughter-in-law, or son-in-law - one of your children who provides you with assistance or care every week. Before we begin, I want to remind you that I am audio-recording our discussion [point to recorder] so that I don't miss any of your comments. Although focus group participants may know one another and may talk about our discussion outside of the study, I will not share your answers with anyone outside of my research team. Also, keep in mind that you don't have to answer any questions that you don't want to.

Are there any questions? [The moderator will answer any participant questions.] At this time, we will begin the focus group.

\section{Opening Question}

1. To begin, let's go around the room and say your first name and talk a little bit about your family.

\section{Introductory Questions}

2. Let's talk a little about your experiences receiving assistance or care from your child. In a typical week, what types of assistance do you receive from your child?

3. Families have a lot of different experiences, especially when it comes to caregiving. With this in mind, I'd like to talk about the positive and negative experiences you've had receiving care from your child.

a. How has it been easy to adjust to the role of having your child provide care for you?

b. How has it been difficult to adjust to the role of having your child provide care for you?

\section{Transition Question}

4. When talking about your health, you and your child may agree or disagree about the types of health behavior you should be doing.

a. What types of things do you agree about?

b. What types of things do you disagree about?

5. I also want to learn more about how your child communicates with you when they are providing you with assistance.

a. What messages do you like?

i. Why do you like these messages?

b. What messages don't you like?

i. Why do you like these messages? 


\section{Key Questions}

Now, I would like us to think about something called freedom-threatening messages. I have provided you with a definition on the yellow handout. As you can read on the yellow handout, freedom-threatening messages are things that your child says when they are providing assistance to you that make you feel like they're controlling your behavior. They might say these things when they are trying to get you to do something related to your health. These messages may make you feel like you are less able to make your own decisions about your health.

Does this definition make sense? What questions do you have so far?

6. Feel free to look back over this yellow sheet as we discuss the next few questions. Keeping this definition in mind, I would like you to give me some examples of freedom-threatening messages you have heard your child use when they are providing assistance to you.

7. Which particular health behaviors are these freedom-threatening messages usually about?

a. Why are the freedom-threatening messages usually about these specific health behaviors?

8. Sometimes freedom-threatening messages make us act differently than what someone wants us to do. Think about a time when your child was providing you with assistance and told you to do something, but you acted differently than what your child asked. What did you do? In other words, how did you act differently?

\section{Ending Questions}

9. If your child wanted to get you to do something related to your health, such as [provide an example of a health behavior that was brought up earlier], how would you like them to communicate that to you?

10. Before we end our discussion, would you like to add anything we missed about your experiences with this topic?

Thank you for taking time to speak with me today! I appreciate your input. 
Appendix E: Study One Questionnaire

Instructions: Please answer the following questions about yourself.

1. What is your age? years

2. What is your sex? (check one)

Male

Female

3. What is the ethnicity with which you most closely identify? (check one)

__ Asian/Asian American

Pacific Islander

Black/African American

Hispanic

Native American

White/Caucasian

Middle Eastern

Other (specify):

4. What is the highest level of schooling you completed? (check one)

__ Less than high school

_ High school graduate/G.E.D. or equivalent

__ Some college, no degree

College graduate or above

5. What is your marital status? (check one)

Married

Widowed

Divorced/separated 
Single, never married Living with partner

6. What is your relationship to the child from whom you receive the most care/assistance? (check one)

__ Biological daughter Adopted daughter Daughter-in-law
___ Biological son Adopted son Son-in-law

7. How many hours per week of care/assistance do you receive from your child? hours per week

8. How many hours per week of care/assistance do you receive from an aide or nurse? hours per week

9. Which of the following activities are you able to do completely on your own, without anyone's assistance? (Check all that apply)

Prepare meals

Take care of shopping needs

Take care of housekeeping

Do laundry

Use the telephone

Transport yourself

Take medication

Manage your finances

Dress yourself

Feed yourself

Walk independently

Use the toilet

Take care of your hygiene 
Appendix F: Study Two Recruitment Flyer

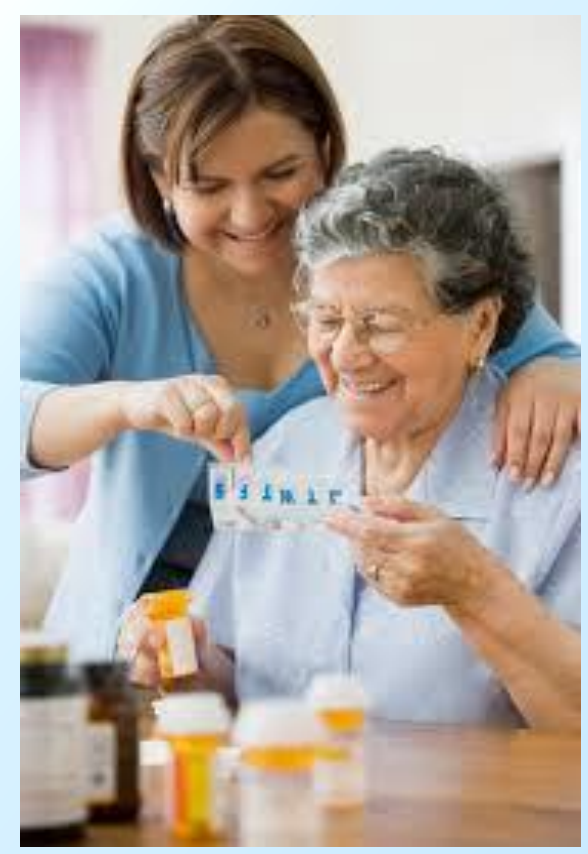

Family Caregivers Needed for a Study about Communication with Aging Parents

Adult children who provide assistance for their aging parent (6o years or older) for $10+$ hours per week are invited to volunteer for a research study

Participants will complete an interview and brief survey about their health-related communication with an older adult parent

(e.g., mother/father, mother/father-in-law) for whom they provide assistance. Interviews will take 45 minutes and will take place at Senior Mons. Evening/weekend sessions are available.

\section{Each participant will receive a $\$ 10$ gift card}

\section{If interested, please call Hannah Ball at (304) 293-3905 or email haball@mix.wvu.edu}

Hannah Ball, Ph.D. Candidate

Department of Communication Studies, WVU

PO Box 6293 | Armstrong Hall 108

WVU IRB approval is on file for this study 


\section{Appendix G: Study Two Cover Letter}

WestVirginiaUniversity.

EBERLY COLLEGE OF ARTS AND SCIENCES

March 2016

Dear Participant:

You are being asked to participate in an interview which is part of research being conducted by Principal Investigator Dr. Keith Weber, Professor of Communication Studies at West Virginia University, and Co-Investigator Hannah Ball, Ph.D. Candidate in the Department of

Communication Studies at West Virginia University. This research examines health-related messages exchanged between older adults and their adult child caregivers. The current study will fulfill requirements toward earning a Ph.D. in Communication Studies for the co-investigator.

To participate in this study, you must provide 10 or more hours of assistance per week to at least one parent (e.g., mother, mother-in-law, etc.) who is 60 of years of age or older. Participation in this interview is voluntary. You do not have to answer any questions that you do not feel comfortable answering. You may refuse to participate or withdraw from participation at any time without penalty or loss of benefits to which you are otherwise entitled.

Please note that interviews will be audio-recorded; however, the researchers will keep anything that you say during the interview strictly confidential. There are no known risks associated with participation in this study. Participation should take about one hour to complete. Remaining in the room indicates that you have agreed to participate in this study.

If you would like more information about this research project, please feel free to contact Hannah Ball at (304) 293-3905 or haball@mix.wvu.edu. If you have any questions about your rights as a research participant, you may contact the West Virginia University Institutional Review Board (IRB) at (304) 293-7073. This study has been acknowledged by West Virginia University's IRB as Protocol \#1602008655.

Thank you for your participation.

Sincerely,

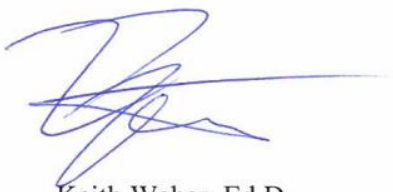

Keith Weber, Ed.D.

Professor

Principal Investigator

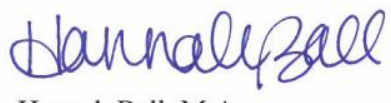

Hannah Ball, M.A.

$\mathrm{Ph} . \mathrm{D}$. Candidate

Co-Investigator 


\section{Appendix H: Study Two Interview Guide}

Good morning/afternoon/evening and thank you for attending today. My name is Hannah Ball and I will be your interview guide.

The purpose of this interview is to talk about messages you have exchanged with your older adult parent to get them to comply with certain health behavior. Before we begin, I want to remind you that I am audio-recording our discussion [point to recorder] so that I don't miss any of your comments. Everything that you say will remain completely confidential and you don't have to answer anything that you don't want to.

Do you have any questions before we begin? [The interview guide will answer any participant questions.] At this time, we will begin the interview.

\section{Opening Question}

1. To begin, I'd like you to tell me what you would like to be called and a little about experience as a caregiver for your older adult parent.

\section{Introductory Question}

2. In a typical week, what types of caregiving tasks do you provide for your parent?

3. How has it been easy to adjust to the role of providing care of your parent?

4. How was it been difficult to adjust to the role of providing care of your parent?

\section{Transition Questions}

5. As I mentioned earlier, this research focuses on how you and your parent talk about their health. From which sources, if any, do you receive information about how to communicate with your parent about their health?

6. What types of health-related behaviors do you have to persuade your parent to do?

a. Have you ever experienced resistance from your parent toward your attempts to get them to do these behaviors?

i. What types of health behaviors does your parent tend to resist?

ii. What do you usually do in response to their resistance? How do you handle it?

iii. Is your response usually effective? Why or why not?

\section{Key Questions}

I'm specifically interested in the effectiveness of the health messages that adult children caregivers give to their older adult parents when persuading them to do something related to their health. Let's talk a little bit about the specific messages you use to convince your parent to engage in a health-related behavior.

7. Using the language you would actually use with your parent, what messages are most effective in gaining compliance from your parents related to their health behavior?

a. What about these messages make them effective? 
8. What types of things do your parents do that are the opposite of what you tell them?

b. What messages do you use to try to counteract this behavior?

i. Are these messages effective? Why or why not?

ii. At what point do you "give in"?

\section{Ending Questions}

9. Think about a piece of advice you would give to other adult children caregivers about how to communicate with their older adult parents to get them to do something related to their health or well-being, such as [provide an example of a health behavior that was brought up earlier]. What would you advise other caregivers to say to their parents to get the parent to do a health behavior?

10. Before we end our discussion, would you like to add anything we missed about your experiences with this topic?

Thank you for taking time to speak with me today! I appreciate your input. 


\section{Appendix I: Study Two Questionnaire}

Instructions: Please answer the following questions about yourself.

1. What is your age? __ years

2. What is your sex? (check one)

Male Female

3. What is the ethnicity with which you most closely identify? (check one)

_ Asian/Asian American Pacific Islander Black/African American Hispanic Native American White/Caucasian Middle Eastern Other (specify):

4. What is the highest level of schooling you completed? (check one)

Did not finish high school High school graduate/G.E.D. or equivalent Some college, no degree Undergraduate degree (Associate, Bachelor's) Graduate degree (e.g., Master's, Ph.D., J.D., MBA)

5. What is your marital status? (check one)

Married Widowed

Divorced/separated Single, never married Living with partner

6. How many children do you have?

7. What is your relationship to the parent to whom you provide the most care/assistance? (check one)

Biological mother Adoptive mother Mother-in-law Biological father Adoptive father Father-in-law 
8. Approximately how many miles away do you live from this parent? miles

9. Approximately how long have you been providing care/assistance to this parent? years months

10. Approximately how many hours per week of care/assistance do you provide to this parent? hours per week

11. Approximately how many hours per week of care/assistance does this parent receive from an aide or nurse? hours per week

12. To what extent have you sought supportive services or professional assistance yourself as a caregiver? (check all that apply)

Respite care

Training regarding how to assist older adults

Support group participation - face-to-face

Support group participation - online

Counseling services

Other (specify):

Please rate each of the following caregiving messages based on two criteria: (a) how realistic it is that you would use that caregiving message with your older adult parent to persuade them to do something and (b) how effective you think using that caregiving message would be to get your older adult parent to do what you asked them to do.

1. You need to get up early in the morning. Don't forget.

$\begin{array}{lllllllll}\text { Not realistic } & 1 & 2 & 3 & 4 & 5 & 6 & 7 & \text { Extremely realistic }\end{array}$

$\begin{array}{lllllllll}\text { Not effective } & 1 & 2 & 3 & 4 & 5 & 6 & 7 & \text { Extremely effective }\end{array}$

If you rated either the realism or effectiveness of using this message as a 4 or below, please explain why: 
2. Are you taking your medication? I need you to take your medication.

$\begin{array}{lllllllll}\text { Not realistic } & 1 & 2 & 3 & 4 & 5 & 6 & 7 & \text { Extremely realistic }\end{array}$

$\begin{array}{lllllllll}\text { Not effective } & 1 & 2 & 3 & 4 & 5 & 6 & 7 & \text { Extremely effective }\end{array}$

If you rated either the realism or effectiveness of using this message as a 4 or below, please explain why:

3. How about you take your medication?

$\begin{array}{lllllllll}\text { Not realistic } & 1 & 2 & 3 & 4 & 5 & 6 & 7 & \text { Extremely realistic }\end{array}$

$\begin{array}{lllllllll}\text { Not effective } & 1 & 2 & 3 & 4 & 5 & 6 & 7 & \text { Extremely effective }\end{array}$

If you rated either the realism or effectiveness of using this message as a 4 or below, please explain why:

4. Should we move this towel so that you don't fall?

$\begin{array}{lllllllll}\text { Not realistic } & 1 & 2 & 3 & 4 & 5 & 6 & 7 & \text { Extremely realistic }\end{array}$

$\begin{array}{lllllllll}\text { Not effective } & 1 & 2 & 3 & 4 & 5 & 6 & 7 & \text { Extremely effective }\end{array}$

If you rated either the realism or effectiveness of using this message as a 4 or below, please explain why: 
5. Don't go outside by yourself! You're likely to fall.

$\begin{array}{lllllllll}\text { Not realistic } & 1 & 2 & 3 & 4 & 5 & 6 & 7 & \text { Extremely realistic }\end{array}$

$\begin{array}{lllllllll}\text { Not effective } & 1 & 2 & 3 & 4 & 5 & 6 & 7 & \text { Extremely effective }\end{array}$

If you rated either the realism or effectiveness of using this message as a 4 or below, please explain why: 


\section{Appendix J: Study Three MTurk Recruitment Script}

Title: Older Adult Communication about Health with their Children

Description: Older adult participants $(60+$ years of age) needed to complete survey about their communication with a child (son/daughter, son/daughter-in-law) who provides them with assistance (e.g., managing finances, grocery shopping, cooking, taking medication, etc.)

We are conducting an academic survey about communication between older adults and their children. If you are at least 60 years of age AND receive about 10 hours or more per week of assistance (e.g., managing finances, managing medication, transportation, grocery shopping, cooking meals, etc.) from your child (son/daughter, son/daughter-inlaw), we would like to hear about your perceptions of health-related communication between older adults and their children. The survey takes approximately 20 minutes to complete and is approved by West Virginia University's Institutional Review Board. Select the link below to complete the survey. At the end of the survey, you will receive a code to paste into the box below to receive credit for taking our survey.

Make sure to leave this window open as you complete the survey. When you are finished, you will return to this page to paste the code into the box.

Survey link: http://wvu.qualtrics.com/SE/?SID=SV_e2GZUVL3FoaNjyl

Provide the survey code here: 
Appendix K: Study Three Stimulus Messages

\section{Freedom Threatening 1, Offering Directives}

"Don't put a towel on the floor outside of your shower and use it as a bathmat! You need to stop doing that. In fact, you ought to get a rubber, non-slip bathmat that you can secure to the floor. You really have no choice."

\section{Freedom Threatening 2, Expressing Doubt}

"Are you using a rubber, non-slip bathmat that you can secure to the floor outside of your shower? Are you sure you're not putting a towel on the floor and using that as a bathmat? I really don't believe you're using the rubber bathmat."

\section{Freedom Threatening 3, Loss-Framing}

"Putting a towel on the floor outside of your shower and using it as a bathmat makes you likely to slide along the floor when you step on it. If you don't get a rubber, non-slip bathmat that you can secure to the floor, you might fall and fracture your hip."

\section{Autonomy-Supporting}

"You might want to stop putting a towel on the floor outside of your shower and using it as a bathmat. Perhaps you could get a rubber, non-slip bathmat that you can secure to the floor. We can sit down and discuss this if you'd like, but ultimately it's your decision." 


\section{Appendix L: Study Three Cover Letter}

\section{W-WestVirginiaUniversity. EBERLY COLLEGE OF ARTS AND SCIENCES}

Dear Participant:

You are being asked to participate in an academic not-for-profit research study being conducted by Principal Investigator Dr. Keith Weber, Professor of Communication Studies at West Virginia University, and Co-Investigator Hannah Ball, Ph.D. Candidate in the Department of Communication Studies at West Virginia University. This research examines health-related messages exchanged between older adults and their adult child caregivers. The current study will fulfill requirements toward earning a Ph.D. in Communication Studies for the co-investigator.

To participate in this study, you must (a) be at least 60 years of age and (b) receive about 10 or more hours per week of assistance from an adult child (e.g., daughter, daughter-in-law, etc.). Participation in this survey is voluntary. You have the right to withdraw from participation at any time without penalty. There are no known risks associated with participation. This study contains a number of checks to make sure that participants are finishing the tasks honestly and completely. As long as you read the instructions and complete the tasks, your HIT will be approved. If you fail these checks, the HIT will be rejected. Completing and submitting this questionnaire indicates that you have agreed to participate in this study. This questionnaire takes about 20 minutes to complete.

Please be aware that any work performed on Amazon MTurk can potentially be linked to information about you on your Amazon public profile page, depending on the settings you have for your Amazon profile. The research team will not be accessing any personally identifying information about you that you may have put on your Amazon public profile page, and will store your MTurk worker ID separately from the other information you provide to us. MTurk worker IDs will only be collected for the purposes of distributing compensation, and will neither be associated with survey responses nor shared with anyone outside of the research team.

If you would like more information about this research project, please feel free to contact Hannah Ball at (304) 293-3905 or haball@mix.wvu.edu. If you have any questions about your rights as a research participant, you may contact the West Virginia University Institutional Review Board (IRB) at (304) 293-7073. This study has been acknowledged by West Virginia University's IRB as Protocol $\# 1604074580$.

Thank you for your participation!

Sincerely,

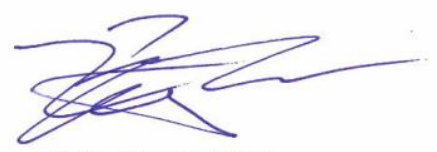

Keith Weber, Ed.D.

Professor

Principal Investigator

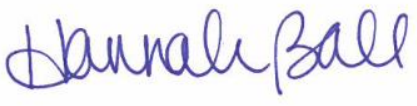

Hannah Ball, M.A.

Ph.D. Candidate

Co-Investigator 


\section{Appendix M: Study Three Questionnaire}

The following set of statements reflect how you react to certain messages. Use the scale below to indicate the extent to which you agree or disagree with EACH statement. There is neither a right nor wrong answer.

\begin{tabular}{|c|c|c|c|c|c|c|c|}
\hline & $\begin{array}{l}\text { Strongly } \\
\text { disagree }\end{array}$ & Disagree & $\begin{array}{l}\text { Somewhat } \\
\text { disagree }\end{array}$ & $\begin{array}{l}\text { Neither } \\
\text { agree nor } \\
\text { disagree }\end{array}$ & $\begin{array}{c}\text { Somewhat } \\
\text { agree }\end{array}$ & Agree & $\begin{array}{c}\text { Strongly } \\
\text { agree }\end{array}$ \\
\hline $\begin{array}{l}\text { I become frustrated when I am unable to make free and } \\
\text { independent decisions. }\end{array}$ & $\mathrm{O}$ & $\mathrm{O}$ & $\mathrm{O}$ & $\mathrm{O}$ & O & $\mathrm{O}$ & $\mathrm{O}$ \\
\hline I become angry when my freedom of choice is restricted. & O & O & $\mathrm{O}$ & $\mathrm{O}$ & $\mathrm{O}$ & $\mathrm{O}$ & O \\
\hline $\begin{array}{l}\text { It irritates me when someone points out things which are } \\
\text { obvious to me. }\end{array}$ & $\mathrm{O}$ & $\mathrm{O}$ & $\mathrm{O}$ & $\mathrm{O}$ & $\mathrm{O}$ & $\mathrm{O}$ & $\mathrm{O}$ \\
\hline Regulations trigger a sense of resistance in me. & $\mathrm{O}$ & O & $\mathrm{O}$ & $\mathrm{O}$ & O & O & O \\
\hline I find contradicting others stimulating. & $\mathrm{O}$ & $\mathrm{O}$ & $\mathrm{O}$ & $\mathrm{O}$ & O & O & $\mathrm{O}$ \\
\hline $\begin{array}{l}\text { When something is prohibited, I usually think, "That's } \\
\text { exactly what I am going to do." }\end{array}$ & $\mathrm{O}$ & O & O & $\mathrm{O}$ & $\mathrm{O}$ & $\mathrm{O}$ & $\mathrm{O}$ \\
\hline I resist the attempts of others to influence me. & O & O & O & O & $\mathrm{O}$ & O & O \\
\hline $\begin{array}{l}\text { It makes me angry when another person is held up as a } \\
\text { model for me to follow. }\end{array}$ & O & $\mathrm{O}$ & $\mathrm{O}$ & $\mathrm{O}$ & $\mathrm{O}$ & $\mathrm{O}$ & $\mathrm{O}$ \\
\hline $\begin{array}{l}\text { When someone forces me to do something, I feel like } \\
\text { doing the opposite. }\end{array}$ & O & O & O & O & O & O & O \\
\hline I consider advice from others to be an intrusion. & $\mathrm{O}$ & $\mathrm{O}$ & $\mathrm{O}$ & $\mathrm{O}$ & $\mathrm{O}$ & $\mathrm{O}$ & $\mathrm{O}$ \\
\hline $\begin{array}{l}\text { Advice and recommendations induce me to do just the } \\
\text { opposite. }\end{array}$ & $\mathrm{O}$ & O & O & O & O & $\mathrm{O}$ & O \\
\hline I am content only when I am acting of my own free will. & $\mathrm{O}$ & $\mathrm{O}$ & $\mathrm{O}$ & $\mathrm{O}$ & $\mathrm{O}$ & O & $\mathrm{O}$ \\
\hline $\begin{array}{l}\text { The thought of being dependent on others aggravates } \\
\text { me. }\end{array}$ & O & O & O & O & O & O & O \\
\hline $\begin{array}{l}\text { It disappoints me to see others submitting to society's } \\
\text { standards and rules. }\end{array}$ & O & O & O & O & O & $\mathrm{O}$ & $\mathrm{O}$ \\
\hline
\end{tabular}


The following set of statements reflect your beliefs about the assistance or care that an adult child should provide to their older adult parent. Adult child refers to any individual's son, daughter, son-in-law, or daughter-in-law who is 18 years of age or older. Older adult parent refers to any parent who is 60 years of age or older. Please indicate how much you agree or disagree with EACH statement using the scale below.

\begin{tabular}{|c|c|c|c|c|c|c|c|}
\hline & $\begin{array}{l}\text { Strongly } \\
\text { disagree }\end{array}$ & Disagree & $\begin{array}{l}\text { Somewhat } \\
\text { disagree }\end{array}$ & $\begin{array}{l}\text { Neither } \\
\text { agree nor } \\
\text { disagree }\end{array}$ & $\begin{array}{l}\text { Somewhat } \\
\text { agree }\end{array}$ & Agree & $\begin{array}{l}\text { Strongly } \\
\text { agree }\end{array}$ \\
\hline $\begin{array}{l}\text { If an adult child decides it is best for an older adult parent's health, } \\
\text { he/she should slip needed medicine into the parent's food so that } \\
\text { the parent has no chance to object. }\end{array}$ & $\mathrm{O}$ & $\mathrm{O}$ & $\mathrm{O}$ & 0 & $\mathrm{O}$ & 0 & 0 \\
\hline $\begin{array}{l}\text { When an adult child knows more than an older adult parent about } \\
\text { how to manage money, the child should take charge of the parent's } \\
\text { spending but explain to the parent why it is necessary to do so. }\end{array}$ & $\mathrm{O}$ & O & $\mathrm{O}$ & 0 & $\mathrm{O}$ & 0 & $\mathrm{O}$ \\
\hline $\begin{array}{l}\text { If a child can explain why a certain diet is best for the parent's } \\
\text { health, the adult child should insist that the older adult parent } \\
\text { follow the diet. }\end{array}$ & $\mathrm{O}$ & $\mathrm{O}$ & O & 0 & $\mathrm{O}$ & 0 & $\mathrm{O}$ \\
\hline $\begin{array}{l}\text { An adult child should insist upon making changes in an older adult } \\
\text { parent's living environment when something is unsafe for the } \\
\text { parent. }\end{array}$ & $\mathrm{O}$ & O & $\mathrm{O}$ & $\mathrm{O}$ & $\mathrm{O}$ & O & $\mathrm{O}$ \\
\hline $\begin{array}{l}\text { When an older adult parent does not want to talk or think about an } \\
\text { obvious health problem, the adult child should insist upon taking } \\
\text { the parent to the doctor. }\end{array}$ & O & 0 & $\mathrm{O}$ & 0 & $\mathrm{O}$ & O & $\mathrm{O}$ \\
\hline $\begin{array}{l}\text { If an older adult parent is mentally confused, the adult child should } \\
\text { make whatever changes in the parent's daily routine that he/she } \\
\text { judges to be best for the parent, even when the parent has lived } \\
\text { that way for many years. }\end{array}$ & $\mathrm{O}$ & O & 0 & 0 & $\mathrm{O}$ & 0 & 0 \\
\hline $\begin{array}{l}\text { When an older adult parent has decided against having an } \\
\text { operation that will prolong his/her life, the adult child should insist } \\
\text { that the parent have the operation. }\end{array}$ & $\mathrm{O}$ & O & $\mathrm{O}$ & $\mathrm{O}$ & $\mathrm{O}$ & 0 & $\mathrm{O}$ \\
\hline $\begin{array}{l}\text { When necessary, an adult child should force an older adult parent } \\
\text { to stick to a treatment the doctor ordered but also explain to the } \\
\text { parent the need to do so. }\end{array}$ & $\mathrm{O}$ & $\mathrm{O}$ & O & $\mathrm{O}$ & $\mathrm{O}$ & $\mathrm{O}$ & O \\
\hline
\end{tabular}


The next part of this survey is about your communication with the adult child (e.g., son/daughter, son/daughter-in-law) who provides you with the most assistance during the week. Assistance could be anything from help with everyday tasks like taking medication, grocery shopping, or transportation, to help with things like getting dressed or making something to eat.

During the next part of this survey, please answer the questions in reference to your adult child who provides you with the most assistance during the week.

Please identify this adult child by typing their initials into the box below. This information is for your reference, only.

How is the adult child you identified above related to you?

Biological daughter

Adopted daughter

O Daughter-in-law

O Biological son

Adopted son

O Son-in-law 
Imagine that the adult child you identified on the previous page says the following to you one day when they are providing you with assistance. Think about how you would feel and what you would actually do after they say this to you.

\section{ONE OF FOUR CAREGIVING MESSAGES WILL APPEAR HERE (SEE APPENDIX K)}

Please respond to the questions on the next few pages of the survey based on how you would feel and what you would do after hearing this message from your child.

How realistic is it that your adult child has used similar language with you when providing you with assistance?

\begin{tabular}{|l|l|l|l|l|l|l|l|l|}
\hline Not realistic & $\bigcirc$ & $\bigcirc$ & $\bigcirc$ & $\bigcirc$ & $\bigcirc$ & $\bigcirc$ & $\bigcirc$ & Realistic \\
\hline
\end{tabular}


Use the scale below to indicate your perceptions of the message you read on the previous page. There is neither a right nor a wrong answer.

If I had received this message from my adult child, it would be...

\begin{tabular}{|c|c|c|c|c|c|c|c|}
\hline & $\begin{array}{l}\text { Strongly } \\
\text { disagree }\end{array}$ & Disagree & $\begin{array}{l}\text { Somewhat } \\
\text { disagree }\end{array}$ & $\begin{array}{l}\text { Neither } \\
\text { agree nor } \\
\text { disagree }\end{array}$ & $\begin{array}{l}\text { Somewhat } \\
\text { agree }\end{array}$ & Agree & $\begin{array}{l}\text { Strongly } \\
\text { agree }\end{array}$ \\
\hline $\begin{array}{l}\text { An example of my adult child trying to make a } \\
\text { decision for me. }\end{array}$ & O & O & $\mathrm{O}$ & O & O & $\mathrm{O}$ & $\mathrm{O}$ \\
\hline $\begin{array}{l}\text { An example of my adult child giving me guidance } \\
\text { rather than making demands. }\end{array}$ & O & O & $\mathrm{O}$ & $\mathrm{O}$ & $\mathrm{O}$ & $\mathrm{O}$ & $\mathrm{O}$ \\
\hline An example of my adult child trying to pressure me. & O & O & O & O & O & O & O \\
\hline $\begin{array}{l}\text { An example of my adult child creating opportunities } \\
\text { for me to provide a reaction. }\end{array}$ & 0 & 0 & 0 & 0 & 0 & 0 & 0 \\
\hline $\begin{array}{l}\text { An example of my adult child threatening my } \\
\text { freedom to choose. }\end{array}$ & $\mathrm{O}$ & O & O & 0 & 0 & O & O \\
\hline $\begin{array}{l}\text { An example of my adult child allowing me to make } \\
\text { my own decision. }\end{array}$ & $\mathrm{O}$ & 0 & 0 & 0 & 0 & $\mathrm{O}$ & $\mathrm{O}$ \\
\hline $\begin{array}{l}\text { An example of my adult child trying to manipulate } \\
\text { me. }\end{array}$ & 0 & 0 & 0 & 0 & 0 & 0 & 0 \\
\hline $\begin{array}{l}\text { An example of my adult child saying something that } \\
\text { is pleasant. }\end{array}$ & 0 & 0 & 0 & 0 & 0 & 0 & 0 \\
\hline $\begin{array}{l}\text { An example of my adult child saying something that } \\
\text { gets in the way of what I want. }\end{array}$ & 0 & 0 & 0 & 0 & 0 & O & O \\
\hline $\begin{array}{l}\text { An example of my adult child saying something that } \\
\text { is reasonable. }\end{array}$ & 0 & 0 & 0 & 0 & 0 & $\mathrm{O}$ & 0 \\
\hline $\begin{array}{l}\text { An example of my adult child saying something that } \\
\text { is fair. }\end{array}$ & 0 & 0 & 0 & 0 & 0 & 0 & 0 \\
\hline
\end{tabular}


Use the scale below to indicate how you felt about the message you read on the previous page. There is neither a right nor a wrong answer.

Imagining that the message you read was something your adult child actually said to you, how did you feel when reading the message?

\begin{tabular}{|c|c|c|c|c|c|c|c|}
\hline & $\begin{array}{l}\text { None of } \\
\text { this feeling }\end{array}$ & $\begin{array}{l}\text { A little of } \\
\text { this feeling }\end{array}$ & $\begin{array}{l}\text { Some of } \\
\text { this feeling }\end{array}$ & Neutral & $\begin{array}{l}\text { A moderate } \\
\text { amount of } \\
\text { this feeling }\end{array}$ & $\begin{array}{c}\text { Quite a bit } \\
\text { of this } \\
\text { feeling }\end{array}$ & $\begin{array}{l}\text { A great } \\
\text { deal of this } \\
\text { feeling }\end{array}$ \\
\hline I felt angry while reading the message. & $\mathrm{O}$ & $\mathrm{O}$ & $\mathrm{O}$ & O & $\mathrm{O}$ & $\mathrm{O}$ & O \\
\hline I felt annoyed while reading the message. & $\mathrm{O}$ & O & O & $\mathrm{O}$ & O & O & O \\
\hline I felt irritated while reading the message. & $\mathrm{O}$ & $\mathrm{O}$ & $\mathrm{O}$ & $\mathrm{O}$ & $\mathrm{O}$ & $\mathrm{O}$ & $\mathrm{O}$ \\
\hline I felt aggravated while reading the message. & $\mathrm{O}$ & $\mathrm{O}$ & $\mathrm{O}$ & O & $\mathrm{O}$ & O & O \\
\hline
\end{tabular}

When answering the questions on this page, assume that you do not currently use a non-slip bathmat on the floor outside of your shower.

Based on the message you read, how would you rate your attitude toward using a non-slip bathmat on the floor outside of your shower instead of a towel?

\begin{tabular}{|r|l|l|l|l|l|l|l|l|}
\hline Bad & 0 & $O$ & 0 & 0 & 0 & 0 & 0 & Good \\
Unfavorable & 0 & 0 & 0 & 0 & 0 & 0 & 0 & Favorable \\
Negative & 0 & 0 & 0 & 0 & 0 & 0 & 0 & Positive \\
Unnecessary & 0 & 0 & 0 & 0 & 0 & 0 & 0 & Necessary \\
\hline
\end{tabular}

Please answer the following question by dragging the slider along the scale below.

Based on the message you read, how likely is it that you will use a non-slip bathmat on the floor outside of your shower instead of a towel within the next week?

\section{Definitely will not}

Definitely will

$\begin{array}{lllllllllll}0 & 10 & 20 & 30 & 40 & 50 & 60 & 70 & 80 & 90 & 100\end{array}$


Use the scale below to indicate your agreement with the following statements based on the message you read, imagining that the message was something your adult child actually said to you. There is neither a right nor wrong answer.

\begin{tabular}{|c|c|c|c|c|c|c|c|}
\hline & $\begin{array}{l}\text { Strongly } \\
\text { disagree }\end{array}$ & Disagree & $\begin{array}{l}\text { Somewhat } \\
\text { disagree }\end{array}$ & $\begin{array}{l}\text { Neither } \\
\text { agree nor } \\
\text { disagree }\end{array}$ & $\begin{array}{l}\text { Somewhat } \\
\text { agree }\end{array}$ & Agree & $\begin{array}{c}\text { Strongly } \\
\text { agree }\end{array}$ \\
\hline $\begin{array}{l}\text { I plan to do the opposite of what the message tells } \\
\text { me to do. }\end{array}$ & $\mathrm{O}$ & O & O & O & $\mathrm{O}$ & $\mathrm{O}$ & O \\
\hline $\begin{array}{l}\text { I think the behavior encouraged by the message is } \\
\text { beneficial. }\end{array}$ & $\mathrm{O}$ & $\mathrm{O}$ & $\mathrm{O}$ & $\mathrm{O}$ & $\mathrm{O}$ & $\mathrm{O}$ & O \\
\hline $\begin{array}{l}\text { Complaining to others about the message would } \\
\text { make me feel better. }\end{array}$ & $\mathrm{O}$ & $\mathrm{O}$ & $\mathrm{O}$ & $\mathrm{O}$ & $\mathrm{O}$ & $\mathrm{O}$ & $\mathrm{O}$ \\
\hline Overall, this message is positive. & $\mathrm{O}$ & $\mathrm{O}$ & $\mathrm{O}$ & $\mathrm{O}$ & $\mathrm{O}$ & $\mathrm{O}$ & $\mathrm{O}$ \\
\hline I approve of the purpose of this message. & $\mathrm{O}$ & $\mathrm{O}$ & O & $\mathrm{O}$ & O & $\mathrm{O}$ & $\mathrm{O}$ \\
\hline $\begin{array}{l}\text { I am motivated to tell other people about my } \\
\text { disagreement with this message. }\end{array}$ & O & $\mathrm{O}$ & O & $\mathrm{O}$ & O & $\mathrm{O}$ & O \\
\hline $\begin{array}{l}\text { I am motivated to spend time with people who } \\
\text { don't do what the message says to do. }\end{array}$ & O & $\mathrm{O}$ & $\mathrm{O}$ & $\mathrm{O}$ & $\mathrm{O}$ & $\mathrm{O}$ & $\mathrm{O}$ \\
\hline I trust the source of this message. & O & O & O & O & O & O & O \\
\hline I am inspired to share my criticism of this message. & O & $\mathrm{O}$ & O & $\mathrm{O}$ & O & $\mathrm{O}$ & $\mathrm{O}$ \\
\hline $\begin{array}{l}\text { I am inspired to get other people to do the opposite } \\
\text { of what the message says to do. }\end{array}$ & O & O & $\mathrm{O}$ & O & $\mathrm{O}$ & $\mathrm{O}$ & $\mathrm{O}$ \\
\hline This message is valuable. & $\mathrm{O}$ & $\mathrm{O}$ & $\mathrm{O}$ & O & $\mathrm{O}$ & $\mathrm{O}$ & $\mathrm{O}$ \\
\hline $\begin{array}{l}\text { I don't feel the need to complain to others about } \\
\text { the message. }\end{array}$ & O & O & O & $\mathrm{O}$ & $\mathrm{O}$ & $\mathrm{O}$ & $\mathrm{O}$ \\
\hline I intend to ignore what the message tells me to do. & $\mathrm{O}$ & $\mathrm{O}$ & $\mathrm{O}$ & $\mathrm{O}$ & $\mathrm{O}$ & $\mathrm{O}$ & $\mathrm{O}$ \\
\hline $\begin{array}{l}\text { I am motivated to act consistently with what the } \\
\text { message wants me to do. }\end{array}$ & O & O & $\mathrm{O}$ & $\mathrm{O}$ & $\mathrm{O}$ & $\mathrm{O}$ & O \\
\hline I will not do what the message says to do. & $\mathrm{O}$ & $\mathrm{O}$ & $\mathrm{O}$ & $\mathrm{O}$ & $\mathrm{O}$ & $\mathrm{O}$ & $\mathrm{O}$ \\
\hline
\end{tabular}


Please answer the following questions about yourself.

How would you classify your current health status?
O Good
O Fair
O Poor

How many hours per week of care/assistance do you receive from your child?

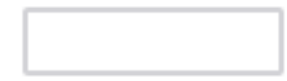

How many hours per week of care/assistance do you receive from an aide or nurse?

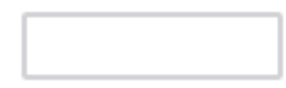

What is your age?

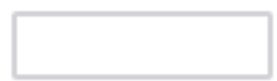

What is your sex?

O Male

O Female

What is the ethnicity with which you most closely identify?
White/Caucasian
O Asian/Asian American
O Pacific Islander
O Black/African-American
O Hispanic
O Native American
O Middle Eastern
Other (please specify): 
What is the highest level of schooling you completed?

Less than high school

O High school graduate/G.E.D. or equivalent

Some college, no degree

College graduate or above

What is your marital status?

O Married

O Widowed

O Divorced/Separated

Single, never married

Living with partner

What is your relationship to the adult child who provides you with the most assistance during the week?

Biological daughter

O Adopted daughter

O Daughter-in-law

O Biological son

O Adopted son

O Son-in-law

To what extent is the communication that you typically receive from your adult child...

\begin{tabular}{|l|c|c|c|c|c|c|c|}
\hline & Not at all & Slightly & Somewhat & Neutral & Moderately & Very & Extremely \\
\hline Respectful & $\mathrm{O}$ & $\mathrm{O}$ & $\mathrm{O}$ & $\mathrm{O}$ & $\mathrm{O}$ & $\mathrm{O}$ & $\mathrm{O}$ \\
Condescending & $\mathrm{O}$ & $\mathrm{O}$ & $\mathrm{O}$ & $\mathrm{O}$ & $\mathrm{O}$ & $\mathrm{O}$ & $\mathrm{O}$ \\
Dominating & $\mathrm{O}$ & $\mathrm{O}$ & $\mathrm{O}$ & $\mathrm{O}$ & $\mathrm{O}$ & $\mathrm{O}$ & $\mathrm{O}$ \\
Polite & $\mathrm{O}$ & $\mathrm{O}$ & $\mathrm{O}$ & $\mathrm{O}$ & $\mathrm{O}$ & $\mathrm{O}$ & $\mathrm{O}$ \\
\hline
\end{tabular}




\section{Appendix N: Freedom Restoration Measure Pilot Test}

On the following pages of this survey, you will be asked to read a message and then answer questions about your reactions to that message. You will also be asked to provide feedback on the instructions and the design of the survey as well as the construction and readability of each question (e.g., is anything confusing, hard to understand, etc.).

Imagine that you have an adult child (e.g., son/daughter, son/daughter-in-law) who provides you with assistance during the week. They say the following to you one day when they are providing you with assistance. Think about how you would feel and what you would actually do after they say this to you.

\section{"Don't put a towel on the floor outside of your shower and use it as a bathmat! You need to stop doing that. In fact, you ought to get a rubber, non-slip bathmat that you can secure to the floor. You really have no choice."}

Please respond to the following questions based on how you would feel and what you would do after hearing this message from your child.

Use the scale below to indicate your agreement with the following statements based on the message you read, imagining that the message was something an adult child caregiver actually said to you. There is neither a right nor wrong answer.

\begin{tabular}{|c|c|c|c|c|c|c|}
\hline $\begin{array}{c}\text { Strongly } \\
\text { disagree }\end{array}$ & Disagree & $\begin{array}{c}\text { Somewhat } \\
\text { disagree }\end{array}$ & $\begin{array}{c}\text { Neither agree } \\
\text { nor disagree }\end{array}$ & $\begin{array}{c}\text { Somewhat } \\
\text { agree }\end{array}$ & Agree & $\begin{array}{c}\text { Strongly } \\
\text { agree }\end{array}$ \\
\hline 1 & 2 & 3 & 4 & 5 & 6 & 7 \\
\hline
\end{tabular}

1. I think that the behavior advocated by the message is beneficial.

2. Overall, the message is positive.

3. I am favorable toward the purpose of the message.

4. I trust the source of this message.

5. This message is valuable.

6. Complaining to others about this message would make me feel better.

7. I don't feel the need to complain to others about the message.

8. I am motivated to tell other people about my disagreement with this message.

9. I am motivated to spend time with people who do the opposite of what the message says to do.

10. I am inspired to share my criticism of this message.

11. I am inspired to convince other people to do the opposite of what the message encourages.

12. I intend to ignore what the message tells me to do.

13. I plan to do the opposite of what the message tells me to do.

14. I will not do what the message tells me to do.

15. I am motivated to act consistently with what the message wants me to do. 
What about these questions, if anything, was confusing or difficult to understand?

What suggestions do you have to improve these questions? Please be as specific as possible.

\section{Please answer the following questions about yourself.}

What is your age (in years)?

What is your sex?

_ Male _ Female

What is the ethnicity with which you most closely identify?

Asian/Asian American
Pacific Islander
Black/African American
Hispanic
Native American
White/Caucasian
Middle Eastern
Other (specify):

